\title{
THE SOCIAL SYSTEM OF WHITE-BREASTED MESITES (MESITORNIS VARIEGATA)
}

\author{
Dissertation \\ for the award of the degree \\ "Doctor rerum naturalium" (Dr.rer.nat.) \\ of the Georg-August-Universität Göttingen
}

within the doctoral program Biology

of the Georg-August University School of Science (GAUSS)

submitted by

Anna Gamero Cabrellez

from Barcelona, Spain

Göttingen, 2013 



\section{Thesis Committee}

Prof. Dr. Peter M. Kappeler, Department of Sociobiology and Anthropology, Georg-August-Universität Göttingen, Behavioral Ecology and Sociobiology Unit, German Primate Center GmbH

Prof. Dr. Julia Ostner, Primate Social Evolution Group, Courant Research Centre Evolution of Social Behavior

\section{Members of the Examination Board}

Reviewer: Prof. Dr. Peter M. Kappeler

Second Reviewer: Prof. Dr. Julia Ostner

\section{Further members of the Examination Board:}

Prof. Dr. Eckhard W. Heymann, Behavioral Ecology and Sociobiology Unit, German Primate Center $\mathrm{GmbH}$

Dr. Antje Engelhardt, Jr Research Group on Primate Sexual Selection, Reproductive Biology Unit, German Primate Centre $\mathrm{GmbH}$

Dr. Mathias Waltert, Department of Conservation Biology, Georg-August-Universität Göttingen

Prof. Dr. Ulrich Brose, Department of Systemic Conservation Biology, Georg-August-Universität Göttingen 



\section{Contents}

Summary .. $\mathrm{i}$

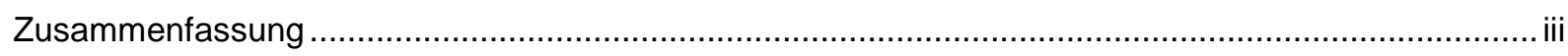

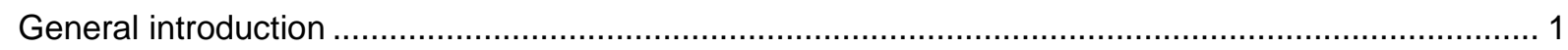

Chapter 1: Characterization of 10 polymorphic microsatellite loci for white-breasted mesites (Mesitornis variegata).....

Chapter 2: Delayed juvenile dispersal and monogamy, but no cooperative breeding in white-breasted mesites (Mesitornis variegata).....

Chapter 3: Patterns of juvenile dispersal and parental costs of family-living in a non-cooperatively breeding bird

Chapter 4: Always together: mate guarding or predator avoidance as determinants of intra-group cohesion in white-breasted mesites?

General discussion

References

Appendices

Curriculum vitae.

Declaration 



\section{Summary}

Animals show great diversity in their social systems, ranging from species living solitarily to species living in highly complex social groups. This variation in social systems provides the perfect setting to investigate evolutionary transitions among social traits. A particularly useful approach consists in comparing closely related species that exhibit different levels of sociality. Social systems have been described differently among distant taxonomic groups. In birds they are generally defined according to the breeding system or social mating system, and most species are socially monogamous, with more complex groups generally characterized by natal philopatry of juveniles and cooperative breeding. Several hypotheses related to the species demography, ecology, life-history and kinship relationships have been proposed to explain the transitions from pair-living to cooperative breeding systems in birds.

White-breasted mesites (Mesitornis variegata) are medium-sized ground-dwelling birds that belong to the family Mesitornithidae. This family of birds is endemic to Madagascar and is composed of two additional allopatric species that show quite different levels of sociality: the brown mesite (Mesitornis unicolor), a pair breeder found in the eastern rainy forests, and the subdesert mesite (Monias benschi), which lives in groups and breed cooperatively in the southern spiny forests. Whitebreasted mesites are usually found in pairs or small groups, that are thought to be family groups, in the dry deciduous forests of western Madagascar, but there is little information on their breeding system and no study has yet examined the genetic relatedness of their small social units.

The general aim of this thesis is first to describe several components of the social system of white-breasted mesites, a species that was previously suggested to breed cooperatively but has precocial chicks which in principle do not require much parental care, and then investigate proximate and ultimate mechanisms that may have shaped this system. To do so I combine genetic, behavioural, morphologic and spatial data collected on 10 to 15 social units of M. variegata in Kirindy forest, Western Madagascar, during five field seasons (October 2009 to April 2012).

The results of this study indicate that white-breasted mesites live in very cohesive stable pairs or small families formed by delayed dispersal of juveniles and that care is provided only by parents. Additionally, contrary to previous suggestions, the food provisioning period for chicks in $M$. variegata is 
intense for 2 months, but can extend to up to 12 months, although at much lower rates. This long parental care period could be related to the juveniles' slow development of foraging skills I observed in this species. The high cohesion of mesite social units, with inter-individual distances rarely exceeding $3 \mathrm{~m}$, seems to be associated to predator avoidance and not to mate defence. Still, breeding partners' high cohesion may indirectly explain their strictly monogamous mating system. Analyses of juvenile dispersal patterns revealed that male juveniles stay longer in families than females, matching with the slower adult male population turnover and the presence of some families containing a "stepmother". Additionally, by comparing adults associated with juveniles with adults living in pairs I show that familyliving can be costly for parents in terms of foraging efficiency and investment in future reproduction, which could underlie the parental intolerance I observed towards older juveniles.

Overall, limitations for independent breeding and solitarily ranging in combination with slow development of foraging skills and parental costs seem to be important factors explaining juvenile dispersal patterns, family formation and stability in this species. Additionally, predation risk selecting for strong intra-group and pair cohesion may affect the mating system in white-breasted mesites and suggests a link between genetic monogamy and predation risk in a socially monogamous species. Based on comparisons with the other mesite species the breeding system of white-breasted mesites could be considered along the transition between a bi-parental and a cooperative breeding system, with some juveniles able to provide help but prevented from doing so by their parents. 


\section{Zusammenfassung}

Das Tierreich zeichnet sich durch eine große Diversität an Sozialsystemen aus, die von einer einzelgängerischen Lebensweise bis hin zum Leben in komplexen sozialen Gruppen reicht. Diese Variation in Sozialsystemen liefert den perfekten Rahmen um die evolutionäre Entwicklung von sozialen Merkmalen zu untersuchen. Ein besonders erfolgsversprechender Ansatz besteht darin, eng verwandte Arten, die sich durch einen unterschiedlichen Grad der Vergesellschaftung auszeichnen, miteinander zu vergleichen. Die Charaktersierung von Sozialsystemen wird für verschiedene taxonomische Gruppen unterschiedlich gehandhabt. Bei Vögeln wird das Sozialsystem normalerweise durch das Brut- und das soziale Paarungssystem charakterisiert. Die meisten Vogelarten sind paarlebend, aber man findet auch komplexere Gruppen welche im Allgemeinen durch das Verbleiben der Jungen am Aufwuchsort und kooperatives Brüten charakterisiert sind. Bisher wurden verschiedene Hypothesen im Zusammenhang mit Demographie, Ökologie, Lebensgeschichte und Verwandtschaftsverhältnissen vorgeschlagen um den Übergang von Paarbrütern zu kooperativen Brutsystemen in Vögeln erklären.

Kurzfuß-Stelzenrallen (Mesitornis variegata) sind mittelgroße, am Boden lebende Vögel, die zur Familie der Mesitornithidae gehören. Diese Vogelfamilie ist endemisch in Madagaskar und beinhaltet zwei weitere allopatrische Arten, welche sich hinsichtlich des Grades der Vergesellschaftung unterscheiden: Die Einfarb-Stelzenralle (Mesitornis unicolor) des östlichen Regenwaldes welche in Paaren brütet und die Monias-Stelzenralle (Monias benschi) des südlichen Dornenwaldes welche in Gruppen lebt und kooperativ brütet. Die Kurzfuß-Stelzenralle hingegen kommt im westlichen Trockenwald vor und lebt für gewöhnlich in Paaren oder kleinen Gruppen von denen angenommen wird, dass es sich um Familiengruppen handelt, wobei allerdings nur wenig Informationen über das Brutsystem vorhanden ist und bisher keine Studie die genetischen Verwandtschaftsverhältnisse innerhalb der kleinen sozialen Einheiten untersucht hat.

Das Hauptziel dieser Arbeit war es erstens die verschiedenen Komponenten des Sozialsystems der Kurzfuß-Stelzenrallen zu beschreiben, ein Art für welche bisher angenommen wurde das sie kooperativ brütet, deren Jungen jedoch Nestflüchter sind und prinzipiell nur wenig elterliche Fürsorge benötigen. Zweitens sollten die proximaten und ultimativen Ursachen untersucht werden, die dieses Sozialsystem geformt haben könnten. Um dieses Ziel zu erreichen habe ich 
genetische, morphologische, räumliche sowie Verhaltensdaten von 10 bis 15 sozialen Einheiten von M. Variegate während fünf Feldsaisonen (Oktober 2009 bis April 2012) im Kirindy-Wald im Westen von Madagaskar gesammelt.

Das Ergebnis dieser Studie zeigt, dass die Kurzfuß-Stelzenralle in sehr kohäsiven stabilen Paaren oder kleinen Familien lebt, die durch eine verspätete Abwanderung der Jungtiere entstehen, und dass nur die Elterntiere sich um die Aufzucht der Brut kümmern. Außerdem versorgen die Eltern ihre Jungen entgegen bisherigen Vermutungen in den ersten zwei Lebensmonaten intensiv mit Nahrung, und auch darüber hinaus bis zum 12. Lebensmonat obwohl mit viel geringerer Häufigkeit. Diese lange Periode der elterlichen Fürsorge hängt wahrscheinlich mit der langsamen Entwicklung der Jungtiere hinsichtlich der für die Nahrungssuche erforderlichen Fertigkeiten zusammen. Die hohe Kohäsion sozialer Einheiten mit inter-individuellen Abständen von selten mehr als drei Metern steht eher mit einer Strategie der Raubfeindvermeidung als einer Strategie zur Verhinderung des Fremdgehens in Verbindung. Dennoch kann die hohe Kohäsion zwischen Paarpartnern das streng monogame Paarungssystem erklären. Die Untersuchung des Abwanderungsverhaltens hat ergeben, dass männliche Nachkommen länger in ihren Familien bleiben als weibliche, was mit der beobachteten langsameren Fluktuation der erwachsenen männlichen Population und dem Vorhandensein von „Stiefmüttern“ in einigen Familien übereinstimmt. Darüber hinaus konnte ich durch den Vergleich von Paaren mit und ohne Nachwuchs zeigen, dass Familienleben für die Eltern hinsichtlich der Effizienz der Nahrungsbeschaffung und hinsichtlich der Investitionen in zukünftige Reproduktion kostspielig ist. Dies könnte die Intoleranz der Eltern gegenüber älteren Nachwuchs erklären, welche ich beobachten habe.

Zusammenfassend kann gesagt werden, dass die Einschränkungen bezüglich unabhängigen Brütens und einzelgängerischen Umherstreifens in Kombination mit der langsamen Entwicklung der Fähigkeiten die im Zusammenhange mit der Nahrungsbeschaffung stehen und elterliche Kosten wichtige Faktoren sind, welche das Abwanderungsverhalten der Jungtiere, die Bildung von Familien und die Familienstabilität in dieser Art erklären. Zusätzlich beeinflusst die Gefahr von Raubfeinden, die mit der starken Kohäsion innerhalb sozialer Einheiten einhergeht, das Paarungssystem bei KurzfußStelzenrallen und legt eine Verbindung zwischen genetischer Monogamie und Raubfeindruck bei sozial monogam lebenden Arten nahe. 
Basierend auf einem Vergleich mit den anderen Arten der Familie der Mesitornithidae könnte das Brutsystem der Kurzfuß-Stelzenralle als Übergansstadium zwischen einem allein auf den beiden Elternteilen basierenden und einem kooperativen Brutsystem erachtet werden in dem einige Jungen fähig wären Hilfe zu stellen, aber von den Eltern daran gehindert werden. 



\section{General introduction}

The study of social systems is key in the field of Behavioural Ecology because it summarizes the interplay of several aspects of a species' life-history, ecology, spatial cohesion, and reproductive strategies (Kappeler and van Schaik 2002). Additionally, animals show great diversity in their social systems, ranging from species living solitarily to species living in highly complex social groups. This variation provides the perfect setting to investigate evolutionary transitions among social traits. Studying closely related species that exhibit different levels of sociality and identifying similar patterns in taxonomically distant groups showing analogous social systems has provided valuable insights into the evolution of social systems (Gonzalez et al. 2013; Rubenstein and Lovette 2007). However, comparative analyses can become difficult when terminology is ambiguous or it is not used consistently, leading to conflicting results among similar studies (e.g. (Shultz et al. 2011) and (Lukas and Clutton-Brock 2013)). In this section I will therefore tackle the terminology, concepts and incongruences used to describe social systems in different taxonomic groups, describe the most common social system in birds, their ecologic and life-history determinants and, current theory in group formation and cooperative behavior in animal societies. Finally, I introduce the bird species this study is based on, the white-breasted mesite (Mesitornis variegata), and the specific questions I will address in the following chapters of this thesis.

\section{Animal social systems: terminology in different taxonomic groups}

An animal social system, society or social unit has been defined as the set of conspecific animals that interact regularly and more so with each other than with members of other such societies (Struhsaker 1969). In insects, social systems have been described according to several criteria comprising brood care, reproductive skew, parent/offspring aggregation and the presence of casts (Costa and Fitzgerald 1996). In vertebrates, particularly mammals, social systems are characterized on the basis of three main components: social organization, social structure and mating system (Kappeler and van Schaik 2002; Kappeler et al. 2013). Social organization describes the size, composition, cohesion and genetic structure of such a set of animals, with animals being either solitary, when individuals generally do not associate with conspecifics, pair-living when they coordinate their activities with a member of the opposite sex, or group-living when more than two individuals associate together (Kappeler and van 
Schaik 2002). Social structure refers to the nature and quality of inter-individual relationships, and mating system describes the number of mating partners of each sex, and can be classified as monogamous, polygynous, polyandrous or promiscuous (Kappeler et al. 2013).

Bird social systems are generally described on the basis of the breeding system or social mating system (Galliard and Ferrière 2008), both denoting the combination of the mating system, the existence and nature of pair-bonds, and sometimes also the parental care pattern (Reynolds 1996; Ligon 1999). Social organization and structure, mating system and social system are often used as synonyms in the avian literature but tend to actually refer to breeding systems (Ligon 1999; Koenig and Dickinson 2004).

\section{Social systems in birds: social monogamy and the role of parental care}

Socio-ecological models provide the link between ecology and behaviour based on the distribution of risks and resources in the environment (Emlen and Oring 1977; Terborgh and Janson 1986). Because fitness is generally determined by different factors in males (access to mates) than in females (access to resources) (Trivers 1972; Clutton-Brock and Parker 1992), different social mating systems in animals can arise depending on the environmental potential for polygamy (Emlen and Oring 1977; Davies 1991). Unlike mammals, both male and female birds are generally capable of providing care equally and thus, the potential a system has to become polygamous not only depends on whether multiple mates, or resources critical to gain multiple mates are economically defendable, but also on the degree to which animals are able to exploit this potential (Emlen and Oring 1977). Ultimately, whether an individual makes use of this potential for polygamy will largely depend on the parental care needed to successfully rear the young (Emlen and Oring 1977). Therefore, the high prevalence of social monogamy in birds is thought to be necessary in order to successfully raise the young (Cockburn 2006). In line with that, in species with precocial young which require little parental care, social polygamy and weaker pair bonds are commonly found (Temrin and Tullberg 1995).

It has been shown that the variation in avian breeding systems has evolved in the context of a combination of life-history predispositions characterizing higher taxa, followed by adaptations to specific ecological factors, shaping the differences among closely-related species or populations (Owens and Bennett 1997). Although in birds there is a great discrepancy between a species social 
mating system and its genetic mating system (Petrie and Kempenaers 1998), the same principles seem to apply. The hierarchical pattern including life-history and ecology is also thought to be responsible for the variation in extra-pair behaviour or degree of polygamy in socially monogamous birds, with parental care needs and reproductive lifespans explaining differences among higher taxonomic clades and breeding density, synchrony and genetic variability explaining population differences in mating strategies (Griffith et al. 2002). Therefore, an approach combining life-history data and ecological factors is necessary to describe and understand the evolution of particular social systems in birds.

\section{Paths to group formation}

Permanent groups of birds can arise either when several individuals, usually from the same generation, form a group after dispersing from the natal territory, or when offspring do not disperse and form a group with their parents (Cahan et al. 2002). The first situation results with the formation of groups composed by predominantly unrelated individuals, and it is explained by classical benefits of group living. These benefits include a decrease in individual predation risk by increased group vigilance (Magurran et al. 1985; Elgar 1989), dilution effects (Bertram 1978; Turchin and Kareiva 1989) or predator confusion (Landeau and Terborgh 1986). Other advantages of grouping refer to increased feeding efficiency (Clark and Mangel 1986), and increased access to social information (King and Cowlishaw 2007) and mates (Höglung and Alatalo 1995). Species particularly vulnerable to predators, which forage more efficiently when aggregated, are expected to live in such non-kin based groups.

The second case, resulting in the formation of families, has been explained by ecological constraints limiting individual access to mates or territories and was regarded as a best-of-a-bad-job strategy for philopatric juveniles (Emlen 1982). Because many bird species are exposed to habitat saturation, constraining their breeding opportunities, the question is why under ecological constraints for independent breeding in only few species juveniles delay dispersal and remain in the natal territory, while in most birds, juveniles disperse and float (Figure 1). Consequently a later hypothesis was proposed to highlight the benefits of philopatry for non-dispersing juveniles that associate with their parents and enjoy higher fitness due to parental nepotism and habitat familiarity (Stacey and Ligon 
1991; Covas and Griesser 2007). An additional hypothesis that focuses on species' life-history traits has been proven useful in explaining the occurrence of this social organization in some lineages but not others, as similar ecological conditions are likely to affect species with contrasting reproductive lifespans differently (Ricklefs 1975; Arnold and Owens 1998). Thus, family groups in birds are often found in species with slower life histories (e.g. long-lived with low levels of productivity) (Russell et al. 2004) under particular social or ecological conditions affecting dispersal decisions (Ekman et al. 1994; Covas and Griesser 2007). Although the theoretical framework on family formation was developed for birds, some of these hypotheses have been also tested in mammals; with studies suggesting that unlike birds, mammals delay dispersal under general benefits of group-living (Russell 2004).

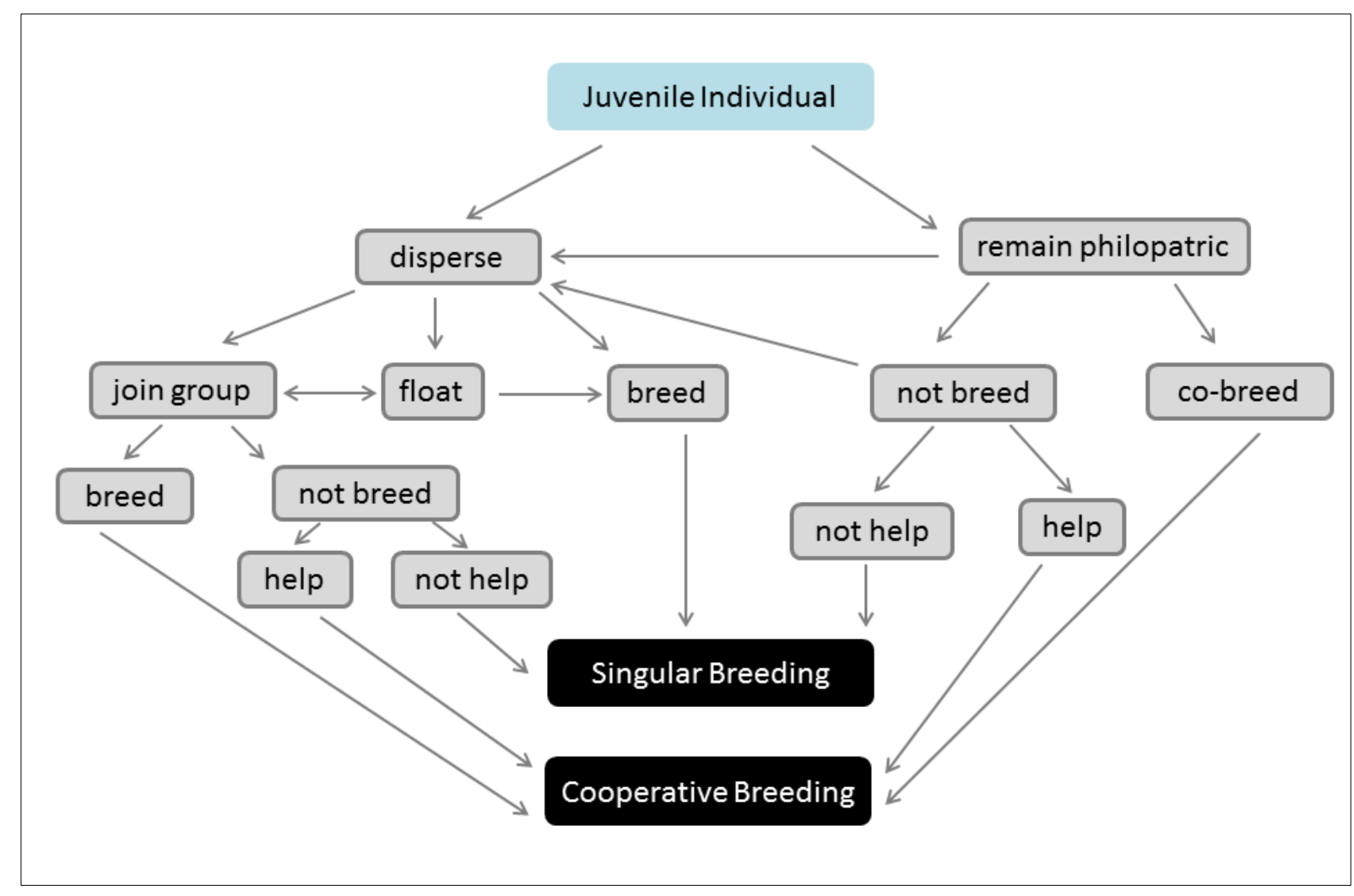

Figure 1. Representation of decisions during an individual's life (grey boxes) leading to particular breeding systems (black boxes), modified from Cahan et al. (2002).

\section{Cooperative behaviour: why help others?}

Cooperation among animals occurs when individuals assist others at a fitness cost for themselves. These behaviours pose a major problem to Darwin's theory of evolution which assumes that 
individuals are competing for reproduction and survival (Darwin 1859). However, cooperation can also be seen as a selfish act if helper individuals also benefit from it (Dawkins 1976). Theoretical and empirical work on cooperation has identified indirect fitness benefits of helping non-descendant kin in kin-based societies (Hamilton 1964a; Hamilton 1964b), and mutualism, reciprocity and manipulation in non-kin based interactions as ultimate explanations of these "altruistic" behaviours (Clutton-Brock 2009).

The specific case of cooperative breeding occurs when more than two individuals participate in rearing a brood or litter of young (Cockburn 1998), and it has been documented in a large variety of taxa (e.g. insects (Bourke 1997), fish (Wong and Balshine 2011), birds (Koenig and Dickinson 2004), mammals (Clutton-Brock 2002)). This term has been used to describe a range of breeding systems in birds including: (a) classic cooperative breeding (breeding pair with non-reproductive helpers), (b) communal breeding (several females lay eggs in a shared nest), and (c) plural breeding (several breeding pairs share a territory and cooperate in foraging, territory and predator defence, and in some cases they share the breeding site) (Ligon 1999). Because most cooperative breeders also live in family groups (Clutton-Brock 2002; Hatchwell 2009) the evolution of helping-at-the-nest has also been largely explained by kin-selection theory (Hamilton 1964a), and the indirect fitness benefits gained by helpers helping to rear close relatives (Emlen 1995). Indeed, comparative studies in different taxa have shown that female monogamy is related to cooperative breeding as it increases within-group relatedness (Hughes et al. 2008; Cornwallis et al. 2010; Lukas and Clutton-Brock 2012). However, cooperative breeding is not that common in mammalian kin-biased societies as it is in birds (Hatchwell 2009), probably because delayed dispersal in many social mammals is due to predator pressure (Krebs and Davies 1993) and ecological constraints for female reproduction in the generally polygynous mammalian groups are less common (Clutton-Brock 1989; Raihani and Clutton-Brock 2010) than in the usually socially monogamous birds (Russell 2004).

Other explanations of helping behaviour in a breeding context, that may apply to both related and unrelated helpers, refer to the payment of rent (Bergmüller and Taborsky 2005), future territory or breeding position inheritance (Queller et al. 2000), share in reproduction (Joste et al. 1985; Burke et al. 1989; Spiering et al. 2010), acquisition of parental care skills for future reproduction (Korndeur 1996), courtship of future mates (Sherley 1990), and social prestige (Zahavi 1995). Because some of 
these mechanisms may act in parallel, it is not surprising that most cooperative interactions occur among kin, for which indirect fitness occur in addition to other potential benefits.

\section{The Malagasy mesites}

Mesites are medium-sized ground-dwelling birds that belong to the family Mesitornithidae, which is endemic to Madagascar. Their phylogenetic relationships with other taxonomic groups are still unresolved since they have been related to Gruiformes (Sibley and Monroe 1990; Livezey 1998), Turniciformes (Livezey and Zusi 2007; Yang et al. 2010), Columbiformes (Hackett et al. 2008; Jetz et al. 2012), Cuculidae (Mayr and Ericson 2004), and Phoenicopteridae and Podicipididae (Brown et al. 2007) by different studies using genetic data and/or morphologic characters. The split between mesites and other avian groups have been dated from 80 to 60 million years ago, during the late Cretaceous, with the two mesite genera, Mesitornis and Monias, diverging about 30 million years ago (Ericson et al. 2006; Brown et al. 2007), around the time when different habitats where already present in Madagascar (Samonds et al. 2013). Not surprisingly, the three existent mesite species are allopatric and confined to these different habitat types, and exhibit different levels of sociality:

The brown mesite (Mesitornis unicolor) is found in the eastern rainy forests and breeds in pairs (Hawkins and Seddon 2003), the subdesert mesite (Monias benschi) lives in groups and breeds cooperatively in the southern spiny forests (Seddon et al. 2003), and the white-breasted mesite

(Mesitornis variegata) live in pairs or small groups, thought to be family groups (Hawkins and Seddon 2003), in the dry deciduous forests of western Madagascar (Evans et al. 1996) (Figure 2). The lack of information on the breeding system of white-breasted mesites is noticeable as they have been considered both pair and cooperative breeders by different authors (Hawkins and Seddon 2003; Cockburn 2006), but no study has corroborated the potential high genetic relatedness of their small social units nor investigated their parental care pattern in detail. All mesite species are considered to have precocial chicks (Hawkins and Seddon 2003), which is surprising, taking into account the high degree of sociality and cooperative breeding found in one species (Seddon et al. 2003), and suggested for another (Cockburn 2006).

Additionally, white-breasted mesites are often followed by canopy-dwelling bird species, particularly crested drongos (Dicrurus forficatus), and more sporadically long-billed greenbuls 
(Bernieria madagascarensis), Madagascar paradise flycatcher (Tersiphone mutata) and rufous vanga (Schetba rufa), among other species (Hawkins 2013). This heterospecific associations seem to be predominantly mutualistic as commensalism, and alarm calling are commonly observed, although kleptoparasitism also occurs (Evans et al. 1996). The effects that heterospecific interactions may have on predation risk perception or on juvenile development of heterospecific alarm call recognition have not been considered, but are likely to affect mesite sociality.

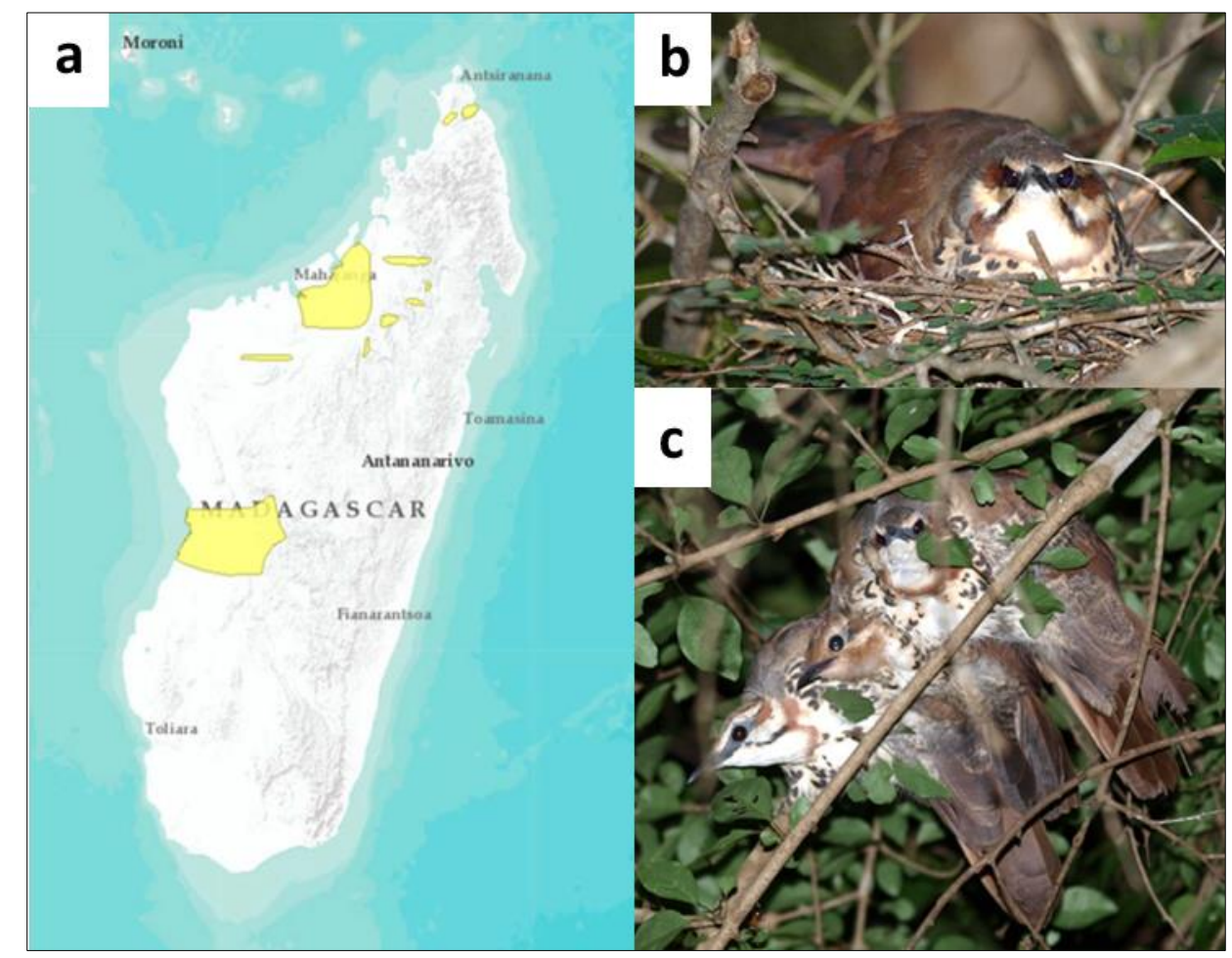

Figure 2. (a) Distribution map of the remaining populations of white-breasted mesites (Mesitornis variegata) (Birdlife International 2012). (b) White-breasted mesite adult male incubating at the nest and (c) adult pair with a 7 week-old chick in a roosting tree.

\section{Aims of this thesis}

The general aim of this thesis is to investigate several components of the social system of whitebreasted mesites, a species that was suggested to be a cooperative breeder but has precocial chicks which in principle do not need much parental care (Hawkins 2013), to set the basis of the level of sociality in this species and to investigate proximate and ultimate mechanisms that may have shaped their social system. 
Using data collected during five field seasons from July 2009 to April 2012, on 10 to 15 social units of M. variegata in Kirindy forest (western Madagascar), I first describe in detail the social system of white-breasted mesites. To do so, I analyse the social organization, mating system, parental care and several life-history traits using an inter-disciplinary approach including a new set of genetic markers developed for M. variegata (Chapter 1) and behavioural, spatial and morphological data. In Chapter 2, I show that white-breasted mesites live in small family groups or pairs, reproduce monogamously and provide bi-parental care to offspring, with no evidence of cooperative breeding. By subsequently comparing mesite social systems regarding life-history traits and ecological factors, I suggest several points that may influence the differences and similitudes in levels of sociality observed among the three species of mesites. Based on these results, I further investigate the patterns of juvenile dispersal in white-breasted mesites and suggest possible determinants affecting juvenile dispersal decisions related to limited breeding vacancies and slow development (Chapter 3). Because parental care is costly (Clutton-Brock 1991), parents are expected to optimize their level of investment in current and future reproduction to maximize their own fitness (Williams 1966; Charnov and Krebs 1974). Thus, parental costs of associating with juveniles are likely to influence parental tolerance and juvenile dispersal decisions, (Tarwater and Brawn 2010a). As parental aggression towards older juveniles occurs in mesites (Chapter 2), in Chapter 3, I test whether family-living is costly for parents by comparing feeding and vigilance behaviour and investment in subsequent breeding attempts for adults living in families compared to adults living in pairs.

Mesite social units are characterized by high intra-group cohesion and all individuals coordinate their daily activities, including predator escape (Evans et al. 1996). They forage on the leaf litter searching for insects with the head down most of the time, which may make them particularly vulnerable to aerial predators (Hawkins 1994). Additionally, in socially monogamous birds, genetic monogamy is rare (present in less than $25 \%$ of species) (Griffith et al. 2002), and mate guarding is used for males to minimize the rate of extra-pair copulations (Birkhead and Møller 1992). Therefore, in Chapter 4, I examine mesite group cohesion as a function of predation risk and adult reproductive state to investigate two potential selective pressures affecting within-group spatial patterns. 
Finally, I summarise the most important results of the thesis, discuss them in relation to other studies, and provide an outlook on future research that could improve our understanding on mesite social behaviour and the evolution of family-living in birds. 
Chapter 1: Characterization of 10 polymorphic microsatellite loci for white-breasted mesites (Mesitornis variegata)

with Andres Buser and Peter M. Kappeler 


\section{Summary}

We characterized 10 specific microsatellite loci for white-breasted mesites (Mesitornis variegata), an endemic bird species from western Madagascar. Nine loci were in Hardy-Weinberg equilibrium, and we detected 4-10 alleles per locus (mean $=6.1$ ). These primers will be used to study the mating system and social organization of white-breasted mesites and may have applications for the conservation of the few remaining populations of this vulnerable and still poorly studied species.

White breasted-mesites (Mesitornis variegata) are endemic birds from the dry deciduous forests of western Madagascar. They are monomorphic, ground-dwelling, medium-sized birds found in pairs or small groups (Hawkins and Seddon 2003). There is only little known on the general biology of this species, and its population genetic structure has not been studied. Here we describe the isolation and characterization of 10 microsatellite loci that were developed to study the social organization and mating system of $M$. variegata. White-breasted mesites are classified as vulnerable in the IUCN red list of threatened species (BirdLife International 2012). Available specific microsatellite markers can be an important tool for species conservation and could be used to assess the viability of the few remaining populations of this species by determining their genetic variability and degree of isolation (Hedrik 2001).

Feather, blood and tissue samples were collected in Kirindy Forest (Kappeler and Fichtel 2012), from birds and embryo remains of predated eggs. Sample collection and export were conducted according to local authority permits. Microsatellite sequences were isolated by ecogenics $\mathrm{GmbH}$ (Switzerland). Size selected fragments from genomic DNA were enriched for simple sequence repeat (SSR) content by using magnetic streptavidin beads and biotin-labelled CT and GT repeat oligonucleotides. The SSR enriched library was analysed on a Roche 454 platform using the GS FLX titanium reagents. The total 18,013 reads had an average length of 201 base pairs. Of these, 1,021 contained a microsatellite insert with a tetra- or a trinucleotide of at least 6 repeat units or a dinucleotide of at least 10 repeat units. Suitable primer design was possible in 340 reads, of which 36 
were tested for polymorphism. We extracted DNA from 75 individuals using DNeasy Blood and Tissue Kit (Qiagen). Reactions of $10 \mu \mathrm{l}$ containing $1 \mathrm{x}$ buffer, $200 \mu \mathrm{M}$ of dNTPs, $0.04 \mu \mathrm{M}$ M13 tailed locus specific forward primer, $0.16 \mu \mathrm{M}$ locus specific reverse primer, $0.16 \mu \mathrm{M}$ universal M13 primer 5'-end labelled with FAM (Metabion), 0.5 units of Hotstar Taq (Qiagen) were used to amplify each locus via the nested PCR procedure described by Schuelke (2000). The PCR profile was $95^{\circ} \mathrm{C}$ for $15 \mathrm{~min}, 30$ cycles of $30 \mathrm{~s}$ at $95^{\circ} \mathrm{C}, 45 \mathrm{~s}$ at $56^{\circ} \mathrm{C}$ (annealing temperature), $45 \mathrm{~s}$ at $72^{\circ} \mathrm{C}$, followed by 8 cycles of 30 $\mathrm{s}$ at $95^{\circ} \mathrm{C}, 45 \mathrm{~s}$ at $53^{\circ} \mathrm{C}$ and $45 \mathrm{~s}$ at $72^{\circ} \mathrm{C}$; and a final elongation phase of $30 \mathrm{~min}$ at $72^{\circ} \mathrm{C}$. PCR products were sized on a 3130XL Genetic Analyzer (Applied Biosystems/Hitachi) and GENEMAPPER V4 (Applied Biosystems) was used to assign genotypes. Observed $(\mathrm{Ho})$ and expected $(\mathrm{He})$ heterozygosity and Hardy-Weinberg equilibrium were calculated using GENEPOP V4.1.4 (Rousset 2008). Description of 10 polymorphic microsatellite loci is provided in Table 1 . We detected 4-10 alleles per locus (mean $=6.1$ ), Ho ranged from 0.288 to 0.853 and nine loci were in Hardy-Weinberg equilibrium. Overall, the described microsatellite markers should be an adequate tool for the study of the social system and conservation of $M$. variegata. 


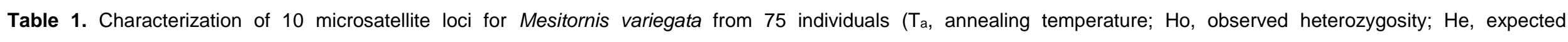
heterozygosity; * deviations from Hardy-Weinberg equilibrium $\mathrm{P}<0.05$ ).

\begin{tabular}{|c|c|c|c|c|c|c|c|c|c|}
\hline Locus & & Primer sequences 5'-3' & Repeat type & Size range $(b p)$ & Alleles $(\mathrm{N})$ & $\mathrm{T}_{\mathrm{a}}\left({ }^{\circ} \mathrm{C}\right)$ & Individuals $(\mathrm{N})$ & Ho & $\mathrm{He}$ \\
\hline \multirow[t]{2}{*}{ Mesvar_01929 } & $\mathrm{F}$ & ACGAGATAAAACGCGGATGC & $(\mathrm{GT})_{15}$ & $68-82$ & 6 & 56 & 75 & 0.680 & 0.621 \\
\hline & $\mathrm{R}$ & GGGGTTGCAAATGGGGAC & & & & & & & \\
\hline \multirow[t]{2}{*}{ Mesvar_05395 } & $\mathrm{F}$ & AGCAAAGAGGATGTTCTGCC & $(\mathrm{AC})_{19}$ & $181-188$ & 5 & 56 & 74 & 0.689 & 0.705 \\
\hline & $\mathrm{R}$ & CTCAGTCTATTGCATGCTTGTG & & & & & & & \\
\hline \multirow[t]{2}{*}{ Mesvar_06758 } & $\mathrm{F}$ & GGACGCTAGGGCAGAGATG & $(\mathrm{CA})_{17}$ & $113-129$ & 7 & 56 & 75 & 0.853 & 0.825 \\
\hline & $\mathrm{R}$ & CTCGCCAACTACGTGGAGG & & & & & & & \\
\hline \multirow[t]{2}{*}{ *Mesvar_07236 } & $\mathrm{F}$ & TGTCGTAGGGAGAGCTGAAC & $(\mathrm{TG})_{17}$ & $81-90$ & 4 & 56 & 73 & 0.288 & 0.552 \\
\hline & $\mathrm{R}$ & GCACTTCGCTAATGCACAG & & & & & & & \\
\hline \multirow[t]{2}{*}{ Mesvar_07348 } & $\mathrm{F}$ & TGGTCCCCATTCCGCCTC & $(\mathrm{TG})_{16}$ & $109-169$ & 10 & 56 & 75 & 0.813 & 0.830 \\
\hline & $\mathrm{R}$ & AGACCTCGGCGTAAAGGAAG & & & & & & & \\
\hline \multirow[t]{2}{*}{ Mesvar_08218 } & $\mathrm{F}$ & GAGGTGCGCCAATACCAAAG & $(\mathrm{GT})_{16}$ & $193-210$ & 7 & 56 & 75 & 0.627 & 0.694 \\
\hline & $\mathrm{R}$ & CCTGCCCTAAGAACGACAAG & & & & & & & \\
\hline \multirow[t]{2}{*}{ Mesvar_09677 } & $\mathrm{F}$ & GCTGGCCCCATTGATTTACG & $(\mathrm{AC})_{17}$ & $75-95$ & 7 & 56 & 75 & 0.813 & 0.772 \\
\hline & $\mathrm{R}$ & TGCTCATTAGCGTGGTTTCAG & & & & & & & \\
\hline \multirow[t]{2}{*}{ Mesvar_12782 } & $\mathrm{F}$ & ACACTTTCAGATGACAGGCTC & $(\mathrm{TG})_{12}$ & $177-182$ & 4 & 56 & 75 & 0.733 & 0.736 \\
\hline & $\mathrm{R}$ & GCAGCTTAATGCTCCACCTG & & & & & & & \\
\hline \multirow[t]{2}{*}{ Mesvar_14701 } & $\mathrm{F}$ & AGGCCAGGTAATCTGAAGGG & $(\mathrm{AC})_{13}$ & $153-158$ & 5 & 56 & 75 & 0.680 & 0.686 \\
\hline & $\mathrm{R}$ & AGGTGATCTGGTAGGGTTGC & & & & & & & \\
\hline \multirow[t]{2}{*}{ Mesvar_17549 } & $\mathrm{F}$ & GCAGAATGGTTATCCTATCTTTTACG & $(\mathrm{GT})_{12}$ & $118-132$ & 6 & 56 & 75 & 0.573 & 0.601 \\
\hline & $\mathrm{R}$ & CGTGAAGTCAGCGGGAATAC & & & & & & & \\
\hline
\end{tabular}


Chapter 2: Delayed juvenile dispersal and monogamy, but no cooperative breeding in white-breasted mesites

(Mesitornis variegata)

with Tamás Székely and Peter M. Kappeler

Behavioral Ecology and Sociobiology 2013 (in press) 


\section{Summary}

Although cooperative breeding is known from only about $9 \%$ of bird species, it has received substantial attention because individuals foregoing their own reproduction to help others represent a long-standing evolutionary puzzle. We studied group formation, breeding system, spatial distribution and several life-history traits of white-breasted mesites (Mesitornis variegata). Based on field observations across 3 years, we found that white-breasted mesites live in year-round stable pairs, and that groups are formed by juvenile philopatry. As other family-living birds, M. variegata exhibit a slow pace-of-life, characterized by high annual adult survival, low productivity, long chick dependence and extended parental care. However, although reproduction is monogamous and juveniles showed interest in their parents' nests, we found no evidence of cooperative breeding. We suggest that slow life-histories, extended parental care and year-round territoriality predispose juvenile mesites to delay dispersal. However, adult intolerance towards older juveniles may prevent them from adopting a cooperative life-style. Comparisons with other species of mesite indicate that monogamy and delayed juvenile dispersal are necessary, but not sufficient for the evolution of cooperative breeding in this family of birds, and that particular ecological and social conditions have facilitated the transition from pair-living to a type of group that may represent a stepping stone in the evolution of cooperative breeding in mesites and other birds.

\section{Introduction}

Cooperative breeding (cooperation of more than two individuals in rearing a single brood of young) is known from only about $9 \%$ of bird species (Cockburn 2006), but it has received substantial theoretical and empirical attention (e.g. (Hatchwell 2009; Cornwallis et al. 2010; Jetz and Rubenstein 2011; Leggett et al. 2012)) because individuals foregoing their own reproduction to help others represents a long-standing evolutionary puzzle. Cooperative breeding requires the (at least temporary) presence of more than two independent individuals; i.e. the formation of groups. Permanent groups can arise either when several individuals form a group after dispersing from the natal territory, or when offspring 
do not disperse and form a group with their parents (Cahan et al. 2002). In the first case, groups are mainly formed by unrelated individuals or distant relatives, depending on the species' dispersal patterns and population viscosity (Rollins et al. 2012; Hatchwell 2009), and classical benefits of groupliving (e.g. decreased predation risk and increased feeding efficiency (Krause and Ruxton 2002)) have been proposed to explain the origins of group-living. Cooperative breeding in some of these societies is related to direct fitness benefits, mediated by the perceived paternity of the brood (Davies 2000) or future prospects of reproduction (Woolfenden and Fitzpatrick 1978; Pen and Weissing 2000). Species that forage more efficiently in groups, particularly vulnerable to predators, and with low reproductive skew are expected to live in such groups.

The formation of family groups, on the other hand, has been explained by the cost-benefit balance between philopatric and dispersing juvenile strategies (Kokko and Ekman 2002) and by the species' life-history traits (Ricklefs 1975; Arnold and Owens 1998). Such families are found most commonly in species with slow pace-of-life (e.g. long lived, low productivity, low population turnover) under social or ecological constraints for dispersal and/or under situations benefiting philopatric strategies (Emlen 1982; Covas and Griesser 2007). Helping behaviour during breeding by previous offspring is largely explained by indirect benefits by increasing the reproductive success of relatives (inclusive fitness) in family groups (Mumme 1992), and direct benefits such as an improved ability to rear offspring (Clutton-Brock 2002) or chances to become breeders (Cockburn 1998). The decision to live in family groups is not necessarily followed by the decision to help during breeding, although the combination of these traits is frequently observed in birds (Komdeur and Ekman 2010).

Recent comparative studies including a broad range of bird species (Cornwallis et al. 2010; Jetz and Rubenstein 2011), as well as others restricted to certain families of birds (Rubenstein and Lovette 2007), have been useful in determining proximate mechanisms of cooperative breeding, such as monogamy and environmental variability. Therefore, further insights into the evolution of cooperative breeding can be gained by comparing the social systems, life histories and ecology of closely related species with different levels of cooperation.

Mesites are tropical birds found in Madagascar that belong to the endemic family Mesitornithidae. Their phylogenetic relations to other bird families are not very clear and they have been allied with the Gruiformes (Sibley and Monroe 1990), Turniciformes (Livezey and Zusi 2007), and 
close to Columbiformes (Hackett et al. 2008) by different studies. This family of birds includes only three species: the brown mesite (Mesitornis unicolor), which lives and breeds in pairs in the eastern rain forests (Hawkins and Seddon 2003), the subdesert mesite (Monias benschi), which lives in the southern spiny forests in groups of related and unrelated individuals and breeds cooperatively (Seddon et al. 2003, Seddon et al. 2005), and the white-breasted mesite (Mesitornis variegata), which lives in the dry deciduous forests of western Madgascar. White-breasted mesites are terrestrial, monomorphic, and have a mean body mass of $110 \mathrm{~g}$ (Ramanitra et al. 2006). They are commonly found in pairs or small groups, assumed to be family units (Hawkins and Seddon 2003). As a result, they have been classified as cooperative breeders (Cockburn 2006), but they have also been characterized as 'at least monogamous' (Hawkins and Seddon 2003). However, the genetic relatedness, age, sex composition and stability of these groups have not been previously studied. Moreover, mesite chicks have been described as precocial (Evans et al. 1996), but food provisioning has been reported in subdesert mesites (Seddon et al. 2003), which suggests a semi-precocial developmental mode, although it is not known for how long chicks are actually dependent on parental care.

Because delayed juvenile dispersal is most commonly found in tropical species with slow life histories, and since this is partly the path of group formation in the closely related M. benschi, whitebreasted mesites may be living in families. However, because of their ground-dwelling habits, their relative small size, and chicks that potentially require little care, family living may not be expected, but other paths to group formation other than delayed dispersal might be possible. We therefore investigated group formation in $M$. variegata by analysing their social organization, i.e. the sex and age composition and genetic structure of social units (Kappeler et al. 2013). We measured group stability, spatial cohesion and several life-history traits to determine whether this tropical species is characterized by a slow pace of life, and whether habitat saturation potentially constrains juvenile dispersal. Finally, we studied the mating system and parental care pattern in this species to establish whether white-breasted mesites breed cooperatively or not.

We predicted that groups are formed by delayed dispersal of juveniles if this species is characterized by high adult survival and if chicks are dependent for several months. In this case we also expected stable pair bonds and cooperative breeding when the mating system is mostly 
monogamous (related helpers have high indirect benefits) (Cornwallis et. al 2010). Alternatively, if mesite chicks are relatively precocial, juveniles would disperse early and groups would not be composed of related individuals. In this case, cooperative breeding would be expected if the mating system is not monogamous, allowing for direct benefits of helpers.

\section{Methods}

We studied a population of white-breasted mesites from October 2009 to April 2012 in Kirindy Forest, a forestry concession managed by the Centre National de Formation, d'Etudes et de Recherche en Environnement et Foresterie (CNFEREF) in western Madagascar. The habitat consists of dry deciduous forest characterized by a hot wet season from November to April, corresponding to the breeding season of white-breasted mesites, and a cooler dry season from May to October. Several grid systems of narrow foot trails with intersections every 25 to $50 \mathrm{~m}$ are present in the area. More detailed information on the study site is provided in Kappeler and Fichtel (2012).

Most of the data were collected in four field seasons: from November 2009 to January 2010, June to September 2010, October 2010 to March 2011 and October 2011 to April 2012, with additional data on group size and composition collected by a local field assistant between these periods, providing about a data point per month for most groups.

Adult and juvenile birds were captured using mist nets. Birds were colour-ringed and a $1.8 \mathrm{~g}$ radio-transmitter mounted on the tail (BD-2 model, Holohill Systems Ltd) was attached to one individual per group. We took blood or feather samples from all captured individuals for genetic analyses. Resident individuals that could not be captured were photographed and identified based on plumage characteristics (Hawkins 1994). We classified the birds into three age categories: chick (<3 months), juvenile (3-12 months), and adult (> 12 months) based on size, and rectrix and tertial shape (Appendix Table A1 and Figure A1).

Birds were located with the help of radio-transmitters, by searching the study site or by waiting for the birds to descend from their traditional roosting trees before dawn. Due to the terrestrial habits of the species and the habituation to humans by most individuals, birds could generally be followed and observed at close proximity $(<7 \mathrm{~m})$ for several hours per day. 


\section{Social organization}

A group/social unit was defined as a cohesive set of individuals that foraged and roosted together. To determine group stability in size and composition, social units were monitored regularly, and all individuals present were noted. Because secondary dispersal is very rare in white-breasted mesites, adult annual survival was calculated for each year as the proportion of colour-ringed individuals resighted the next year (Ebbinge et al. 1991). The spatial position of each group was recorded every 20 minutes with a portable GPS device (76CSX, Garmin) to determine group home range size, stability and overlap with neighbouring groups. We used the bootstrap function of the R package "move" (Kranstauber and Smolla 2013) to create plots of home range size estimates using minimum convex polygons (MCPs) based on different numbers of locations. Visual inspection of plots from 8 different groups revealed that asymptotes were achieved after about 53 locations. Therefore, home range sizes were estimated and plotted for social units for which at least 55 geographic locations were available per season (non-breeding: July-August, and breeding: December-February) based on MCPs calculations using Arcview GIS 3.3. For social units with more locations, 55 randomly selected locations were used for the analysis to avoid differences related to differential sampling effort. Because of the secretive behaviour of the species and their range outside the path system of our study area, data on home range overlap was only available for 7 neighbouring groups during the non-breeding season in 2010. We used data from 5 of these groups and two non-neighbouring groups for the analysis of within-group seasonal variation in home range because these were the only groups for which we had enough spatial data from both breeding and non-breeding seasons.

\section{Breeding behaviour}

We recorded the identity and the order in which birds were involved in nesting site inspections (climbing or flying to bushes giving a bubbling call, often carrying a twig). We recorded nest building behaviour by noting the number of times each bird brought nest material and the time it spent building the nest. Active nests were found by regularly monitoring nests found under construction or by following adults going back to incubate at the nest. We recorded the clutch size of each nest, and we took a blood sample from the brachial vein and weighed each chick on the nest shortly after hatching. Chicks were not individually marked at the nest because of their small tarsi size. When remains of 
depredated or abandoned eggs were found, we took a sample of the embryonic tissue for genetic analyses.

We monitored 21 nests until they failed or chicks left, using a custom-made video surveillance system consisting of a motion detector camera connected to a digital recorder in a waterproof box (Neumann, Ettlingen, Germany), powered by a car battery (see Pyritz et al. 2013). We set the system to record from 5:00 to 19:00 (local time, corresponding to daylight hours) at $1 \mathrm{frame} / \mathrm{s}$ in the absence of movement at the nest and at 25 frame/s when a movement was detected to reduce the size of the digital recordings. The camera was situated 1.5 to $3 \mathrm{~m}$ from the nest as soon as possible after the nest was found. We used times when the nests were unattended to install the cameras and to check the nests to minimize disturbance. All birds returned to incubate shortly after the set up and measurements were finished. The identity of caring individuals, the time spent incubating and the rate at which they fed the chicks were determined by analysing the footage from each nest, which could be downloaded with a portable monitor, a remote control and a hard disk. The digital recorder and battery were placed at $10-20 \mathrm{~m}$ from the nest, allowing for regular checks of the system, change of battery and download of the recordings without disturbing the incubating birds.

Because the bird incubating at 19:00h was always the same bird incubating the next morning at 5:00h, and this species is not active at night, we assumed that night incubation was uninterrupted and entirely done by this individual, following Seddon et al. (2003). Therefore, we provide values for full day (0:00-24:00h) and daytime incubation (5:00-19:00h) below.

Parental care share was calculated based on four data sets: inspecting nest sites (151 inspections from 17 pairs), nest building (13.9 hours of observations from 8 breeding pairs), incubation (173 complete days of video recordings on 21 nests from 12 different pairs), and chick care and parental aggression (371 hours of observations of 15 pairs with offspring, including video recordings from hatchlings at the nest). Offspring age was certain for 19 out of 26 broods. For the remaining 7 broods, which were found when juveniles were older than 4 months, we assumed they had hatched in March, because white-breasted mesites are seasonal breeders and in our study population $75 \%$ of the surviving offspring hatched that month. 


\section{Genetic analyses}

We used the same protocols and 9 of the 10 microsatellite markers described in Gamero et al. (2013)a to genotype 75 individuals using DNA extracted from feathers, blood and tissue. We excluded one of the loci from the analysis because it deviated significantly from Hardy-Weinberg equilibrium (Gamero et al. 2013) due to a high frequency of null alleles (>0.30). We determined the sex of all birds using the P2/P8 primers described in Griffiths et al. (1998). PCR products obtained from the sex determination test were sized on a 3130XL Genetic Analyzer (Applied Biosystems/Hitachi) due to the small size difference (10 bp) between them. This test produced two products of $385 \mathrm{bp}$ and $395 \mathrm{bp}$ for females, and one product of $385 \mathrm{bp}$ for males of M. variegata.

\section{Parentage and relatedness analysis}

We used COLONY V2 (Jones and Wang 2010) to assign paternity of juveniles and chicks, and to assign pairs of full and half siblings. We implemented the full likelihood method, a polygamous mating system without inbreeding (recommended when analysing parentage of offspring from several breeding seasons (Jones and Wang 2010)), and a genotyping error rate of 0.01 . We assumed that the percentage of candidate fathers and mothers sampled in our population corresponded respectively to the percentage of adult males (90\%) and females (65\%) sampled. We included as candidate parents all individuals hatched the previous year or before, regardless of whether they were re-sighted in the area. We accepted the most likely parentage assignments with a probability of more than 0.80 . All second most likely parentage assignments had very low probabilities, ranging from 0.002 to 0.14 . We accepted full-sibling and half-sibling clusters with a probability higher than 0.80 .

We used COANCESTRY V1 (Wang 2011) to calculate Queller and Goodnight's (1989) pairwise relatedness coefficients between all individuals.

\section{Statistical analyses}

All statistical tests were conducted with IBM SPSS Statistics 20 . All values are given as mean \pm SD, obtained from averaged values per social unit or individual. Likewise, statistical tests were performed on averaged values per social unit or individual to avoid pseudo-replication. We tested the distribution 
of the variables with a Shapiro-Wilk test and used parametric or non-parametric statistics accordingly. We used Wilcoxon signed rank tests to compare sex differences in parental care share and seasonal differences in group size, and a paired sample t-test for seasonal differences in home range size within social units.

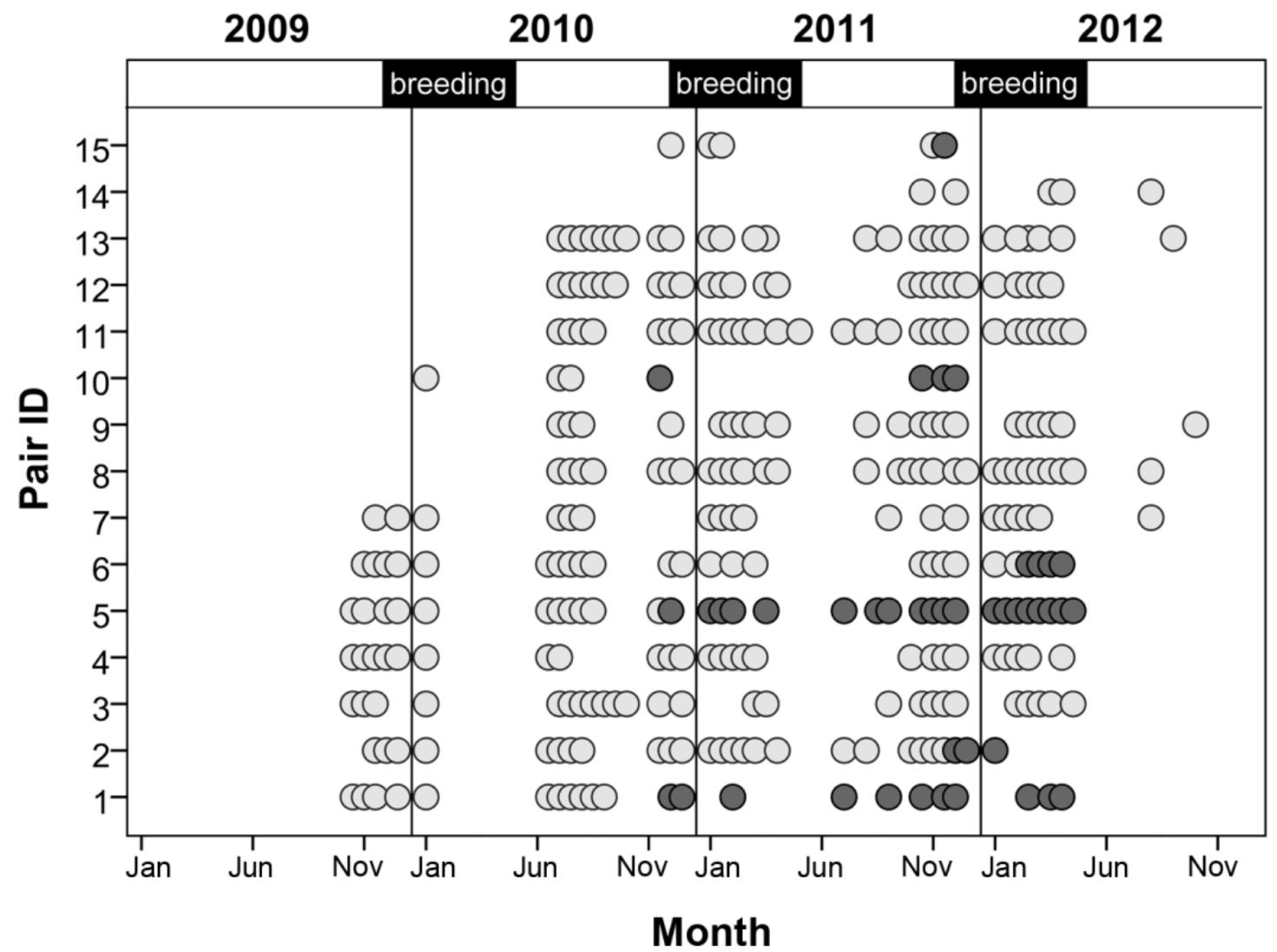

Figure 1 Pair stability in white-breasted mesites over a 3 year study period. Each dot represents at least one observation per fortnight and pair. Different shading refers to an adult change (see Results)

\section{Results}

\section{Social organization}

Social units consisted of an adult male, an adult female and 0 to 2 juveniles. Group size was significantly higher during the non-breeding season ( $2.8 \pm 0.4$ individuals) than during the breeding season $(2.1 \pm 0.2$ individuals); $(Z=3.541 ; P<0.001 ; N=18)$. Adult birds had a mean annual survival of $0.87 \pm 0.05$ and were in general stable members of one group during the study period (Figure 1). We 
detected six changes in adult composition in 15 social units that were followed for one $(\mathrm{N}=2)$, two $(\mathrm{N}=6)$ or three years $(\mathrm{N}=7)$. Four out of six seemed to be a consequence of the death of one partner since these individuals were never re-sighted in the area. The remaining two cases were females that deserted their mate for a neighbouring male that had just lost its partner. Juvenile composition changed annually, with no juvenile staying in the same social unit for more than 13 months.

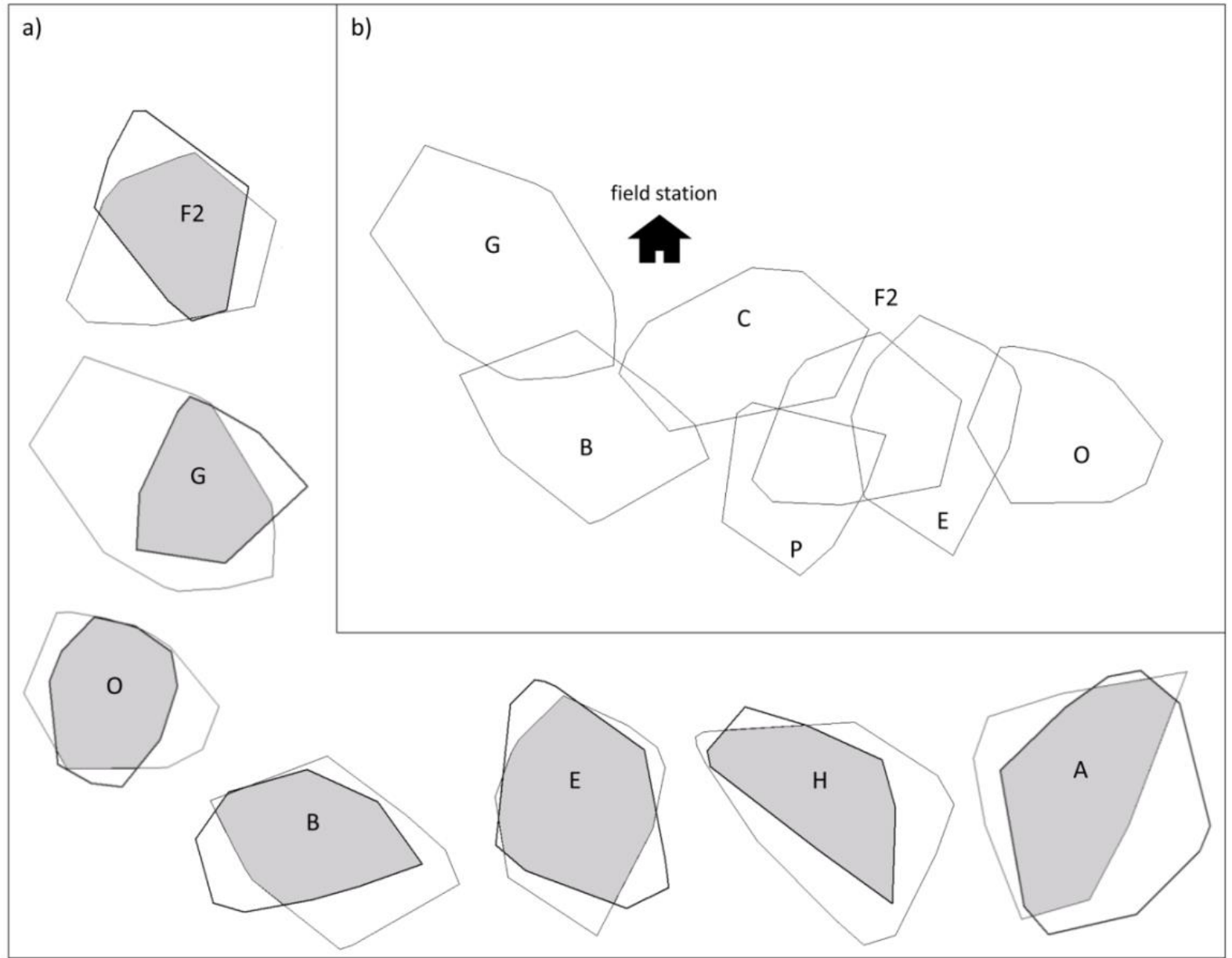

Figure 2. Minimum convex polygons (MCP) calculated from 55 locations for each white-breasted mesite social unit representing (a) within group home range variation between the breeding (thick lines) and non-breeding periods (narrow lines) and (b) between group overlap during the non-breeding season 
Table 1. Parentage assignments for 43 white-breasted mesite offspring (28 chicks sampled at the nest and 15 juveniles of 5 - 13 months of age) based on 9 microsatellites (Gamero et al. 2013a). Offspring IDs in italics correspond to assignments with a probability lower than 0.95

\begin{tabular}{|c|c|c|c|c|c|c|c|}
\hline $\begin{array}{l}\text { Chick } \\
\text { ID }\end{array}$ & $\begin{array}{l}\text { Brood } \\
\text { ID }\end{array}$ & $\begin{array}{c}\text { Brood } \\
\text { size }\end{array}$ & $\begin{array}{l}\text { Group } \\
\text { ID }\end{array}$ & Year & $\begin{array}{l}\text { Sampled } \\
\text { adults }\end{array}$ & $\begin{array}{c}\text { Assigned } \\
\text { mother }\end{array}$ & $\begin{array}{c}\text { Assigned } \\
\text { father }\end{array}$ \\
\hline B21, B22 & 1 & 2 & B & 2011 & all & adult female & adult male \\
\hline B25 & 2 & 2 & C & 2011 & all & adult female & adult male \\
\hline B38, B40 & 3 & 2 & C & 2012 & all & adult female & adult male \\
\hline B16, B17 & 4 & 2 & E & 2011 & all & adult female & adult male \\
\hline B56, B58 & 5 & 2 & E & 2012 & all & adult female & adult male \\
\hline B20, B27 & 6 & 2 & $\mathrm{~F}$ & 2011 & all & adult female & adult male \\
\hline B36 & 7 & 2 & F2 & 2012 & all & adult female & adult male \\
\hline B63, B67 & 8 & 2 & G1 & 2012 & all & adult female & adult male \\
\hline B49, B53 & 9 & 2 & $\mathrm{H}$ & 2012 & all & adult female & adult male \\
\hline B18, B19 & 10 & 2 & 12 & 2011 & all & adult female & adult male \\
\hline B61 & 11 & 2 & 12 & 2012 & all & adult female & adult male \\
\hline B47 & 12 & 2 & $\mathrm{H} 1$ & 2012 & adult male & - & adult male \\
\hline B51 & 12 & 2 & $\mathrm{H} 1$ & 2012 & adult male & - & - \\
\hline B23, B24 & 13 & 2 & 0 & 2011 & adult male & - & adult male \\
\hline B43, B44 & 14 & 2 & $\mathrm{O}$ & 2012 & adult male & - & adult male \\
\hline F70, F71 & 15 & 2 & $P$ & 2011 & adult male & - & adult male \\
\hline B54 & 16 & 1 & $P$ & 2012 & adult male & - & adult male \\
\hline Juvenile & Social & Group & & & & & \\
\hline ID & Unit ID & size & & & & & \\
\hline B2 & 1 & 3 & $F$ & 2009 & all & adult female & adult male \\
\hline$B 4 b, \mathrm{~F} 9$ & 2 & 4 & C & 2009 & all & - & adult male \\
\hline F17 & 3 & 3 & $\mathrm{H}$ & 2009 & all & adult female & adult male \\
\hline F25 & 4 & 4 & B & 2009 & all & adult female & adult male \\
\hline F40, F41 & 5 & 4 & $M$ & 2010 & all & - & adult male \\
\hline F46 & 6 & 3 & $\mathrm{G}$ & 2010 & all & adult female & adult male \\
\hline F51 & 7 & 3 & $\mathrm{~F} 2$ & 2010 & all & - & adult male \\
\hline F100 & 8 & 3 & $\mathrm{~F}$ & 2012 & all & adult female & adult male \\
\hline F101 & 9 & 3 & $\mathrm{~B}$ & 2012 & all & adult female & adult male \\
\hline F86 & 10 & 3 & G1 & 2012 & all & adult female & adult male \\
\hline B6 & 11 & 4 & $\mathrm{~J}$ & 2009 & adult female & - & - \\
\hline F52 & 12 & 3 & O & 2010 & adult male & - & adult male \\
\hline $4 a$ & 13 & 3 & A & 2009 & adult male & - & adult male \\
\hline
\end{tabular}


Parentage was tested for 15 juveniles belonging to 11 groups (Table 1). For all juveniles for which the adult male of the group was sampled $(\mathrm{N}=14)$, this adult male was assigned as the genetic father. Maternity assignments of the 13 juveniles for which the adult female of the group was sampled revealed that only 7 could be assigned to the putative mother, while the rest $(\mathrm{N}=6)$ could not be assigned to any other female sampled in the study area. Relatedness coefficients between each of these 6 offspring and the adult female of the group was $-0.167 \pm 0.13$ (range: -0.357 to -0.024 ), indicating that these females were unrelated to the juveniles of the group. All paternity assignments were at $>0.95$ probability, except for offspring $\mathrm{B} 4 \mathrm{~b}$, for which the probability was 0.92 . All maternity assignments were at $>0.95$ probability, except for offspring F86, for which the probability was 0.81 .

Home ranges were fairly stable throughout the year, since analysis of size and overlap within social units in different seasons revealed a $55.8 \pm 11.5 \%$ home range overlap and no significant size differences (non-breeding: $9.41 \pm 1.71$ ha; breeding: $7.34 \pm 2.50$ ha; $t=1.945 ; P=0.100, N=7 ;$ Figure 2a). Home ranges also overlapped among neighbours during the non-breeding season (Figure 2b).

\section{Breeding variables}

White-breasted mesites laid 1 or 2 eggs per clutch ( $1.92 \pm 0.18 ; \mathrm{N}=39$ nests from 16 breeding pairs) and pairs produced up to three clutches per breeding season. Successful nests were active for 28 30 days (egg laying period: 2 - 3 days, incubation: 25 days, and brooding chicks at the nest: 1 - 2 days). Hatchling weight was $9.34 \pm 0.70 \mathrm{~g}$, based on 23 chicks from 10 pairs.

\section{Parental care share}

Nest building

Males exhibited more inspecting of nesting sites than females $(Z=-2.596 ; P=0.009)$ and juveniles (the latter including only the 7 social units with juveniles, Table 2). The individual initiating this behaviour was in $83 \%$ of the cases the adult male of the group, while adult females and juveniles initiated 16 and $1 \%$ of inspections, respectively. Adult males brought nest material at higher rates than adult females $(Z=-2.521 ; P=0.012)$, but both sexes spent the same amount of time building the nest $(Z=0.169 ; P=$ 0.866). We recorded only one juvenile male bringing nest material on two occasions. 
Incubation

Nests were incubated $94.8 \pm 2.3 \%$ of the time (full day). Interruptions in the incubation had a mean duration of $34.9 \pm 20.0$ minutes, and were mainly related to a change in the incubating bird (87.7 \pm $16.2 \%)$, and rarely to a break within an incubation bout (12.3 $\pm 16.2 \%)$. Full day incubation was done only by adult individuals and was male-biased $(Z=-3.059, P=0.002)$, but daytime incubation was female-biased $(Z=2.197 ; P=0.028$, Table 2). The incubation pattern consisted generally of two bouts (Figure 3): females incubated only during daylight (from about 6:00-7:00h until about 13:00-14:30h), and males started incubating in the early afternoon (13:30-15:00h) until the next morning (5:00-6:00h).

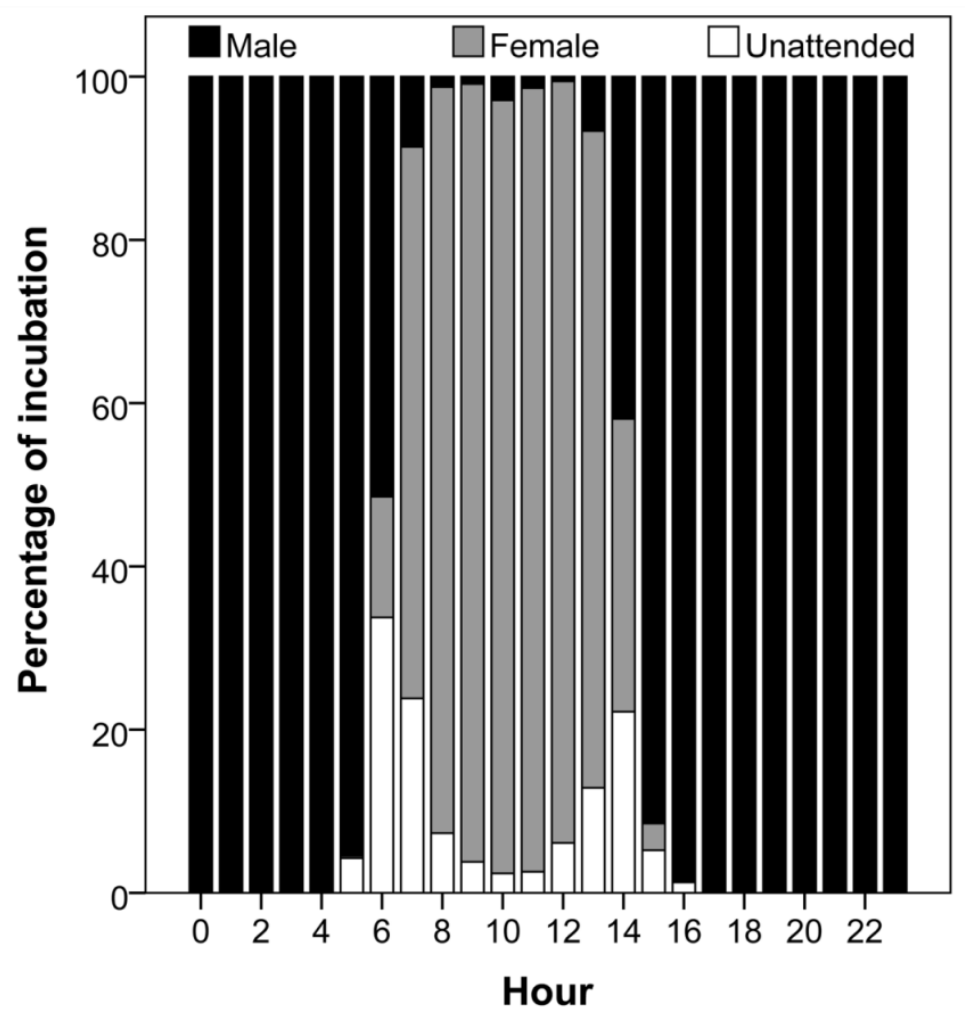

Figure 3. Incubation pattern for white-breasted mesites representing the percentage of incubation done by males (black), females (grey) and left unattended (white) for each hour of the day based on mean values per breeding pair ( $\mathrm{N}=21$ nests from 12 pairs; daylight period (5:00-19:00)) 


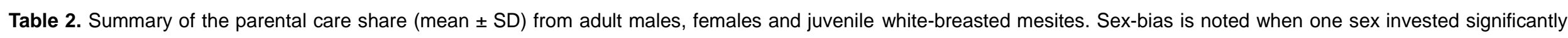

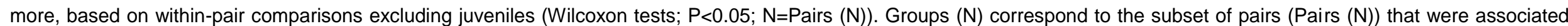
with at least one juvenile

\begin{tabular}{|c|c|c|c|c|c|c|}
\hline Parental investment & Adult male & Adult female & Juveniles & Pairs (N) & Groups (N) & Sex-bias \\
\hline Inspecting nesting sites (\% participation) & $84.1 \pm 26.2$ & $40.4 \pm 36.6$ & $11.1 \pm 21.7$ & 17 & 7 & Male \\
\hline Nest building rate (visits/ min) & $0.23 \pm 0.10$ & $0.13 \pm 0.05$ & rarely & 8 & 2 & Male \\
\hline Nest building bouts (min) & $2.92 \pm 1.68$ & $3.64 \pm 2.78$ & rarely & 7 & 2 & - \\
\hline Full day incubation (hours) & $15.94 \pm 0.49$ & $6.79 \pm 0.61$ & 0.0 & 12 & 3 & Male \\
\hline Daytime incubation (hours) & $5.94 \pm 0.49$ & $6.79 \pm 0.61$ & 0.0 & 12 & 3 & Female \\
\hline Feeding chicks (food items/ hour ${ }^{*}$ chick) & $1.27 \pm 1.41$ & $1.00 \pm 1.11$ & - & 15 & 0 & - \\
\hline
\end{tabular}


Offspring food provisioning and aggression

Chicks have the eyes open, are mobile and able to walk shortly after hatching. They leave the nest within 12-36 hours after hatching and follow their parents. Food provisioning is done at high rates for two months ( $4.3 \pm 3.1$ food items per chick and hour; $\mathrm{N}=10$ social units), after which adults rarely feed them $(0.1 \pm 0.1$ food items per chick and hour; $\mathrm{N}=13$ social units; Figure 4$)$. Adult males and females provide food at similar rates $(Z=-1.274 ; P=0.203$; Table 2$)$, and no juvenile was recorded in the groups during the chick provisioning time. Adults were observed chasing juveniles that were older than 7 months at low rates $(0.1 \pm 0.2$ chases per chick and hour; $N=10$ social units), but never younger than that age (Figure 4).

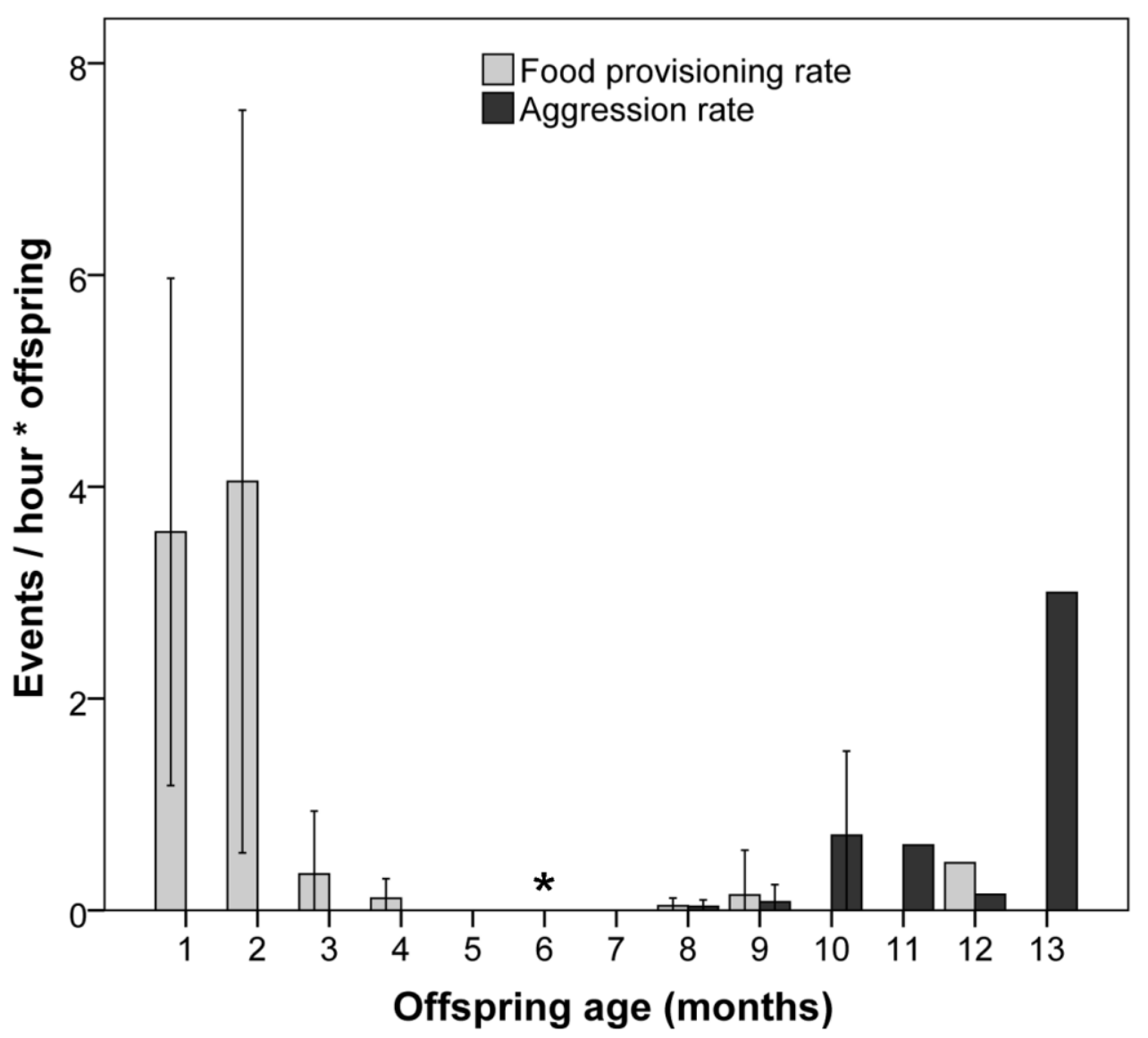

Figure 4. Mean $\pm S D$ of adult food provisioning and aggression rate to offspring in respect to their age, based on 26 broods/ social units from 15 pairs ( ${ }^{*}$ no observation available at this age) 


\section{Mating system}

All copulations observed $(\mathrm{N}=16)$ involved social breeding partners. We had samples from all the social fathers and of $73 \%$ of the social mothers of the 28 chicks sampled at the nest and tested for parentage (Table 1). Paternity could be assigned for 27 chicks, and social and genetic fathers corresponded in all cases. The paternity of the remaining chick could not be assigned and was assumed to be an extrapair sired chick. Maternity could be assigned only for the chicks for which the sample of the caring female was available. In all these cases (19 chicks) social mothers were assigned as genetic mothers. All paternity assignments were at 0.95 probability, except for offspring B21 and B47, for which the probabilities were 0.93 and 0.86 , respectively. All maternity assignments were at 0.95 probability. Summary of full and half sibling relationships including all offspring (chicks and juveniles) is provided in Table 3. Mean exclusion probabilities of the full sibling clusters were 0.98 (range: $0.81-1.0$ ).

Table 3. Full sibling and half sibling clusters for 43 white-breasted mesite offspring (28 chicks and 15 juveniles). IDs in italics denote cluster probabilities lower than 0.95

\begin{tabular}{cccccc}
\hline $\begin{array}{c}\text { Full sibling } \\
\text { cluster }\end{array}$ & Pair & $\begin{array}{c}\text { Full siblings } \\
\text { IDs }\end{array}$ & $\begin{array}{c}\text { Full siblings } \\
\text { Mother }\end{array}$ & $\begin{array}{c}\text { Full siblings } \\
\text { Father }\end{array}$ & $\begin{array}{c}\text { Half Siblings } \\
\text { IDs }\end{array}$ \\
\hline 1 & A & 4a & $?$ & Male_1 & - \\
2 & B & B21, B22, F25, F101 & Female_1 & Male_2 & - \\
3 & C & B25, B38, B40 & Female_2 & Male_3 & B4b, F9 \\
4 & C1 & B4b, F9 & $?$ & Male_3 & B25, B38, B40 \\
5 & E & B16, B17, B56, B58 & Female_3 & Male_4 & - \\
6 & F & B20, B27, B2, F100 & Female_4 & Male_5 & - \\
7 & F2 & F51 & $?$ & Male_6 & B36 \\
8 & F2 & B36 & Female_5 & Male_6 & F51 \\
9 & G & F46 & Female_6 & Male_7 & B63, B67, F86 \\
10 & G1 & B63, B67, F86 & Female_7 & Male_7 & F46 \\
11 & H & B49, B53, F17 & Female_8 & Male_8 & B47 \\
12 & H1 & B47 & $?$ & Male_8 & B49, B53, F17 \\
13 & H1 & B51 & $?$ & $?$ & - \\
14 & I2 & B18, B19, B61 & Female_9 & Male_9 & - \\
15 & J & B6 & Female_10 & $?$ & - \\
16 & M & F40, F41 & $?$ & Male_10 & - \\
17 & O & F52, B23, B24, B43, B44 & $?$ & Male_11 & - \\
18 & P & F70, F71, B54 & $?$ & Male_12 & - \\
\hline
\end{tabular}




\section{Discussion}

\section{Group formation}

White-breasted mesites live in stable pairs and groups, the latter of which are formed by delayed dispersal of recent offspring that stay in the natal territory for up to 13 months. They show a typical pattern of a 'slow pace-of-life' species: high adult survival, small clutch sizes and a maximum of 2 juveniles per year.

Juvenile dispersal can be constrained by the unavailability of good territories (Komdeur 1992) and mates (Hatchwell and Komdeur 2000), and is thought to be a result of a low population turnover found in species with high adult survival (Arnold and Owens 1998). In white-breasted mesites, social units do not generally tolerate neighbours and adults show territorial defence against other groups regardless of the season (Hawkins 1994). However, they seem unable to maintain stable borders and exclusive territories as home ranges overlapped among neighbours and borders changed across seasons.

The inability to defend territories while being aggressive to neighbours could suggest that the study area was saturated with groups, which may be a result of the high adult annual survival (Arnold and Owens 1998). However, although habitat saturation constrains independent breeding of juveniles, it is not sufficient to explain why juveniles stay in the natal area, as habitats without breeding vacancies are also found in species that do not delay juvenile dispersal. The decision to stay at home instead of dispersing and becoming a floater seems to be related to an intrinsic benefit of the natal territory, such as extended parental care, which can increase survival and life time reproductive success of juveniles that stay longer (Stacey and Ligon 1991; Ekman et al. 2000; Tarwater and Brawn 2010a). In this species of mesite, adults showed extended parental care as they also irregularly fed chicks older than 2 months (the age at which they seem to become nutritionally independent), at very low rates until they were 12 months of age.

According to the Stark and Ricklefs' (1998) classification of different chick developmental modes, mesite chicks can be classified as semi-precocial. In many semi-precocial species, such as members of the Laridae and Alcidae (Stark and Ricklefs 1998), it is obvious why mobile chicks cannot get access to food by themselves, as food sources are distant (Ricklefs 1979) and require the ability to 
fly and fish. However, in the case of mesites, chicks leave the nest within 1-2 days after hatching and follow their parents while they feed on terrestrial arthropods, but do not try to get food by themselves until they are about 3 weeks old. Because M. variegata find arthropods by flicking leaves over (Hawkins 1994), small sized chicks may not be able to access this food resource until a more advanced age. Alternatively, mesite chicks may need a long time to acquire the foraging skills necessary for independent survival, as found in other species delaying dispersal (Heinsohn 1991). Accordingly, food provisioning time in this semi-precocial species lasts about as long as in tropical altricial birds (Schaefer et al. 2004; Tarwater and Brawn 2010b), which tend to feed the chicks after the post-fledging period longer than temperate species (Russell et al. 2004).

\section{Breeding system}

The breeding system of white-breasted mesites is characterized by monogamy and bi-parental care. Parental care is male-biased during the pre-hatching period and lacks sex bias during the posthatching period, in contrast to the female-only incubation reported previously (Evans et al. 1996). Importantly, we found no evidence of cooperative breeding. Juveniles only rarely participated in early stage breeding activities (e.g. inspecting nest sites and anecdotally in nest building); they were never observed incubating and were never present during the chick provisioning phase. Based on direct observations and paternity analysis of 28 chicks, the reproductive system of $M$. variegata can be classified as monogamous. The only chick that was not sired by a social father was from a newly formed pair, half way through the breeding period after the disappearance of the previous breeding female. All pairs had invested in at least one breeding attempt by then, and it was possible that the new female had previously been paired with another male.

Comparative studies in insects (Hughes et al. 2008), birds (Cornwallis et al. 2010) and mammals (Lukas and Clutton-Brock 2012) revealed that female monogamy promotes cooperative breeding in family-living species as it results in an increase in within-group relatedness, and thus enhanced inclusive fitness benefits for non-reproducing helpers. Monogamy may thus be necessary for, or at least an important factor facilitating evolutionary transitions to cooperative breeding. 
The presence of some families in which the breeding female was not related to the juveniles of the group or to any other female in the area suggests that they had replaced the previous breeding female. Because in this monogamous species direct reproductive benefits are not likely for juveniles from the previous year, this decrease in within-group relatedness and reduced inclusive fitness benefits for potential helpers, may explain the lack of cooperative breeding in these cases, similarly to promiscuous family-living birds (Cornwallis et al. 2010).

In most mesite groups, though, the juveniles were the recent offspring of both breeding adults, providing juveniles with potential high inclusive fitness of helping in their parents' next breeding attempt. Indeed some juveniles seemed interested in their parents' nests; however, adults were not very tolerant towards older juveniles, particularly after the start of the breeding season. It seems then, that the nature of social relationships may be more important than kin selection in explaining the absence of cooperative breeding in white-breasted mesites. That may explain both the extent to which juveniles can stay in the natal territory (Tarwater and Brawn 2010a) and the bi-parental care found in this species. Aggression towards juveniles near the nesting sites is also indicated as the mechanism preventing cooperative breeding in the family living Siberian jay (Perisoreus infaustus) (Ekman et al. 1994). Therefore, the breeding system of $M$. variegata could be considered as somewhere along the transition from a bi-parental to a cooperative breeding system.

Adult aggression towards older juveniles may also imply that the benefits for parents to retain juveniles from the previous year decrease with offspring age and that juvenile delayed dispersal is costly for their parents, particularly when it coincides with the next breeding attempt. This is supported by the observation that even though some pairs laid up to three clutches per season, re-nesting was only observed after a nest failure, and no pair that had a brood of young, even consisting of fairly nutritionally independent juveniles (2 - 3 months of age) was observed to do so.

\section{Comparison of mesite social systems}

Because life-history traits of closely related species are relatively similar (Pieenar et al. 2013), and mesite species have similarly small clutch sizes and low productivity (Hawkins and Seddon 2003, Seddon et al. 2003), slow life histories may be the general pattern in mesites. Slow life histories have 
been suggested to select for family-living in birds (Covas and Griesser 2007), and consequently may predispose mesites to delayed juvenile dispersal. The differences in the social systems between mesite species may subsequently arise because of adaptation to local ecological conditions as each species is confined to a different forest type. For example, the pair-living brown mesite found in the eastern mountainous rain forests make seasonal altitudinal migrations which result in non-stable, small territories (Evans et al. 1996). In this case, juvenile dispersal may be less constrained than in the two other species exhibiting juvenile philopatry (Seddon et al. 2005) and stable, packed territories (Seddon et al. 2003), and/or the benefits for juveniles staying in the natal area may be lower for brown mesites, which do not defend territories year-round (Hawkins and Seddon 2003). Likewise, juvenile delayed dispersal found in some populations of carrion crows (Corvus corone) seems to be related to year-round territoriality of their parents (Baglione et al. 2005).

The larger groups characteristic of subdesert mesites may form because of higher predation risk in the much more open habitats this species inhabits (Hawkins and Seddon 2003). Additionally, higher prevalence of multi-male groups in $M$. benschi may be a consequence of a male-biased adult sex ratio (Seddon et al. 2003), which can lower male reproductive opportunities.

The pattern of adults providing care is also found in the cooperative breeding subdesert mesite, in which parental care is shared between male and female adult birds of the group, with individuals younger than a year old rarely contributing to it (Seddon et al. 2003). Thus, the occurrence of cooperative breeding in the generally monogamous subdesert mesites (Seddon et. al 2005) may be facilitated by higher social tolerance towards philopatric individuals than in white-breasted mesites, allowing juveniles to stay longer and to help. However, other direct and long-term fitness benefits of group-living, such as extra-group paternity and higher survival were also suggested to play a role in the emergence of helping behaviour, particularly in males (Seddon et al. 2005).

In summary, we suggest that a combination of slow life-history and adaptations to local ecological and social conditions may explain the similitudes and differences in patterns of group formation and breeding systems among the three species of mesite. Despite a strong phylogenetic signal of cooperative breeding in birds (Ligon and Burt 2004), particular ecological and social conditions seem to play an important role in the evolution of this breeding system at lower taxonomic levels. 


\section{Ethical statement}

All procedures were approved by the Ministére d'Eaux et Forêt of Madagascar (210/09, 184/10, $342 / 10,237 / 11,056 / 12)$. 
Chapter 3: Patterns of juvenile dispersal and parental costs of family-living in a non-cooperatively breeding bird

with Peter M. Kappeler

Submitted to Animal Behaviour 


\section{Summary}

Delayed juvenile dispersal has been recognised as the first step towards most cooperative breeding systems. As a consequence, most studies to investigate family formation have focused on cooperatively breeding species, for which estimating the costs and benefits of delayed dispersal is difficult due to confounding indirect fitness benefits for helpers. Juveniles may delay dispersal in response to ecological constraints of dispersal and/or benefits of philopatry, with parents predicted to adjust their tolerance towards independent offspring according to their direct fitness benefits. In this study, we investigated the patterns of juvenile dispersal in white-breasted mesites (Mesitornis variegata), non-cooperatively breeding terrestrial birds in which young show large variation in the period they stay in association with their parents. We also compared adults living either in pairs or in families to quantify potential costs of extended juvenile association. Our results indicate that juveniles develop their foraging skills slowly, and that particularly male juveniles stay longer in their natal family, which corresponds to a slower adult male population turnover. Therefore, a situation characterised by fewer breeding vacancies for juvenile males, combined with poor foraging skills and potential high costs of ranging solitarily, may explain the temporal female-biased dispersal found in this study. Additionally, parental costs associated with family-living may mediate the increase in adult aggression towards older offspring, resulting in the dissolution of families and preventing cooperative breeding in this family-living bird. This study also highlights the fact that cost-benefit analyses from both parents' and offspring's perspective can provide valuable insights into family formation and maintenance.

\section{Introduction}

Formation of families occurs among animals when juveniles delay dispersal and remain in their natal group after becoming independent and has been recognised as a first step to most cooperative breeding systems. Because early dispersal and independent breeding are assumed to be the optimal strategy to maximise fitness under most circumstances, the first studies on family formation focused on potential ecological constraints on juvenile dispersal (Emlen 1982). The unavailability of breeding 
territories (Komdeur 1992), mates (Hatchwell and Komdeur 2000), or high mortality during dispersal (Heg et al. 2004; Ridley et al. 2008) have been identified as the main ecological factors enhancing delayed primary dispersal.

Because many species in which juveniles do not delay dispersal and become floaters also experience these constraints, an alternative hypothesis highlighting the benefits of philopatry was proposed to explain family formation (Stacey and Ligon 1991). Accordingly, juveniles staying in their natal territory may benefit from living in a familiar environment and from associating with their parents (Ekman et al. 1994). More specifically, the skill hypothesis (Koenig et al. 1992; Langen 1996) predicts that juveniles stay in the natal territory during the time they develop their foraging skills. Benefits of philopatry are generally expected for territorial species that are tolerant towards independent juveniles, develop slowly and exhibit some sort of extended parental care (Baglione et al. 2005; Covas and Griesser 2007; Ekman et al. 1994; Langen 1996).

However, because parental care is costly (Clutton-Brock 1991), parents should only prolong care or exhibit extended tolerance towards juveniles when this strategy does not entail high costs and/ or substantially increases offspring fitness (Ekman and Rosander 1992; Mcnamara et al. 1994), as parents are expected to optimize their level of investment in current reproduction, self-maintenance and future reproduction, respectively (Charnov and Krebs 1974; Williams 1966). Many empirical bird studies have indeed documented a decrease in future egg size (Nager et al. 2001), clutch size (Hanssen et al. 2005) and offspring viability (Linden and Møller 1989) as well as in adult survival (Jacobsen et al. 1995; Visser and Lessells 2001) for individuals investing more in the current reproductive event. Thus, extended costs of parental care related to retaining independent juveniles can affect adult tolerance towards offspring (Tarwater and Brawn 2010a), juvenile dispersal decisions and family formation.

Because most species that breed cooperatively also live in kin-based groups (Hatchwell 2009), research on the evolution of family-living has largely focused on species that breed cooperatively. However, analyses comparing solitary/ pair-breeding species with family-living cooperative breeders inevitably suffer from confounding effects related to inclusive fitness benefits for juvenile helpers, which may influence their dispersal decisions. Therefore, a more direct approach 
towards illuminating the evolution of family-living consists of studying species exhibiting delayed dispersal without cooperative breeding (Komdeur and Ekman 2010).

White-breasted mesites (Mesitornis variegata) are terrestrial birds endemic to Madagascar that live in stable pairs or small families in packed territories (Gamero et al. 2013b). Mesite groups are very cohesive and all individuals within a group tend to move around together and coordinate their activities (Evans et al. 1996). They have a slow life history and a monogamous mating system, but they do not breed cooperatively. In a previous study, we showed that parents are intolerant towards older juveniles; particularly during the beginning of the next breeding attempt (Gamero et al. 2013b). White-breasted mesites are seasonal breeders that can lay several clutches per breeding season but produce only one brood of young per year (Gamero et al. 2013b). The chicks are semi-precocial and leave the nest and follow their parents a few hours after hatching, but they do not start foraging on their own until they are about 3 weeks old. Subsequently, they are fed for about 2 months, which could be a consequence of the long time needed for juveniles to learn how to feed efficiently.

In this study we first investigate the patterns of juvenile dispersal in white-breasted mesites. Since family-living and extended parental care are generally more common in species with altricial chicks, we assess the development of foraging skills of semi-precocial juvenile mesites and its potential effect in their time of dispersal. Additionally, as white-breasted mesites live in saturated habitats, we investigate whether limitations on breeding vacancies could affect juvenile dispersal decisions. Finally, because adults exhibit less tolerance towards older juveniles we compare adults associated with juveniles or in pairs to quantify potential parental costs of family-living. We predicted that juvenile mesites develop their foraging skills slowly, that temporal sex-biased dispersal, should it occur, would match the adult population turnover for each sex, and that family-living has costs for parents (e.g. lower intake rate and feeding efficiency, higher vigilance rate and lower investment in future reproduction) as compared to adults living in pairs without juveniles.

\section{Methods}

The study was conducted in Kirindy Forest, western Madagascar, where a population of whitebreasted mesites was monitored from October 2009 to April 2012. The habitat consists of a dry 
deciduous forest with a pronounced dry and a shorter wet season, the later corresponding to the breeding period of white-breasted mesites. Systems of narrow foot trails with intersections every 25 to $50 \mathrm{~m}$ were used to find and follow these terrestrial birds.

Fledged juveniles and adult birds were captured using mist nets, individually marked with plastic colour rings, and a $1.8 \mathrm{~g}$ radio-transmitter mounted on the tail (BD-2 model, Holohill Systems Ltd) was attached to one individual per group. We photographed all resident birds that could not be captured and ringed to allow individual identification based on plumage characteristics (Hawkins 1994). This research adheres to all legal requirements and guidelines of the governments of Germany and Madagascar and to the ASAB/ASB guidelines for the use of animals in behavioural research.

\section{Feeding and vigilance behaviour}

White-breasted mesites feed mainly on terrestrial arthropods buried under the leaf litter (Andriatsitohaina 2013), obtained by flicking leaves over with rapid head movements. This foraging technique requires that birds keep the head down most of the time, which makes the number of trials for food, number of items consumed and vigilance scans easy to distinguish, as the neck and head position are different in each case. During foraging, social units of $M$. variegata are often followed by other canopy dwelling birds (mainly crested drongo (Dicrurus forficatus), but also occasionally, rufous vanga (Schetba rufa), Madagascar paradise flycatcher (Terpsiphone mutata) and long-billed greenbul (Bernieria madagascarensis)) that give alarm calls to which mesites respond with anti-predator behaviours (mainly freezing). Thus, the presence of these other birds may affect the vigilance behaviour of mesites.

From $18^{\text {th }}$ October to $29^{\text {th }}$ November 2011 (late dry season), we conducted focal observations during foraging of 31 birds from 12 different social units, corresponding to three individual types: "juvenile family", 7-8 month old juvenile birds associated with their parents ( $\mathrm{N}=7 ; 5$ males and 2 unsexed individuals); "adult family", adult birds associated with juveniles from the previous year and parents of the previous category of individuals ( $\mathrm{N}=12 ; 6$ males and 6 females); and "adult pair", pairs of adult birds that were not associated with juveniles of the previous year ( $\mathrm{N}=12 ; 6$ males and 6 
females). We determined age (juvenile vs. adult) based on rectrix and tertial shape (Appendix Table A1 and Figure A1). Juveniles were nutritionally independent at the time of data collection.

We used a digital voice recorder to record information on the duration of the focal animal observation session (in seconds), date, individual and group identity, number of food trials, number of vigilance scans, distance to nearest group member (in meters), number of paces (i.e. number of steps when walking without foraging or scanning), presence/absence of other associated bird species, and individual type for each focal observation. During the focal observations the head of the bird was always visible and we discarded all observations of less than 30 seconds. We had an average of 11.2 \pm 3.2 observations per individual, and all focal observations were conducted by the same observer $(A G)$.

\section{Sex-bias in juvenile dispersal}

Because offspring could not be followed continuously throughout the study period, it was not possible to determine the dispersal time for each individual with respect to their sex. We therefore used an indirect measurement of sex-biased juvenile dispersal. We determined the proportion of male offspring in broods with respect to their age. Since there is no sex dimorphism in neither hatchling (t-test: $t=$ 0.444; $d f=20 ; P=0.662 ; N=22$ ) nor adult body mass ( $t$-test: $t=0.066 ; d f=12, P=0.948 ; N=14$ ), which usually predicts differential juvenile mortality for dependent offspring (Clutton-Brock 1986), we assumed that changes in the proportion of males in broods with age would correspond to different dispersal times between sexes.

The sex of chicks and juveniles was determined by genetic analyses of DNA extracted from feathers or blood, using the P2/P8 primers (Griffiths et al. 1998). We classified juveniles in four age categories: (1) 0-3 months; (2) 3-6 months; (3) 6-9 months and (4) 9-13 months based on characteristic changes in plumage, size, and iris coloration (Appendix Table A1 and Figure A1). Because mesites produce 1 or 2 chicks per brood, we pooled all offspring from different broods and the same age category belonging to the same pair to calculate the proportion of males for a given age class. Broods that were observed for a long period spanning several age classes were only included once in the analysis with the older age class. 


\section{Investment in reproduction (egg volume)}

We measured all eggs found (maximum breadth, $B$; length, $L$ and mass, $M$ ). Egg mass was measured for most eggs several times at different stages of the incubation period. We calculated egg volume $\left(\mathrm{mm}^{3}\right)$ with the formula $0.484^{*} \mathrm{~L}^{*} \mathrm{~B}^{2 *} 10^{-3}$ and egg gravity index $\left(\mathrm{Gl}\left(\mathrm{g} / \mathrm{cm}^{3}\right)\right)$ as $\left(10^{6 *} \mathrm{M}\right) /\left(\mathrm{L}^{*} \mathrm{~B}^{2}\right)$. We used a general linear mixed model to calculate the regression parameters of the relation between the average Gl per clutch and the day of incubation from the clutches of known laying date $(\mathrm{N}=68$ measurements of 26 clutches from 14 different females), controlling for the effect of clutch identity nested in female identity as random effects. We subsequently used the regression coefficients between day of incubation and GI to estimate the laying dates for the nests found after the incubation had begun (Day of incubation $=188.40-0.34^{*} \mathrm{Gl}$; estimating error=1.87 days). White-breasted mesites have an incubation period of 25 days and a median laying period of 2 days (Gamero et al. 2013b).

\section{Survival analysis}

We used Kaplan-Meier survival analysis to calculate sex differences in adult survival probability from 30 color-ringed birds (12 adult males and 18 adult females). Because in white-breasted mesites secondary dispersal is very rare (Gamero et al. 2013b), we assumed that a bird died during the study period when it was not seen in the study area anymore and its partner was re-sighted later on with a different partner or alone. Otherwise we classified the individuals as having survived until the end of the study period. Because this species breeds seasonally, and $75 \%$ of the surviving chicks in our study hatched in March, we assumed that all birds hatched that month. We counted the number of months each individual was observed in the area and added to that the months passed between March until the first sighting, for juvenile birds, and an additional 12 months for individuals captured as adults, which allowed us to broadly control for survival differences due to the fact that some individuals were first captured as juveniles (age $<1$ year old) and some already as adults (age $>1$ year old). Three individuals were individually marked in November 2006 for a different research project (Ramanitra et al. 2006) and because of a lack of information on their plumage characteristics or capturing location (residents/ dispersers) they were all assumed to be yearlings. 


\section{Statistical analyses}

To test whether rates of vigilance were influenced by individual type, we used a generalised linear mixed model (GLMM) with a Poisson error structure and a log link function. We controlled for the distance to other group members, number of paces and date ( $1=1^{\text {st }}$ October) as covariates, presence of other bird species as fixed factor, the standardised duration of the observation as offset variable, and individual nested in group as random factors. We log-transformed the distance to other group members, number of paces and the duration of the observation to achieve moderately symmetric distributions.

To investigate whether individual type influenced feeding efficiency, we used the proportion of successful trials as a response variable in a GLMM with a binomial error structure. We included the distance to other group members, number of paces, date and number of scans as covariates, presence of other bird species as fixed factor, the standardised duration of the observation as offset variable and individual nested in group as random factors. We log-transformed all continuous variables except observation date to achieve symmetric distributions. We checked whether the number of food items ingested (intake rate) differed between individual types with a GLMM model fitted with the same controlling variables as for the feeding efficiency model but a Poisson error structure and a log link.

To test whether the presence of juveniles from the previous year influenced the investment of their mothers in the next reproductive event, we used a GLMM with a Gaussian error structure. We used the square root transformation of the average egg volume per clutch as a response variable and we controlled for female identity, as random factor, and clutch (first vs. replacement), laying date (log transformed) as fixed effects. Presence of previous juveniles was included as a fixed factor with three levels (a: no juveniles present, b: juveniles dispersed before the start of the next mating season, and c; juveniles present after the start of the next mating season).

Differences in sex-ratio with respect to offspring age (from 0 to 4 , described above) were determined using a GLMM with a Binomial error structure with parent pair identity as random factor. Finally, we investigated whether the months to dispersal (November 2011 (1) until April 2012 (6)) correlated with the average values of feeding efficiency (items/trial) and intake rate (items/minute) of 5 of the 7 juveniles for which we also had dispersal data. 
Because group size of family groups was always 3 except for one group which had 4 individuals, we did not control for group size in our models. We used the Likelihood ratio test (LRT) to estimate the overall significance of factors with more than 3 levels by comparing the model with and without the corresponding factor. Likewise, model significance was calculated for each model using the LRT to compare a null model including only the random (and offset variable in the case of Binomial and Poisson models) with the final model.

We checked model stability by comparing the estimates obtained from a model excluding each data point or subject one by one with the estimates of a model with all data points, and we also assessed the variance inflation factors of all models. For the model fitted with a Gaussian error structure, we also checked whether residuals were homogeneous and normally distributed by visually inspecting a qqplot and the plot of residuals against fitted values. For the models fitted with a Poisson error structure, we checked that there was no overdispersion. We detected no problems or violation of the assumptions in any of our models.

All statistical tests were calculated in R 2.15.0 (R Development Core Team 2012), using the Ime4, languageR and car packages (Baayen 2011; Bates et al. 2011; Fox and Weisberg 2011) to fit general/generalised linear mix models, and the Olsurv package (Diez 2012) for the survival analysis.

\section{Results}

Correlates of feeding and vigilance behaviour in mesites

Feeding efficiency $\left(L R T: X^{2}=14.65 ; d f=2: P<0.001\right)$ and vigilance rate $\left(L R T: X^{2}=20.28 ; d f=2 ; P<0.001\right)$ were influenced by individual type, but not intake rate $\left(L R T: X^{2}=2.14 ; \mathrm{df}=2 ; \mathrm{P}=0.343\right)$. The number of scans per observation had a negative effect on feeding efficiency (Table 1) and the only factors affecting intake rate were the number of paces and date of the observation (Table 2). Birds decreased vigilance in the presence of other bird species and when closer to another group member (Table 3). 
Foraging and vigilance behaviour, and patterns of dispersal in juvenile mesites

Juveniles had lower feeding efficiency (estimate $\pm S E=0.243 \pm 0.11 ; z=2.18 ; P=0.030$; Figure 1) and vigilance rates (estimate $\pm S E=-0.473 \pm 0.10, z=-4.87, P<0.001$; Figure 2) than their parents. Month to juvenile dispersal negatively correlated with intake rate (Pearson correlation: $t=-3.75 ; r=-0.91$; $\mathrm{P}=0.033 ; \mathrm{N}=5$ ) and feeding efficiency (Pearson correlation: $t=-6.50 ; r=-0.97 ; \mathrm{P}=0.007 ; \mathrm{N}=5$ ). Broods were more male-biased with increasing age (estimate $\pm S E=1.050 \pm 0.393 ; z=2.67 ; P=0.008$; Figure 3) and adult males survived longer (50.16 \pm 3.84 months) than females (41.56 \pm 3.54 months) (logrank test: $x^{2}=4.19 ; d f=1 ; p=0.041 ;$ Figure 4).

Table 1. Summary of the generalised linear mixed model for the effect of individual type ("juvenile family", "adult family" and "adult pair") on mesite feeding efficiency. Significant effects are shown in bold

\begin{tabular}{lllll}
\hline Feeding efficiency & estimate & SE & z value & $P$ \\
\hline Intercept & -1.742 & 0.36 & -4.80 & $<0.001$ \\
Presence of sentinels (yes) & -0.156 & 0.09 & -1.71 & 0.088 \\
Distance to nearest group member & -0.057 & 0.05 & -1.04 & 0.300 \\
Number of scans & -0.204 & 0.08 & -2.61 & $\mathbf{0 . 0 0 9}$ \\
Date & -0.012 & 0.01 & -2.26 & $\mathbf{0 . 0 2 4}$ \\
Number of paces & -0.070 & 0.05 & -1.45 & 0.147 \\
Individual type (ref. Adult pair) & & & & \\
$\quad$ Juvenile family & -0.535 & 0.13 & -4.28 & $<\mathbf{0 . 0 0 1}$ \\
$\quad$ Adult family & -0.293 & 0.11 & -2.72 & $\mathbf{0 . 0 0 6}$
\end{tabular}

Binomial GLMM; $N=343$ observations; 31 individuals; 12 groups; model significance: $X^{2}=29.06 ; d f=7 ; P<0.001$

\section{Comparisons among adults}

Adults that were not associated with juveniles had higher feeding efficiency (Table 1; Figure 1), but similar intake (Table 2) and vigilance rates (Table 3; Figure 2) than adults in families. Egg volume was significantly influenced by the presence of juveniles from the previous year $\left(L R T: X^{2}=6.23 ; d f=2\right.$ : $\mathrm{P}=0.044$ ), so that females that had no associated juveniles laid bigger eggs than females that were still associated with juveniles from the previous year during the mating season (Table 4). 


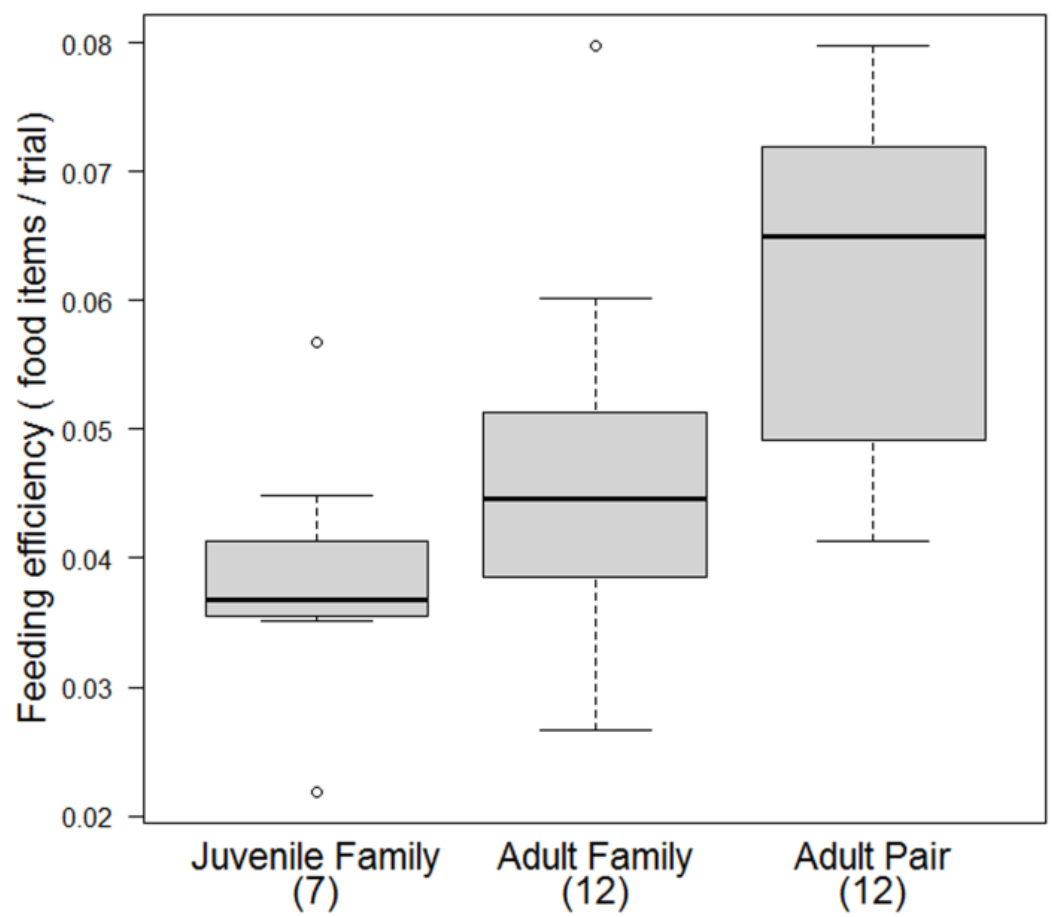

Figure 1. Feeding efficiency of juveniles and adults living in either families or pairs calculated from average values per individual. Numbers in brackets indicate sample sizes

\section{Discussion}

The most important results of this study revealed that white-breasted mesite juveniles had lower feeding efficiency and vigilance rates than their parents, but that all birds had similar food intake rates. Furthermore, male juveniles tended to stay in their natal group longer than females, and adult survival was higher for males than females. Moreover, adults had lower feeding efficiencies when associated with juveniles than when living in pairs, and the presence of juveniles during the following breeding season had a negative effect on the size of the subsequent eggs laid by their mothers. Below, we discuss these effects to evaluate the potential costs and benefits for adults and juveniles affecting the formation and maintenance of small family groups. 


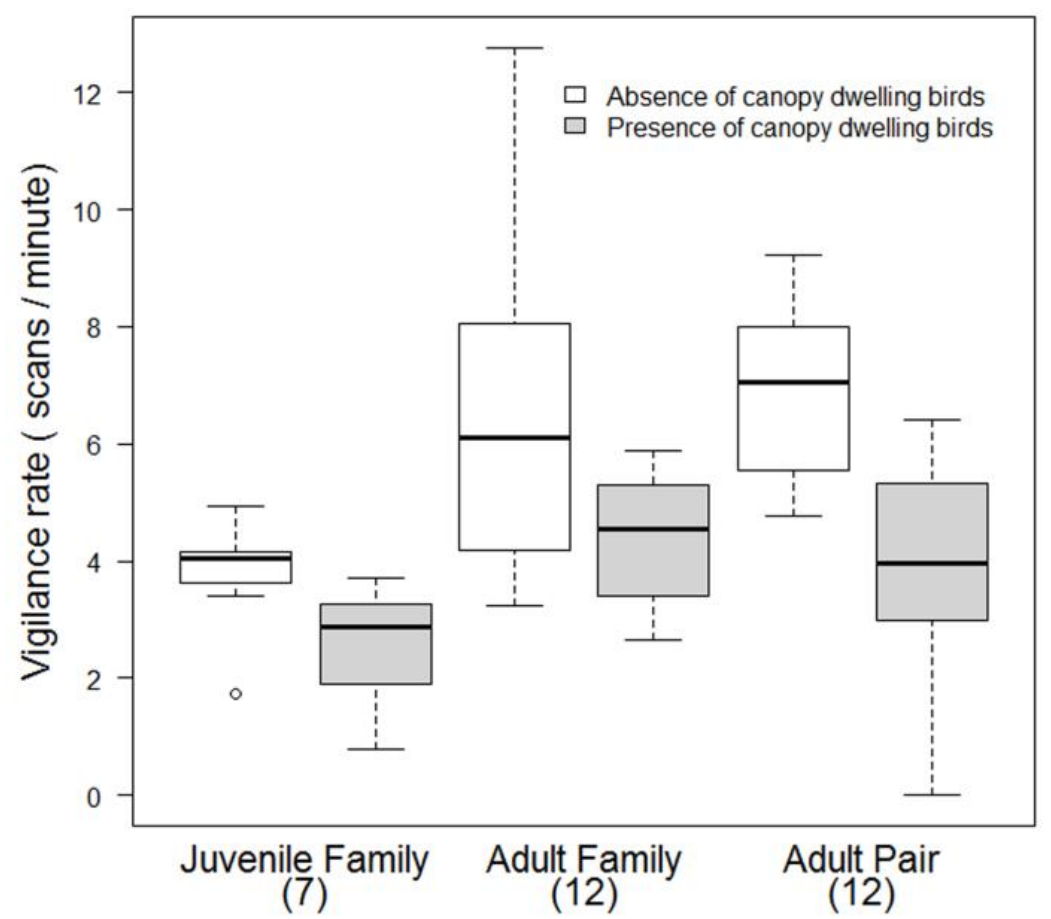

Figure 2. Vigilance rate for juveniles and adults living in either families or in pairs in the presence (grey boxes) and absence (white boxes) of other canopy dwelling birds, calculated from average values per individual. Numbers in brackets indicate sample sizes

\section{Feeding and vigilance behaviour of white-breasted mesites}

Mesites had lower feeding efficiency when they were more vigilant, which may be a result of the number of interruptions during foraging caused by the increased number of scans (Cowlishaw et al. 2004). Food intake rate in mesites was negatively affected by the number of paces, which may indicate that they changed the foraging patch more often when they did not find food (Krebs et al. 1974). Mesites decreased their rates of vigilance behaviour in the presence of other canopy-dwelling birds, a pattern also found in other terrestrial bird (Ridley and Raihani 2007) and mammal species (Sharpe et al. 2010) that regularly associate with drongos (Dicrurus sp.), presumably because of higher perceived safety in the presence of other species that regularly give alarm calls (Goodale et al. 2005) and mob predators (Nijman, 2004). Also, as found for primates (Treves 1998; Treves et al. 2001) and other birds (Fernández-Juricic et al. 2007; Randler 2005), vigilance rates were lower when 
individuals were closer to other group members. Thus, in both situations, mesites are likely to be less vulnerable to predators (Carere et al. 2009; Oommen and Shanker 2010).

The observation date had a negative influence on intake rate, feeding efficiency and vigilance rate, which may be a consequence of reduced food availability with the progressing dry season. Our results indicate that individual vigilance, which affected foraging efficiency, was reduced in less risky situations and throughout the study, when food availability probably decreased. Below we consider the trade-off between foraging and vigilance when discussing the patterns of juvenile dispersal and the parental costs of family-living in mesites.

Table 2. Summary of the generalised linear mixed model for the effect of individual type ("juvenile family", "adult family" and "adult pair") on mesite food intake rate. Significant effects are shown in bold

\begin{tabular}{lllll}
\hline Intake rate & estimate & SE & z value & $P$ \\
\hline Intercept & 1.838 & 0.359 & 5.13 & $<\mathbf{0 . 0 0 1}$ \\
Presence of sentinels (yes) & -0.071 & 0.091 & -0.78 & 0.434 \\
Distance to nearest group member & -0.058 & 0.052 & -1.12 & 0.263 \\
Date & -0.015 & 0.005 & -2.71 & $\mathbf{0 . 0 0 7}$ \\
Number of scans & 0.017 & 0.080 & 0.22 & 0.827 \\
Number of paces & -0.200 & 0.047 & -4.29 & $<0.001$ \\
Individual type (ref. Adult pair) & & & & \\
$\quad$ Juvenile family & -0.191 & 0.135 & -1.42 & 0.155 \\
$\quad$ Adult family & -0.145 & 0.119 & -1.22 & 0.223
\end{tabular}

Poisson GLMM; $\mathrm{N}=343$ observations; 31 individuals; 12 groups; model significance: $\mathrm{X}^{2}=34.70 ; \mathrm{df}=7 ; \mathrm{P}<0.001$

\section{Foraging skills and patterns of dispersal in juvenile mesites}

In cooperative breeding birds, male-biased help has been regarded as a consequence of the general tendency of females to disperse (Cockburn 1998; Greenwood 1980), although studies of sex-biased dispersal usually refer to the proportion and dispersal distances of each sex (Clarke et al. 1997), but not the differential timing of dispersal. In white-breasted mesites all juveniles eventually disperse within their first year (Gamero et al. 2013b). However, we found that juvenile females dispersed earlier 
than males, and seemed to find a breeding vacancy closer to their natal home range than juvenile males, which were rarely recruited in our study site, although this last impression is based on a small sample size (see Appendix Table A4). Besides, only male juveniles were still philopatric when the next mating season had begun, missing part or their entire first reproductive season. Additionally, we found that adult females had lower probability of survival, and in a previous study we showed that in this population the habitat was saturated with breeding pairs (Gamero et al. 2013b). Overall, these results suggest higher breeding constrains for male juveniles than for female juveniles in this population.

Table 3. Summary of the generalised linear mixed model for the effect of individual type ("juvenile family", "adult family" and "adult pair") on mesite vigilance rate. Significant effects are shown in bold

\begin{tabular}{lllll}
\hline Vigilance rate & estimate & SE & z value & $P$ \\
\hline Intercept & 2.644 & 0.194 & 13.60 & $<\mathbf{0 . 0 0 1}$ \\
Presence of sentinels (yes) & -0.405 & 0.061 & -6.69 & $<\mathbf{0 . 0 0 1}$ \\
Distance to nearest group member & 0.070 & 0.032 & 2.18 & $\mathbf{0 . 0 3 0}$ \\
Date & -0.013 & 0.004 & -3.69 & $<\mathbf{0 . 0 0 1}$ \\
Number of paces & -0.069 & 0.032 & -2.18 & $\mathbf{0 . 0 2 8}$ \\
Individual type (ref. Adult pair) & & & & \\
$\quad$ Juvenile family & -0.562 & 0.132 & -4.24 & $<\mathbf{0 . 0 0 1}$ \\
$\quad$ Adult family & -0.089 & 0.120 & -0.74 & 0.459
\end{tabular}

Poissson GLMM; N=343 observations; 31 individuals; 12 groups; model significance: $X^{2}=95.30 ; d f=6 ; P<0.001$

We found that juvenile mesites at an age of 7-8 months were less vigilant and less efficient at obtaining food than their parents, although they seemed to be nutritionally independent 2-3 months after hatching, since parental food provisioning is rare after that age (Gamero et al. 2013b). Because in white-breasted mesites, feeding efficiency is compromised by the degree of vigilance (see above), juveniles may benefit from protection by their parents while developing foraging skills, allowing them to decrease their vigilance rate and concentrate on foraging, as also found in the family-living whitewinged chough (Corcorax melanorhamphos) (Heinsohn 1987) and the common crane (Grus grus) (Alonso and Alonso 1993), for example. This interpretation is consistent with the fact that intake rate was the same for all family members, regardless of their age. Other studies revealed that juveniles 
reach adult rates of scanning and feeding only a few weeks (Sullivan 1988) or months (Alonso and Alonso 1993; Goss-Custard and Durell 1987; Whitfield 1985) after fledging, indicating that juvenile mesites require at least as much time to develop adult-like foraging skills than other bird species in which juveniles associate very long with their parents (Avilés and Bednekoff 2007). Moreover, we found a negative relationship between month of juvenile dispersal and both feeding efficiency and intake rate, indicating that juveniles with lower foraging skills during our study dispersed later in the season.

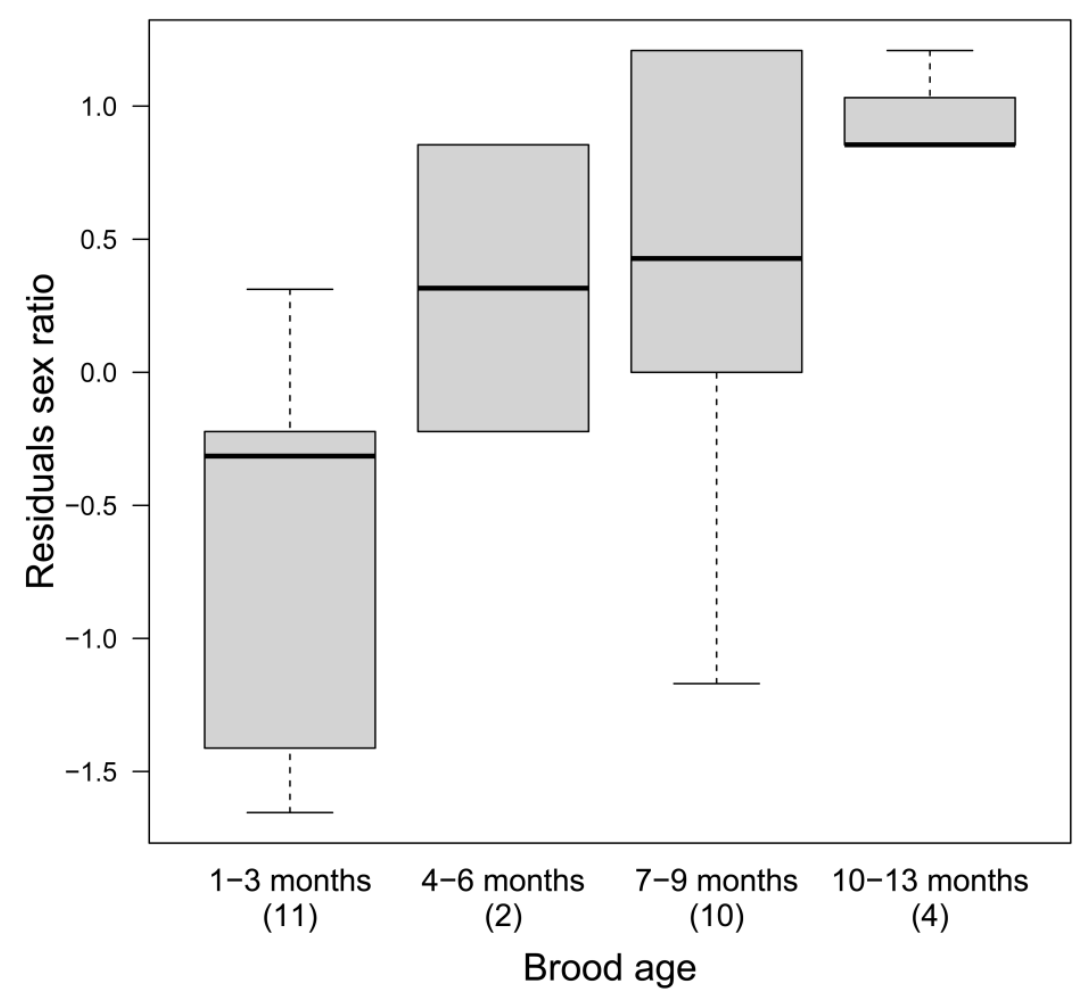

Figure 3. Residuals of the proportion of male offspring in broods associated with their parents as a function of their age ( $\mathrm{N}=45$ offspring). The number of broods per age class are indicated in brackets

In contrast to the closely related subdesert mesite (Seddon 2001), in white-breasted mesites, dispersing when breeding vacancies are not available will most likely result in juveniles floating alone, because neither groups of floating juveniles nor juveniles joining unrelated resident groups as subordinates have been recorded (Gamero et al. 2013b). Additionally, high intra-group cohesion is modulated by predation risk and even adult birds rarely range alone in this species (Chapter 4). Floating is known to be costly for juveniles roaming alone (Ridley et al. 2008), and theoretical models 
predict that in saturated habitats high survival of dispersing juveniles will result in dissolution of families especially if offspring retention is costly for the parents (Kokko and Lundberg 2001). Therefore, a situation with limited breeding vacancies for juvenile males combined with poor foraging skills and potential costs of ranging solitarily may result in particularly male juveniles delaying dispersal in this species. However, experimental evidence, as shown for superb fairy-wrens (Malurus cyaneus) (Pruett-Jones and Lewis 1990) and western bluebirds (Sialia mexicana) (Dickinson 2004), and analyses comparing fitness consequences for mesite juveniles pursuing different dispersal strategies would be needed to test this hypothesis.

\section{Costs of family-living for mesite parents}

Feeding costs for parents associating with independent young have been found in barnacle geese (Branta leucopsis), as parents wintering together with offspring spent less time foraging as a result of an increase in time spent vigilant compared to adults wintering without juveniles (Black and Owen 1989). However, in white-breasted mesites, although increased vigilance rate had a negative effect on feeding efficiency, feeding costs for adults living in families were not related to increased vigilance in the presence of offspring, as parents had similar vigilance rates than adults without offspring. Instead, because white-breasted mesite social units are generally very cohesive during foraging, the lower feeding efficiency of adults associated with offspring compared to pairs could be a consequence of increased scramble competition for food in larger groups.

A decrease in vigilance rate, however, might have been expected for individuals living in larger groups or families (Roberts 1996) than in pairs, in the absence of nepotistic vigilance (Griesser 2003) and/or when all individuals are vigilant at similar rates. In white-breasted mesites, a decrease in parental vigilance may be too risky in light of the low levels of scanning of associated juvenile birds, as observed in common cranes (Avilés 2003). 


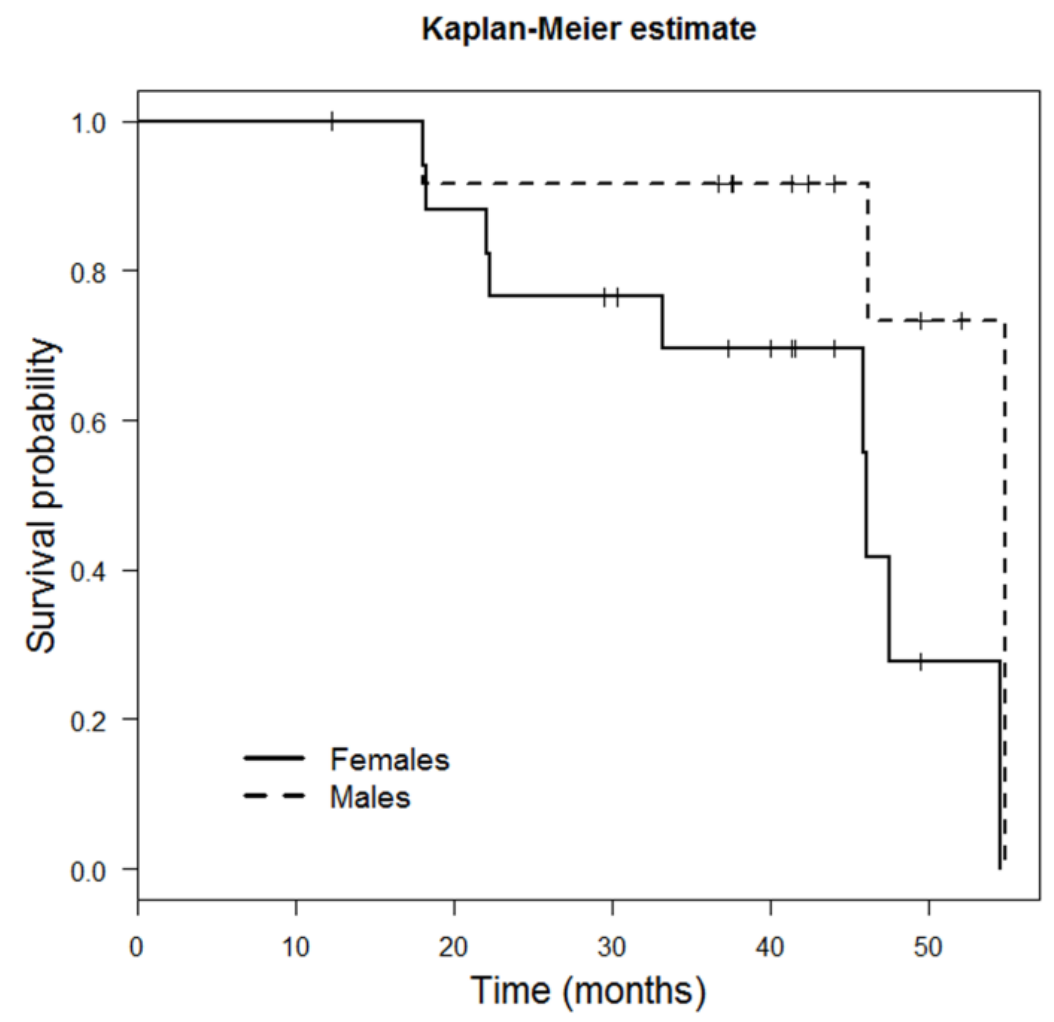

Figure 4. Kaplan-Meier survival curves for adult white-breasted mesite males ( $N=12$; dashed line) and females ( $N=18$; solid line). Hatch marks represent censored individuals

We also found costs in the next reproductive event for parents that were still associated with previous year's offspring during the breeding season. Females' association with juveniles, possibly resulting in higher food competition during egg production, could explain their reduced investment in eggs. This decrease in egg volume could have survival consequences for the subsequent chicks of these females, particularly due to their semi-precocial development (Ochi 2009). Additionally, since parents are predicted to optimize their level of investment in current and future reproduction and extend care only when it considerably increases offspring fitness (Charnov and Krebs 1974; Williams 1966), retention of juveniles in white-breasted mesites may increase juvenile fitness and outweight the observed parental costs. Likewise, in western slaty-antshrike (Thamnophilus atrinucha), parents start breeding later when associated with juveniles (Tarwater and Brawn 2010b), but juveniles survive better when they remain philopatric after reaching nutritional independence (Tarwater and Brawn 2010a). Still, these parental costs may explain why parents were sometimes aggressive towards 
juveniles older than 7 months of age (Gamero et al. 2013b). Although the levels of parental aggression are low, they are likely to have some effect on dispersal decisions of juvenile mesites, probably by setting an upper limit to the period juveniles can stay in the family, as found for other bird species (Tarwater and Brawn 2010a), and future studies should focus on social interactions surrounding dispersal to explore this possibility in more detail.

Table 4. Summary of the general linear mixed model testing the effect of the presence of juveniles (no juveniles, juveniles during non-mating and juveniles during mating season) on the volume of the eggs their mothers laid in the next breeding attempt. Significant effects are shown in bold

\begin{tabular}{lllll}
\hline Egg volume & estimate & $\mathrm{SE}$ & $\mathrm{t}$ value & $\mathrm{P}$ \\
\hline Intercept & 3.518 & 0.049 & 71.46 & $<\mathbf{0 . 0 0 1}$ \\
Presence of juveniles (ref. No juveniles) & & & & \\
$\quad$ Non-mating season & -0.042 & 0.031 & -1.35 & 0.187 \\
$\quad$ Mating season & -0.073 & 0.029 & -2.49 & $\mathbf{0 . 0 1 9}$ \\
Clutch order (replacement) & -0.026 & 0.036 & -0.70 & 0.487 \\
Laying date & -0.002 & 0.001 & -2.38 & $\mathbf{0 . 0 2 4}$ \\
\hline Gaussian GLMM; N=35 clutches; 13 females; model significance: $\mathrm{X}^{2}=22.43 ; \mathrm{df}=4 ; \mathrm{P}<0.001$.
\end{tabular}

In summary, we suggest that a situation with limited breeding vacancies for juvenile males, combined with poor foraging skills and potential high costs of ranging solitarily, may result in the observed sex-biased dispersal pattern. Additionally, parental costs associated with family-living may influence the levels of adult aggression towards older offspring particularly around the next breeding attempt, resulting in the dissolution of families and the lack of cooperative breeding in this monogamous family-living bird. More generally, this study shows that a framework including a costbenefit analysis of group-living from both parents' and offspring' perspective in a non-cooperative breeding species can provide valuable insights into family formation and maintenance. 
Chapter 4: Always together: mate guarding or predator avoidance as determinants of intra-group cohesion in white-breasted mesites?

with Peter M. Kappeler 


\section{Summary}

Being a member of a cohesive social unit can have fitness benefits such as decreased predation risk, increased feeding efficiency and enhanced access to social information and mates. However, competition and the risk of parasite transmission exert centrifugal forces on group-living animals. Thus, the actual degree of cohesion is expected to vary as a function of several social and ecological factors. White-breasted mesites (Mesitornis variegata) are medium-sized terrestrial birds endemic to the dry deciduous forests of western Madagascar. They live in stable breeding pairs or small family groups, mate monogamously and often form short heterospecific associations with canopy-dwelling bird species that give alarm calls to which mesites respond with anti-predator behaviours. We investigated the potential effects of predation risk and mate defence on mesite group cohesion by analysing inter-individual distances as a function of group size, alarm call events, the size of associated heterospecific flocks, and the adults' reproductive state. Mesite social units were very cohesive, particularly in families, when associated with smaller heterospecific flocks, and after an alarm call event. Adult reproductive state did not influence partners' cohesion, but dyad associations in families were biased towards breeding pairs in the mating season, possibly mediated by decreased parental tolerance to juveniles during the reproductive season. We suggest that predation pressure associated with a terrestrial life-style selects for high within-group cohesion, which may have an indirect effect on the monogamous mating system of white-breasted mesites, indicating a potential link between predation risk and genetic monogamy in socially monogamous species.

\section{Introduction}

Many animals associate in groups (Krause and Ruxton 2002). One of the most evident benefits of group living is the per capita decrease in predation risk. This can be a result of increased group vigilance, i.e. the many eyes effect (Magurran et al. 1985; Elgar 1989), dilution effects (Bertram 1978; Turchin and Kareiva 1989) or predator confusion (Landeau and Terborgh 1986). Other advantages of grouping relate to increased feeding efficiency (Clark and Mangel 1986), access to social information 
(King and Cowlishaw 2007) and mates (Höglung and Alatalo 1995). In contrast, competition and the risk of parasite transmission exert centrifugal forces on group-living animals (Côté and Poulin 1995; Krause and Ruxton 2002). Thus, animals may tend to aggregate or increase cohesion under conditions of high predation risk (Carere et al. 2009; Sogard and Olla 1997), whereas under circumstances of food scarcity and high competition for resources, animals may decrease cohesion or range in smaller sub-groups (Chapman et al. 1995; Bustnes et al. 2013; Sogard and Olla 1997).

However, groups are rarely a collection of homogeneous individuals, since age and sex composition and kinship relationships are variable among groups and can affect grouping patterns (Avilés 2003; Wey and Blumstein 2010). In addition, in mixed-species associations, group cohesion can be altered by the presence of particular species that often give alarm calls, mob predators, kleptoparasitise or forage in similar trophic niches (Eguchi et al. 1993; Sridhar et al. 2009; Kotogama and Goodale 2004; Sridhar and Shanker 2013). Therefore, group size, and particularly the degree of group cohesion are expected to vary as a function of different social and ecological factors.

Formation of pair bonds during breeding and bi-parental care constitutes the most common breeding system in birds (Cockburn 2006). This system is thought to be necessary in order to successfully raise offspring (Emlen and Oring 1977), but extra-pair copulations are common in pairliving birds (Griffith et al. 2002; Westneat et al. 1990) and can increase the costs of parental care for males when they care for non-sired young. Therefore, males should adopt strategies to reduce these costs, including decreased care provided to young when extra-pair copulations are prevalent (Møller and Cuervo 2000), or increasing paternity certainty (Petrie and Kempenaers 1998) by engaging in mate guarding behaviour or by copulating frequently with their partner during the female fertile phase (Chuang-Dobbs et al. 2001, Brylawski and Whittingham 2004). Mate guarding is usually found in species where males can regularly stay close to their mates, whereas frequent copulations seem to be the strategy of species in which males have to eventually leave their mates alone, for example in order to find food for courtship feeding (Birkhead and Møller 1992).

White-breasted mesites (Mesitornis variegata) are medium-sized ground-dwelling birds endemic to Western Madagascar that live in year-round stable pairs or small families, in which breeding partners mate monogamously and cooperate in the care of offspring (Gamero et al. 2013b) and territory defence (Evans et al. 1996). Pairs sing all year round in synchronised duets which have 
been suggested to function in territory defence (Hawkins and Seddon 2003). They are also often in association with canopy-dwelling bird species, predominantly crested drongo (Dicrurus forficatus), and occasionally, rufous vanga (Schetba rufa), Madagascar paradise flycatcher (Terpsiphone mutata) and long-billed greenbul (Bernieria madagascarensis) (Evans et al. 1996). During these associations, mesites respond with anti-predator behaviours to heterospecific alarm calls. Mesites often freeze as a response to a predator encounter or alarm calls, but may also run away, flicking the tail and hissing, and group members may flee in all directions and freeze nearby when directly attacked by a predator (Evans et al. 1996).

We studied white-breasted mesite group and pair cohesion to investigate whether cohesion of social units in this species is modulated by predation risk and/or adult reproductive state. We predicted that if predation risk affects within-group spatial distribution, group cohesion will increase with (a) decreasing group size, (b) in the absence of canopy-dwelling birds and (c) after an alarm call. If mesite pair cohesion is a mechanism to mate-guard the breeding partner, we expected that breeding partners will stay in closer proximity to each other during the mating season compared to the non-mating period.

\section{Methods}

Observational data were collected in two field seasons: November 2010 to March 2011 and October 2011 to April 2012 in Kirindy Forest (western Madagascar), a forestry concession managed by the Centre National de Formation, d'Etudes et de Recherche en Environnement et Foresterie (CNFEREF). The habitat is a dry deciduous forest characterized by two marked ecological seasons: a hot wet season from December to April, corresponding to the breeding season of white-breasted mesites, and a cooler dry season from May to November. The study area includes grid systems of narrow foot trails with intersections every 25 to $50 \mathrm{~m}$. Birds were captured using mist nets and colourringed. Resident individuals that could not be captured were photographed and identified on the basis of plumage characteristics (Hawkins 1994). All procedures were approved by the Ministére d'Eaux et Forêt of Madagascar (184/10, 342/10, 237/11, 056/12). 


\section{Behavioural observations}

White-breasted mesite groups/social units, formed by 2 adults (male and female breeders) and recent offspring (0-2 juveniles) (Gamero et al. 2013b), were followed continuously on a regular basis, and the distance (in meters) between all group members was noted each 5 minutes. Observation duration ranged from 10 minutes to about 2.5 hours and was terminated when the focal birds were lost by the observer or until they ascended to their roosting tree. We recorded contextual information for each scan on mesite group size and identity, adult reproductive state, the heterospecific flock size (i.e. number of other bird species associated with the mesite group) and the general activity of the group (i.e. foraging, travelling, preening, singing, nest building, fighting with neighbours, resting and inspecting nesting sites). Adult reproductive state (mating vs. non-mating) was determined by the behaviour of birds: "mating" comprised the period from the first time we observed the birds inspecting nesting sites, building nests, copulating or courtship feeding until the time they started incubation; and "non-mating" comprised the rest of observations. Group identity, size and adult reproductive state were constant within an observation.

We collected data from 2,493 (85\%) of the 2,950 potential scans during 321 observations on 23 mesite social units. The $15 \%$ missing values correspond to periods in which the birds were out of sight. Additionally, we noted the time and a short description of each event related to alarm calling and potential predator presence (i.e. birds freezing after an alarm call, predator encounter or predator attack). For 65 such events we had data on the cohesion of the group before (1-5 min before) and after (1-5 min after) the event, as well as group size and identity, and the presence and size of heterospecific flocks associated.

During this study, juvenile age, estimated by plumage characteristics (Appendix Table A1 and Figure A1), ranged from 7 to 13 months old, ages at which juveniles are already nutritionally independent from their parents (Gamero et al. 2013b).

\section{Statistical analyses}

We included only the scans during which mesites were foraging or travelling because these were the two most common activities, and other bird species associate with mesites only in these contexts. 
Additionally, because mesites breed predominantly during the wet season, group size is smaller and other bird species are rarely in association with mesites at this time, we subset the data by ecological seasons to disentangle the effects of the number of individuals of other bird species associated, mesite group size and reproductive state to avoid confounding effects due to variable vegetation cover or food availability in different ecological seasons and collinearity problems between variables (i.e mating season vs. wet season vs. absence of other bird species associated). We also excluded the few observations on a group of four individuals as it was the only group of this size, leaving group size comparisons in 2 (pairs) vs. 3 individuals (families).

Prior to the analyses, we tested for potential temporal autocorrelation of the data by comparing each model (see model descriptions below) that included the effect of data autocorrelation with the same model without this effect, using a likelihood ratio test (LRT). Because for all our models the LRTs indicated that these effects were non-significant, we assumed that our 5 minute interval scans were independent and therefore, we did not include temporal correlation structures in the final models.

To test the effect of predation risk on group cohesion we used two approaches: First including data from only the dry season ( $\mathrm{N}=546$ scans from 48 observations and 12 mesite groups), we used a GLMM with a Gaussian error structure to compare average distances to nearest group member per scan. Because distance to the nearest group member was very skewed, we used the negative inverse transformation of this distance as a response variable (transformation selected with the Box-Cox method (Box and Cox 1964)) with respect to the date of the observation (as continuous variable), number of heterospecific birds associated (from 0 to 3 ) and mesite group size (2-3) as fixed factors. Group identity and observation were included as random factors. Second, we compared the average distance to the nearest group member per scan (square root transformed) before and after an alarm call. We controlled for the effect of group size (2-3), the number of heterospecific birds associated (03), and group and observation identity as random factors using a GLMM with a Gaussian error structure ( $\mathrm{N}=130$ scans from 65 observations and 13 mesite groups).

To investigate the effect of the mating season on the cohesion between breeding partners we used only data from the wet season and we excluded the few cases in which other bird species were associated with mesites ( $\mathrm{N}=1,190$ scans from 162 observations and 14 mesite groups). We compared the distances between breeding pairs (also negatively inverse transformed) as a function of their 
reproductive state, controlling for group size, activity (walking vs. foraging) and date as fixed effects using a general linear mixed model (GLMM) with a Gaussian error structure. Group identity and observation were included as random factors.

Additionally, using data only for the wet season, we calculated an association index (Al) for families ( 3 individuals) as the difference in cohesion between breeding partners and the average of the distances between adult-juvenile dyads: $\mathrm{Al}=($ dist. $\delta$ to +$))-[(($ dist. $\delta$ to juv $)+($ dist. $q$ to juv $)) / 2]$. Negative values of this index indicate that within a group, the breeding partner dyad is more closely associated than dyads formed by juveniles and adults. We tested whether the association index within social units changed depending on the reproductive state of the adult birds with a GLMM with a Gaussian error structure, controlling for juvenile age (in months) and activity as fixed factors ( $\mathrm{N}=279$ scans from 30 observations and 5 groups). Observation identity and group identity were included as random factors.

We checked homogeneity and normal distribution of residuals by visually inspecting the plot of residuals against fitted values and the qqplot. Variance inflation factors and model stability were tested for all models. We did not detect problems or violation of the assumptions for any of the models. We tested all models against null models fitted to the same data but including only the random factors with LRTs to investigate model significance (Faraway 2006).

All statistical tests were calculated in R 2.15.0 (R Development Core Team 2012). We used the "Ime4", "nIme", "languageR" and "car" packages (Baayen 2011; Jose Pinheiro et al. 2013; Fox and Weisberg 2011; Bates et al. 2011) to fit GLMM models.

\section{Results}

In our final data set ( $\mathrm{N}=2,019$ scans from 20 social units), values of up to $1 \mathrm{~m}$ inter-individual distance represented $72.4 \pm 7.7 \%$ of the scans for distance to nearest group member and $63.8 \pm 11.4 \%$ for breeding partners' distance (Figure 1). Scans when birds were further than $3 \mathrm{~m}$ from each other accounted for only $1.2 \pm 1.5 \%$ of the observations regarding nearest group member, and $5.1 \pm 6.2 \%$ for distances between breeding partners (Figure 1). Thus, mesite groups were very cohesive most of the time. 


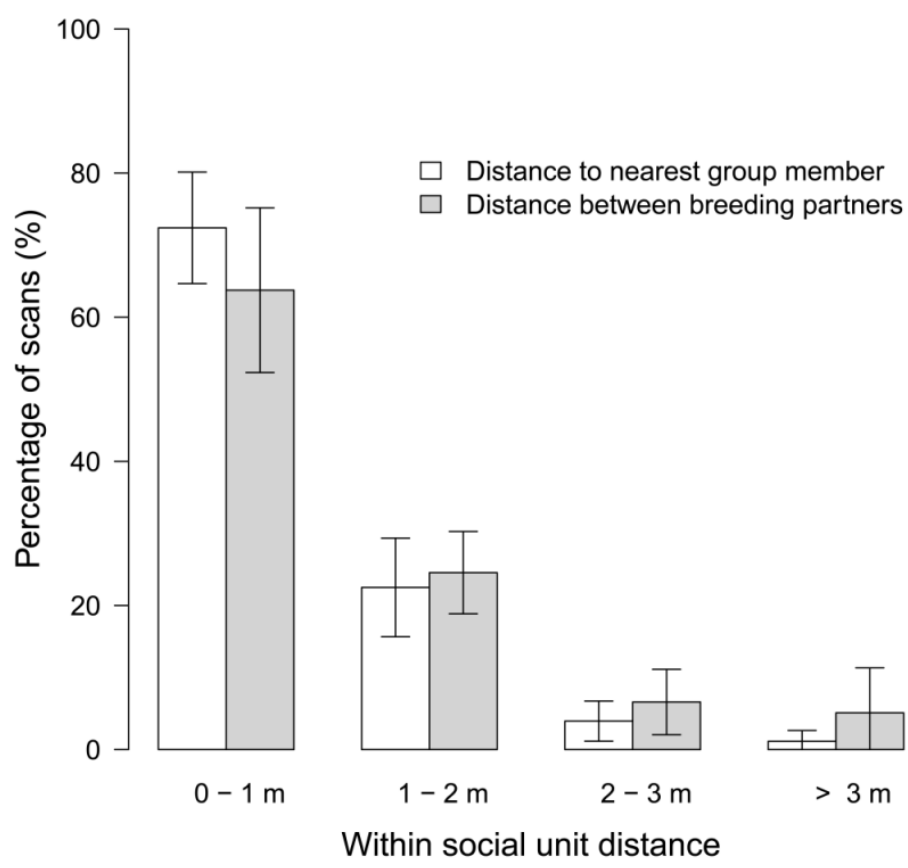

Figure 1. Percentage of scans (mean $\pm S D$ ) in which mesites were within a distance of $1,2,3$ or more than 3 meters to the nearest group member (white bars) and to the breeding partner (grey bars).

Average distance to nearest group member increased when mesites were associated with larger heterospecific flocks (Table 1, Figure 2) and decreased in larger mesite groups (Table 1, Figure 3). For the 65 events regarding alarm calls, group cohesion was lower before than after the alarm call (Table 2, Figure 4).

Table 1. Results of the GLMM model investigating within-group mesite cohesion with respect to the number of associated heterospecific birds and mesite group size. Reference levels for activity and mesite group size factors are "foraging" and "2" respectively. Significant effects are shown in bold.

\begin{tabular}{lllll}
\hline Distance nearest group member $(\mathrm{m})$ & $\mathrm{B}$ & $\mathrm{SE}$ & $\mathrm{t}$ & $\mathrm{P}$ \\
\hline Intercept & -1.099 & 0.266 & -4.135 & $<\mathbf{0 . 0 0 1}$ \\
Activity (walking) & -0.037 & 0.037 & -1.015 & 0.310 \\
Mesite group size (3) & -0.047 & 0.019 & -2.460 & $\mathbf{0 . 0 1 4}$ \\
No. of heterospecific birds associated & 0.027 & 0.010 & 2.677 & $\mathbf{0 . 0 0 8}$ \\
Date & 0.002 & 0.001 & 2.104 & $\mathbf{0 . 0 3 6}$
\end{tabular}

Gaussian GLMM: 546 scans; 48 observations; 12 groups; model significance: $x^{2}=16.65 ; d f=4 ; P=0.002$ 
None of the factors included in the model for breeding partners' cohesion were significant, and the full model did not differ from the null model including only the random effects $\left(L R T: X^{2}=1.21 ; d f=4\right.$; $\mathrm{P}=0.876$ ). The pattern of association among individuals of a group changed with respect to the adults' reproductive state, so that breeding partner dyads were more closely associated with each other during the mating period than during the non-mating period (Table 3).

Table 2. Summary of the GLMM model investigating the effect of an alarm call in within-group mesite cohesion, controlling for the effect of mesite group size and the number of other bird species associated. Reference levels for alarm and mesite group size variables correspond to "before" and "2" respectively. Significant effects are shown in bold.

\begin{tabular}{lllll}
\hline Distance to nearest group member $(\mathrm{m})$ & $\mathrm{B}$ & $\mathrm{SE}$ & $\mathrm{t}$ & $\mathrm{P}$ \\
\hline Intercept & 0.865 & 0.080 & 10.86 & $<\mathbf{0 . 0 0 1}$ \\
Alarm (after) & -0.150 & 0.064 & -2.324 & $\mathbf{0 . 0 2 2}$ \\
No. of heterospecific birds associated & 0.126 & 0.067 & 1.896 & 0.063 \\
Mesite group size (3) & 0.020 & 0.092 & 0.217 & 0.829
\end{tabular}

Gaussian GLMM: 130 scans; 65 observations; 13 groups; model significance: $X^{2}=9.12 ; d f=3 ; P=0.028$

\section{Discussion}

For most of the scans, birds were within $3 \mathrm{~m}$ of each other, indicating that overall, social units were very cohesive during foraging and travelling. Cohesion was particularly high in family groups, when associated with smaller heterospecific flocks and after an alarm call. Breeding partners' cohesion was not affected by their reproductive state, but breeding dyads in groups were more closely associated with each other during the mating season than during the non-mating season.

\section{Group cohesion and predation risk}

In accordance with the predictions linking social unit cohesion to predation risk, mesite groups were more cohesive after an alarm call event. Many social animals give alarm calls to signal the presence of predators which are usually followed by anti-predator responses of other group members 
(Caro 2005). In mesites, responses to conspecific and heterospecific alarm calls are mainly characterized by freezing, since mesites rely on their cryptic colouration. However, when attacked by aerial predators, all group members simultaneously fly in an erratic manner in different directions and freeze nearby (Evans et al. 1996), which could be a strategy to confuse predators. The confusion created to the predator may be enhanced when all birds start their escape very close to each other, as prey density has been found to decrease predator hunting success because of the impaired predator ability to single out individuals when prey is very cohesive (Jeschke and Tollrian 2007). Similarly, a study on walleye pollocks (Theragra chacogramma) showed that this fish species formed schools immediately after a predator attack (Ryer and Olla 1998), and flock cohesion in common starlings (Sturnus vulgaris) is higher with increasing predation risk (Carere et al. 2009).

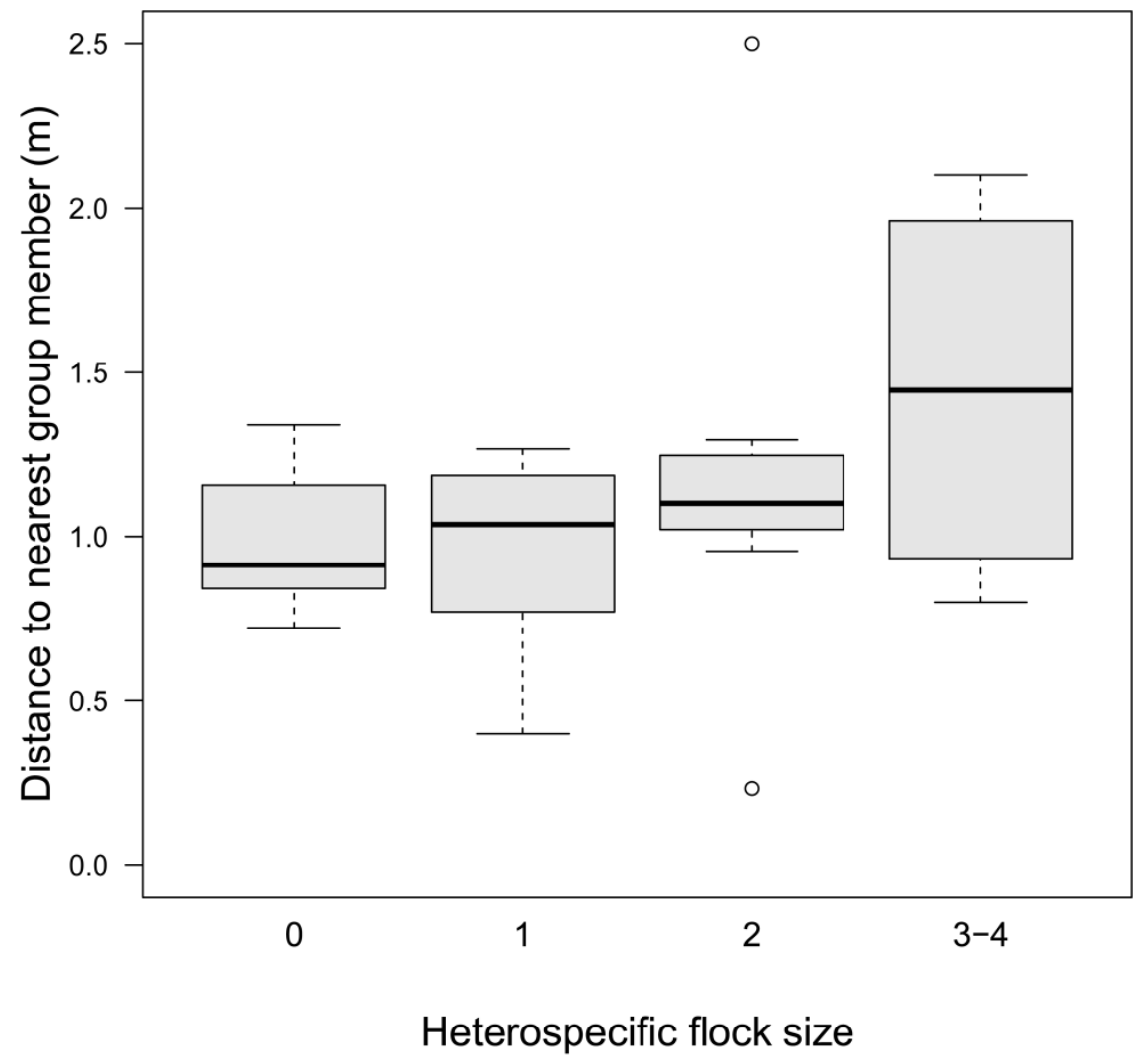

Figure 2. Distance to nearest group member of white-breasted mesite social units with respect to the size of associated heterospecific flocks, based on mean values per social unit. 
Likewise, mesites were less cohesive when ranging together with larger flocks of canopydwelling birds. The presence of birds that are situated higher in the canopy and are able to detect predators more efficiently than individuals on the ground (McGowan and Woolfenden 1989) can be particularly beneficial for white-breasted mesites, which only forage on the ground, with the head down most of the time to flick leaves over to obtain food (Hawkins 1994). Similarly, groups of pied babblers (Turdoides bicolor) are less cohesive and vigilant when sentinels are perching in a higher position (Radford et al. 2009). The effect of other bird species was flock size dependent, which might indicate a decreased per capita predation risk for mesites with increasing heterospecific flock size. However, although mesite group cohesion was significantly lower when associated with heterospecifics, the effect of the presence of other bird species on mesite spatial distribution was relatively small, suggesting that either the risk of predation is still considerably high in these associations or that mesites use other behavioral adjustments in response to reduced predation risk. In line with the second possibility, in another study we found that mesites reduce vigilance behavior in the presence of associated bird species (Chapter 3).

Additional conspecific group members had an opposite effect on group cohesion than increased heterospecifics, indicating that group size effects in white-breasted mesites are conditional on group composition. These contrasting group-size effects underline the need to consider group composition when predicting perceived predation risk. The increase in group size in white-breasted mesites is due to the presence of juvenile individuals (Gamero et al. 2013b), which are less vigilant and less efficient at obtaining food than adult birds (Chapter 3). Similarly, the presence of generally less vigilant juveniles that may still require some parental care, increased the vigilance rate in common cranes (Grus grus) and barnacle geese (Branta leucopsis) (Black and Owen 1989; Avilés and Bednekoff 2007). Moreover, in some birds and mammals, juveniles are less reliable when giving alarm calls as they are unable to correctly distinguish predator from non-predator species (Robinson 1981; Hollén et al. 2008; Kullberg and Lind 2002). Juvenile mesites associating closer with their parents could reduce their predation risk if they are not as competent as adults in predator detection, and/or if their time for vigilance is constrained by other activities such as foraging. Also, in species that relay on crypsis to avoid predators, such as white-breasted mesites, ranging in bigger groups of conspecifics can increase how detectable they are to predators (Jackson et al. 2005; Riipi et al. 2001), resulting in the higher cohesion we observed in family groups. 


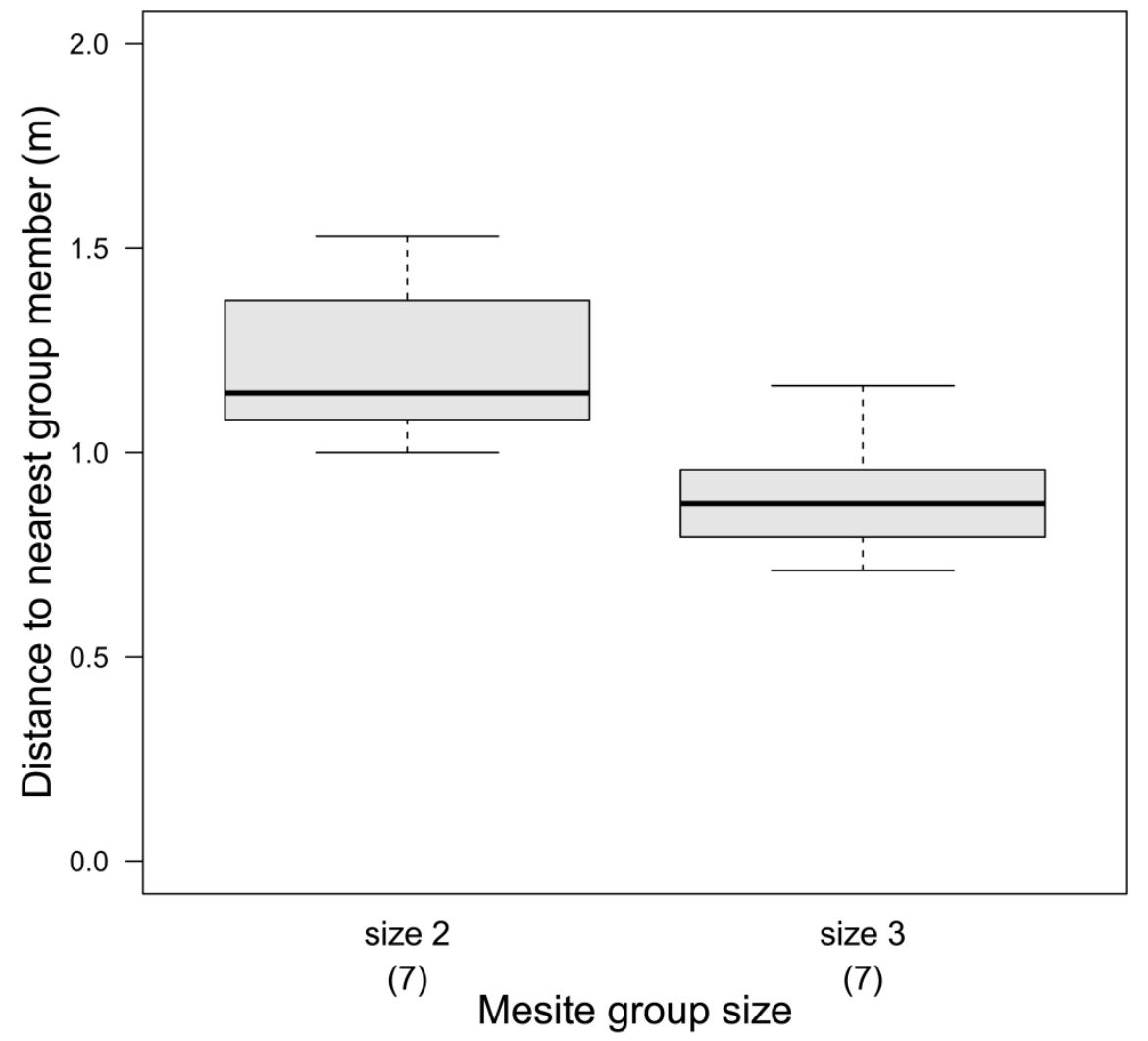

Figure 3. Average distance to nearest group member of white-breasted mesite social units of different group sizes, based on average values per social unit. Numbers in brackets indicate sample sizes.

\section{Pair cohesion and mate guarding}

We did not find support for the hypothesis that high cohesion relates to mate guarding in mesites since breeding partners' distance to each other was constantly small and did not change with respect to their reproductive state. Therefore, other factors may influence the strictly monogamous mating system of white-breasted mesite. For example, the lack of mate guarding in the also genetically monogamous ringed plover (Charadrius hiaticula) has been related to breeding in open habitats (i.e. males are able to see their mates at far distances) and the potential costs for females engaging in extra-pair copulations in terms of reduced male care (Wallander et al. 2001). The high year-round cohesion in white-breasted mesites (i.e. breeding partners were within $3 \mathrm{~m}$ distance for about $95 \%$ of the scans) probably allows males to see the whereabouts of their partners most of the time, even in their dense habitat (Hawkins 1994), with no need for males to remain particularly closer to their mates 
during their fertile phase. Additionally, high group cohesion due to other factors, such as predation risk, may limit the possibility of solitary extra-territorial forays to obtain extra-pair copulations in this species.

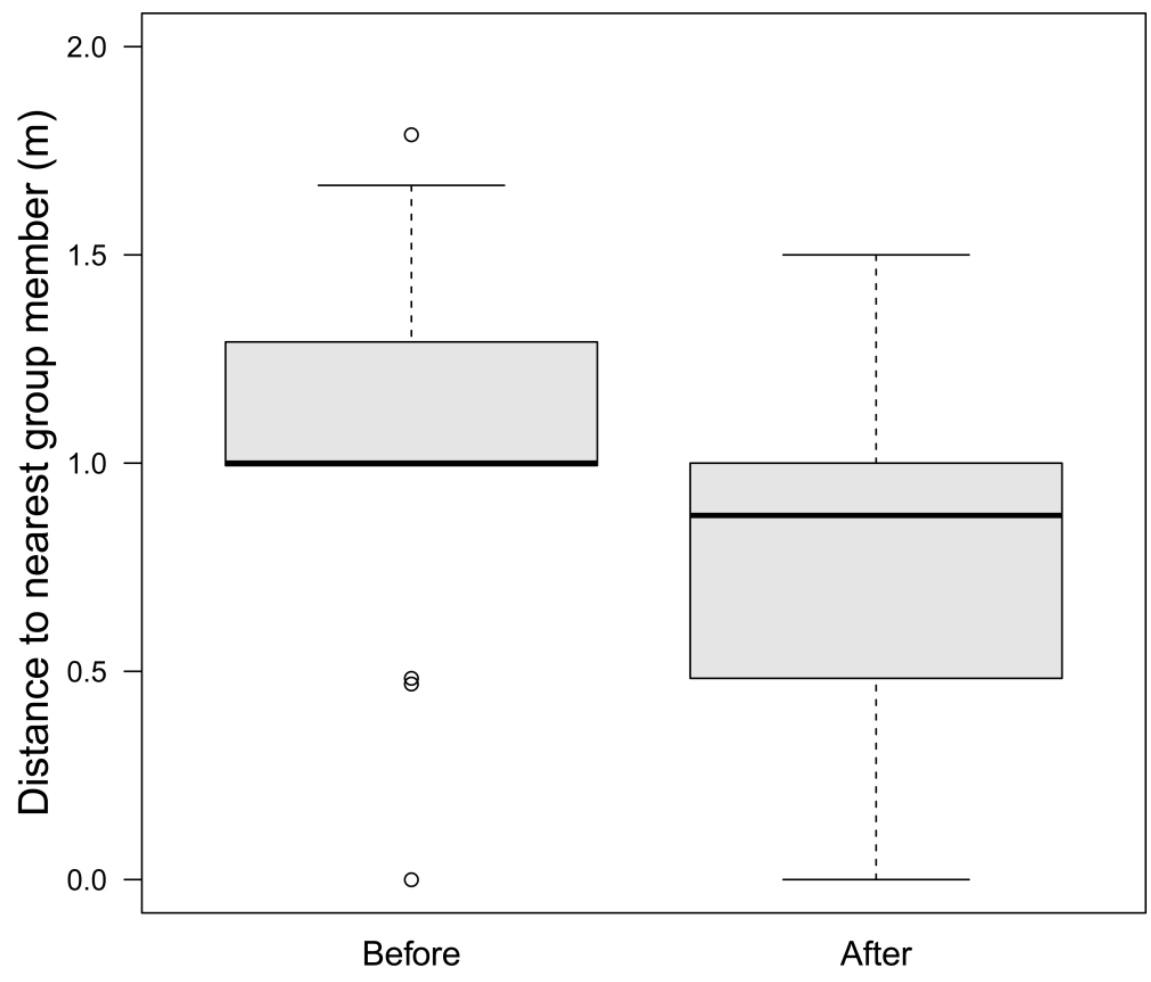

(13)

Alarm call

(13)

Figure 4. Distance to nearest group member of white-breasted mesite social units, before and after an alarm call event, based on mean values per social unit. Numbers in brackets indicate sample sizes.

Territoriality has also been suggested as a mate-guarding strategy because it reduces the probability that other males enter the territory and potentially gain extra-pair copulations with the territory owner's mate (Birkhead and Møller 1992). White-breasted mesites are territorial and although home range overlap between neighbours is large (Gamero et al. 2013b), encounters with neighbours are uncommon. Additionally, like some species that guard their partners vocally (Hall 2004), whitebreasted mesites duet most frequently during the beginning of the breeding season. Their duets are mainly initiated by males, and are thought to be a cooperative display that functions in territory defence (Evans et al. 1996). However, if a paired female starts singing, she is rapidly approached by 
her mate, which joins her to form a vocal duet so that females practically never sing alone (AG pers. obs.). Paired males often sing solo songs as females do not always join them in producing duets (Evans et al. 1996). This sex difference could indicate that males need to signal the mating status of their mates and that they use vocal mate defence to guard their females, as found in the closely related subdesert mesite (Monias benschii), in which duets function as a mutual mate defence strategy (Seddon et al. 2002). White-breasted mesite duet functionality in territorial defence has been described (Evans et al. 1996), but to date, this and other hypotheses such as potential mate defence functions have not been tested experimentally.

Table 3. Summary of the GLMM model testing within-group association index (see text for details) in respect to adult reproductive state. Reproductive state and activity factors have as reference levels "mating" and "foraging" respectively. Significant effects are shown in bold.

\begin{tabular}{lllll}
\hline Association index (AI) & B & SE & t & P \\
\hline Intercept & 0.091 & 0.586 & 0.156 & 0.876 \\
Reproductive state (non-mating) & 0.324 & 0.143 & 2.260 & $\mathbf{0 . 0 2 5}$ \\
Activity (walking) & 0.526 & 0.323 & 1.630 & 0.104 \\
Juvenile age & -0.017 & 0.053 & -0.312 & 0.755
\end{tabular}

Gaussian GLMM: 279 scans; 30 observations; 5 groups; model significance: $x^{2}=10.01 ; d f=3 ; P=0.018$

Based on a small sample size, we found a seasonal difference in the association index, with adult-juvenile dyads being more closely associated during the non-mating season compared to the mating season. Parental aggression towards juveniles, which can start when juveniles are about 8 months old (Gamero et al. 2013b) and usually corresponds to the onset of the mating season, may explain the decrease in adult-juvenile dyads' cohesion in the mating period. Parental intolerance towards independent juveniles during the breeding period has also been found for other family-living birds (Ekman et al. 1994; Tarwater and Brawn 2010a). The association pattern in mesites was not influenced by juvenile age, indicating no effect of offspring age on levels of parental care or juvenile protection provided by parents. 
In summary, we showed a pronounced group cohesion in mesites, which seems to be mainly directed to avoid predation and not to mate guard the breeding partner. Association between dyad members was dependent on adults' reproductive state and was possibly mediated by decreased parental tolerance towards juveniles during the reproductive season. We suggest that predation pressure selecting for high within-group cohesion may have an indirect effect on the mating system in white-breasted mesites. The potential link between predation risk and genetic monogamy proposed in this study could be further investigated to understand the mechanisms underlying the variation in extra-pair paternity found in socially monogamous species. 


\section{General discussion}

In this section I summarise the most important results of this thesis, including the description of the social system, the patterns and determinants of juvenile dispersal and lack of cooperative breeding in white-breasted mesites, and discuss them with respect to other studies. Finally, based on the findings of this thesis, I highlight several open questions with regard to the social behaviour of white-breasted mesites that should be considered in subsequent studies, and I encourage future directions for the research on the evolution of family-living in birds.

\section{White-breasted mesite social system}

Overall, the results of my study on the different components of the social system of white-breasted mesites indicate that this species lives in saturated habitats, in very cohesive pairs or small families, that breeding partners reproduce monogamously, that care is provided only by adult parents, and that mesites are characterized by a slow life-history (Chapter 2).

\section{Social organization}

White-breasted mesite social units consisted of an adult male, an adult female and up to 2 juveniles, and group size was larger during the non-breeding season than during the breeding season (Chapter 2). The new specific set of microsatellite markers for $M$. variegata that I used to study the social organization and mating system were relatively polymorphic (Chapter 1), allowing me to show that, although in most cases juveniles were the offspring of both adults of the group, in some families only the adult male of the group was related to the juveniles, while the adult female was unrelated to them (Chapter 2). The presence of "stepmothers", together with the low secondary dispersal I observed in this population, suggests that the mothers of these juveniles died and were replaced by a new female. This is consistent with the higher adult survival probability for males than for females (Chapter 3). Few species have been reported to adopt the partner's previous offspring after the formation of a new pair (Alatalo et al. 1983; Martin 1989; Meek and Robertson 1991). Adoption of unrelated offspring is more often found in precocial birds for which parental care costs are thought to be lower than in species with 
food provisioning (Kalmbach 2006). During this study, I did not observe food provisioning to unrelated offspring by replacement females (Chapter 2), which could have indicated some parental care.

Social units were in general very cohesive (i.e. inter-individual distances very rarely exceeded $3 \mathrm{~m}$, Chapter 4). Individuals within a group were closer to each other after an alarm call, and when they were associated with smaller heterospecific flocks, both situations in which predation risk is likely to be higher (Ridley and Raihani 2007). For ground-dwelling mesites that forage mainly with the head down (Hawkins 1994), the presence of heterospecific birds ranging high in the canopy and giving alarm calls may decrease their perceived predation risk, as indicated by the mesites' decrease in vigilance rate in these circumstances (Chapter 3). Additionally, when white-breasted mesites are attacked by an aerial predator, all members of the group simultaneously fly in different directions in an erratic manner and freeze nearby (Evans et al. 1996), probably to confuse the predator. The confusing effect on the predator may work better when mesite individuals are very close to each other, as high prey cohesion diminishes predator capturing efficiency because of the reduced ability by predators to single out prey in these situations (Jeschke and Tollrian 2007). In general, these results suggest that predation risk mediates social unit cohesion and possibly constraints individuals to range solitarily in this species.

\section{Mating system}

Both the social and genetic mating system in white-breasted mesites can be classified as monogamous (Chapter 2). The low occurrence of extra-pair copulations in this species (2\%) does not seem to be due to intense mate guarding or high copulation rates, which has been found to decrease the frequency of extra-pair sired offspring in other bird species (Birkhead and Møller 1992; ChuangDobbs et al. 2001; Brylawski and Whittingham 2004). Instead, the high general cohesion among breeding pair dyads due to predation pressure and regardless of their reproductive state (Chapter 4) can indirectly be responsible of the low level of extra-pair paternity I detected in white-breasted mesites (Chapter 2). Breeding density, synchrony and genetic variability have been suggested as ecological factors explaining inter and intra-specific differences in mating strategies in birds (Griffith et al. 2002). However, the effect of pair cohesion due to other factors, such as predation risk, which may 
limit the possibility of solitary extra-territorial forays to obtain extra-pair copulations, has not yet been investigated.

Social monogamy is the most prevalent avian social mating system, but only $10 \%$ of bird species are classified as having a truly monogamous mating system (Griffith et al. 2002). Although most bird species breed in the tropics (Hawkins et al. 2003), empirical studies on birds have been mainly conducted on temperate species (Stutchbury and Morton 2001). This research bias towards temperate species, which are known to differ greatly in life-history strategies from tropical species (Skutch 1949; Peach et al. 2001; Russell et al. 2004), has had a strong effect on the development of a theoretical framework for avian behavioural ecology. It has been claimed that genetically monogamous mating systems are more common among lower latitude species (Stutchbury and Morton 2001), but the scarce number of studies on tropical birds makes this claim still premature (Macedo et al. 2008). However, if with the addition of new studies on tropical breeding birds this pattern is confirmed, our current view of high prevalence of promiscuity in socially monogamous birds (Griffith et al. 2002) may greatly change.

\section{Parental care pattern}

Bi-parental care is common among birds (in about $80 \%$ of bird species both parents provide care to the brood (Cockburn 2006)) and is also the pattern in white-breasted mesites. In Chapter 2, I showed that mesite chicks are semi-precocial (according to the Stark and Ricklefs' (1998) classification of different chick developmental modes). Contrary to previous suggestions (Hawkins 2013), chicks are dependent on parental food provisioning for about 2 months, which is similar to other tropical altricial birds (Schaefer et al. 2004; Tarwater and Brawn 2010b). Longer periods of parental care are generally found in tropical species as compared to temperate ones (Russell et al. 2004), which has been suggested to account for higher prevalence of family-living and cooperative breeding at lower latitudes (Arnold and Owens 1998; Covas and Griesser 2007). The long parental food provisioning that I observed until juveniles reached 12 months of age, although at much lower rates after juveniles were older than 2 months (Chapter 2), may be related to the foraging technique used by M.variegata, which consists nearly exclusively on finding arthropods by flicking leaves over (Andriatsitohaina 2013). This technique may either be difficult to learn by juveniles or the occurrence of chicks not feeding 
independently may relate to developmental constraints (Marchetti and Price 1989). Slow development of foraging skills has been found in species in which juveniles delay dispersal (Heinsohn 1991; Langen 1996).

Substantial chick dependence in mesites probably affects the strength of the pair bonds (Chapter 2), similar to the longer pair bonds observed in birds with altricial chicks as compared to precocial birds (Temrin and Tullberg 1995). Additionally, breeding partners showed a high degree of coordination in incubation and brooding at the nest, with eggs and chicks left unattended at predictable times of the day and only for short periods (Chapter 2). High parental cooperation and nest attendance during incubation and small number of visits at the nest has been found in populations inhabiting environmentally harsh conditions (AIRashidi et al. 2010) or subjected to high nest predation (Conway and Martin 2000; Evans and Stutchbury 2012). Because mesites build simple open nests and adults have a cryptic plumage, the high nest attendance and low levels of activity around nests may decrease the probability that visual predators spot the eggs, the chicks and the adults themselves. Because the eggs were generally predated by snakes at night, and the attacks on incubating or brooding adult birds were performed by diurnal visual predators (pers. obs.), the incubation pattern may reflect more an adjustment to the adults' predation risk than to the eggs', as observed in the red-breasted nuthatch (Sitta canadensis) experimentally exposed to dummy predators of eggs and adult birds (Ghalambor and Martin 2000).

\section{Why do juvenile mesites delay dispersal?}

Detailed information on several components of white-breasted mesite's social system (Chapter 2) suggested that juvenile delayed dispersal could be a function of a long process of developing foraging skills, the low breeding opportunities in a saturated habitat or a combination of both. In Chapter 3, I investigated juvenile dispersing patterns in more detail, concluding that males stay longer in association with their parents than females, and that juveniles had poorer foraging skills than their parents. Overall, a habitat saturated with groups (Chapter 2) and the higher mortality probability for adult females than males, suggest that juvenile males have lower chances to find a breeding vacancy, similar to superb fairy wrens (Pruett-Jones and Lewis 1990). I also showed that juveniles seem to compensate for their poor feeding efficiency by reducing vigilance rate, resulting in similar intake rates 
as their parents. Therefore, because mesite social unit cohesion is generally very high (Chapter 4) and dispersing individuals do not join other groups unless they become breeders (Chapter 2), constraints for solitary ranging coupled with lower breeding vacancies for males and poor foraging skills (Chapter 3) may explain why particularly male juveniles in this species do not become floaters right after reaching nutritional independence and even miss entire breeding seasons by remaining philopatric.

\section{Why do juvenile mesites not help?}

Although previous suggestions of cooperative breeding in white-breasted mesites (Cockburn 2006), and the juveniles' interest for their parents' subsequent nests, I did not find any evidence of cooperative breeding in this species (Chapter 2). Hamilton's rule predicts that an individual will help another only when the costs of helping will be lower than the benefits obtained from this act as a function of the relatedness coefficient between the two participants (Hamilton 1964a; Hamilton 1964b). In my study, potential helpers (i.e. previous year juveniles) were in most cases related to both breeders and still did not help. Why then did related mesite juveniles not help? In precocial species where chicks do not need a lot of parental care, the presence of helpers may not increase the survival of the brood, as suggested by the very low prevalence of cooperative breeding in species with precocial chicks (Cockburn 2006). However, in Chapter 2, I showed that mesite chicks although precocial in mobility, are dependent on parental care for a long period of time and their survival could probably be enhanced when more individuals help in parental care, although this was not found for the closely related subdesert mesites (Seddon et al. 2003).

In groups containing some unrelated helpers, helping behaviour is generally influenced by the perceived paternity of the brood and the potential direct reproductive benefits of helpers (Davies 2000). That is the case of the cooperative breeding scrub wrens (Sericornis frontalis) with groups generally containing a recent male offspring as helper, which help more at the nest when his mother has been replaced by an unrelated female, as juveniles share paternity of the brood with their fathers

in this later case (Magrath and Whittingham 1997). However, based on the results on the mating system, direct reproductive benefits for male juveniles were not observed in white-breasted mesite "stepmother" families (Chapter 2). 
High predation of nests by visual predators (i.e. several corvid species) has been suggested to prevent cooperative breeding in Siberian jays (Perisorious infaustus), a monogamous family-living bird, in which juveniles are not allowed to access the nests by adult birds (Ekman et al. 1994). High nest predation risk in white-breasted mesites, which seems to constraint the number of visits at the nest and select for few and long daily incubation bouts, may explain why extra individuals are restricted to participate in incubation, brooding or feeding chicks at the nests. Therefore, parental intolerance towards older juveniles mediated by either a potential increase in predation at the nests and/or adult costs of family-living (i.e. lower feeding efficiency and smaller eggs laid by females when juveniles are present for a longer period (Chapter 3)), may supress cooperative breeding in whitebreasted mesites.

\section{Comparisons with other mesites' social systems}

Closely-related species tend to have similar life-histories (Pienaar et al. 2013). That seems to be the case for the three mesite species, which share small clutch sizes and low productivity (Hawkins and Seddon 2003; Seddon et al. 2003). Additionally, slow life-histories are associated with high prevalence of delayed juvenile dispersal and extended parental care (Russell et al. 2004). Slow-life histories may then predispose mesites to delayed juvenile dispersal. However, only two species seem to show juvenile philopatry. Because the split between the two mesite genera, Mesitornis and Monias, is dated about 30 million years ago (Ericson et al. 2006; Brown et al. 2007), corresponding to the time when different habitats where already present in Madagascar (Samonds et al. 2013), and the three mesite species are allopatric and confined to these habitat types, their different levels of sociality could be a result of adaptations to local ecological conditions. The lack of year-round territoriality associated with altitudinal migrations in brown mesites (Evans et al. 1996) may decrease the benefits of juvenile natal philopatry and long association with parents, as also found in different populations of carrion crows without year-round territoriality (Baglione et al. 2005) as compared to the year-round territorial subdesert and white-breasted mesites (Seddon et al. 2003, Chapter 2). On the other hand, pronounced within-group cohesion in $M$. variegata (Chapter 4) and the open habitats subdesert mesites inhabit, suggesting a high predation pressure for both species, may explain their higher degree of sociality (Hawkins and Seddon 2003). 
The occurrence of cooperative breeding in subdesert mesites groups with the presence of unrelated individuals as compared to white-breasted mesite families may be related to direct reproductive benefits due to a less strict monogamous mating system in $M$. benschi (Seddon et al. 2005) than in M. variegata (Chapter 2). On a proximate level, adult intolerance towards juveniles seems to play a role in dispersal and helping decisions of white-breasted mesites (Chapter 2 and 3). Although no information on social interactions is available for subdesert mesites, groups are partially formed by natal philopatry and reproductive success is higher in groups with more related females, suggesting that juveniles are allowed to stay longer and help in this species (Seddon et al. 2003; Seddon et al. 2005).

A different approach to investigate the evolution of sociality in mesites using comparative analyses and including also other closely related groups of birds may not be particularly informative in this case because it would be highly influenced by the phylogeny used since phylogenetic relationships of mesites with other avian groups are still not very clear (Sibley and Ahlquist 1990; Ericson et al. 2006; Hackett et al. 2008).

\section{Conclusions}

This is the first study that combined genetic, behavioural and spatial data on white-breasted mesites. In this thesis I showed that white-breasted mesites live in stable pairs or small families formed by delayed dispersal of predominantly juvenile males and that they are pair breeders. From the juveniles' perspective, a saturated habitat with low breeding opportunities as a result of the high adult survival, especially of males, could explain the temporal female-bias dispersal. Additionally, potential costs of ranging solitarily (suggested by the high group cohesion related to predation risk), which may be particularly high for juvenile individuals with poor foraging skills, may select for long associations of juveniles with their parents. From the parents' perspective, foraging and reproductive costs of familyliving as compared to pair-living could mediate their tolerance towards juveniles and affect family stability in this species (Figure 1). On the other hand, high intra-group and pair cohesion may affect the mating system in white-breasted mesites and suggests a link between genetic monogamy and predation risk in a socially monogamous species. Comparisons with other mesites revealed that the breeding system of white-breasted mesites may represent a transition between a bi-parental and a 
cooperative breeding system, with some juveniles ready to provide help but being prevented to do so by their parents. More generally, this study shows that cost-benefit analyses from the parents' and offspring's perspective are necessary to understand family formation and stability. Moreover, I showed that investigating family-living species that do not breed cooperatively can also provide valuable information on the evolution of cooperative breeding, as delayed dispersal is a prerequisite to most cooperative breeding systems.

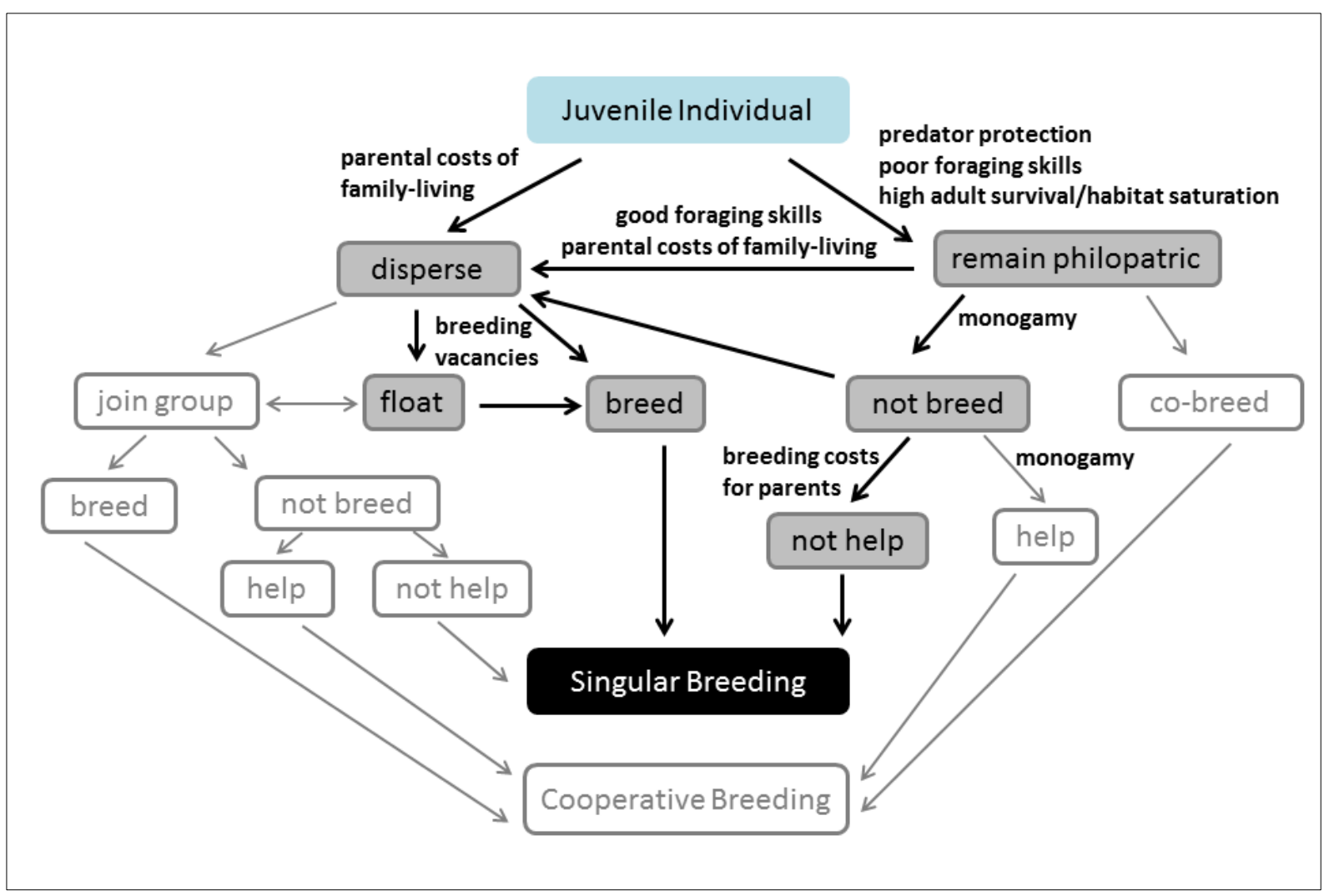

Figure 1. Representation of the decisions during an individual's life leading to particular breeding systems, modified from Cahan et al. (2002). Text in bold represent the effects observed in this study that may have influenced juvenile decisions (grey boxes). White boxes represent the paths that were not observed in this study.

\section{Outlook}

In this study I revealed the generalities of the social system of this rare Malagasy bird. Still, some open questions remain, and a number of new questions have arisen based on the results of this thesis which require further investigation: 
First, the results on slow development of foraging skills, parental costs of long association with juveniles and predation risk affecting mesite cohesion, suggest that the juvenile strategy to delay dispersal could be beneficial when breeding opportunities are low (particularly for male juveniles). However, evidence of potential costs of floating (i.e. lower survival and recruitment probability) for juveniles dispersing earlier with respect to individuals staying in the natal area longer (Gienapp and Merilä 2011) would be needed to support the "benefits of philopatry" hypothesis in this species.

Additionally, the mesite vocal system is characterized by a relatively large repertoire size for a non-passerine species and by the presence of songs used in conflict and cooperation situations (Seddon 2002; Hawkins 2013). White-breasted mesite calls have been described qualitatively (Evans et al. 1996), but to date no study has provided quantitative or experimental data on different call types or call functionality in this species. Obtaining detailed information on call functionality can unravel how social units are capable of maintaining high cohesion and coordination, and whether genetic monogamy in this species is partly a consequence of mate-defence duets. Moreover, this study revealed that heterospecific associations with canopy-dwelling birds can be beneficial for mesites with respect to predator protection (Chapter 3 and 4), as mesites often rely on the alarm calls these other bird species emit. The time in the family unit may also be used by philopatric juveniles to socially learn from their parents which heterospecific vocalizations serve as alarm calls and future studies could focus on the development of heterospecific call recognition in this species.

White-breasted mesites are listed as vulnerable by the IUCN (BirdLife International 2012), although this assessment is mainly based on data from Hawkins (1994). Because white-breasted mesites are confined to western dry deciduous forests (Hawkins 1994) and there has been a massive loss of this habitat in Madagascar in the last decades (Ganzhorn et al. 2001), the current mesite population may be much lower than previously estimated. Therefore, new population estimates are needed to reassess the conservation status of white-breasted mesites. Additionally, with the new set of microsatellite markers described in this study (Chapter 1), genetic tools are available to investigate the genetic variability and degree of isolation (Hedrick 2001) of the remaining populations of whitebreasted mesites, which could be used to direct conservation effort to particular mesite populations.

More generally, future research on delayed dispersal should focus on family-living birds that do not cooperate during breeding. Because most of the work on juvenile delayed dispersal has been 
conducted on birds that live in families and exhibit cooperative breeding, confounding effects due to inclusive fitness benefits for helpers cannot be disentangled from other factors that drive dispersal decisions (Komdeur and Ekman 2010). Instead, studying family-living birds that do not cooperate during breeding provides a better approach to investigate juvenile delayed dispersal, although these studies are still rare (Ekman et al. 1994; Tarwater and Brawn 2010a). Additionally, non-cooperatively breeding family-living birds can be seen as transitional systems from pair-living to more complex societies or vice versa and are likely to provide valuable insights into the evolution of cooperative breeding. With a recent phylogeny including nearly all avian species (Jetz et al. 2012) and relatively detailed data on many bird taxa, the necessary tools for large scale comparative analyses in birds are available. Therefore, comparative analyses including ecological factors and life-history traits, similar to previous studies on cooperative breeding species (Rubenstein and Lovette 2007; Cornwallis et al. 2010; Lukas and Clutton-Brock 2012) would be a valuable next step to investigate the evolution of family-living in birds. 


\section{References}

Alatalo R, Lundberg A, Ståhlbrandt K (1983) Do pied flycatcher males adopt broods of widow females? Oikos 41:91-93

Alonso JA, Alonso JC (1993) Age-related differences in time budgets and parental care in wintering common cranes. The Auk 110:78-88

AlRashidi M, Kosztolanyi A, Kupper C, Cuthill I, Javed S, Szekely T (2010) The influence of a hot environment on parental cooperation of a ground-nesting shorebird, the Kentish plover (Charadrius alexandrinus). Frontiers in Zoology 7:1

Andriatsitohaina M (2013) Etude du comportement alimentaire de la mesite variee (Mesitornis variegata) dans la concession forestiere de Kirindy CNFEREF. Departement de Biologie Animale Universite d'Antananarivo, Antananarivo

Arnold KE, Owens IPF (1998) Cooperative breeding in birds: a comparative test of the life history hypothesis. Proceedings of the Royal Society of London Series B: Biological Sciences 265:739-745

Avilés JM (2003) Time budget and habitat use of the common crane wintering in dehesas of southwestern Spain. Canadian Journal of Zoology 81:1233-1238

Avilés JM, Bednekoff PA (2007) How do vigilance and feeding by common cranes (Grus grus) depend on age, habitat, and flock size? Journal of Avian Biology 38:690-697

Baayen RH (2011) languageR: Data sets and functions with "Analyzing linguistic data: a practical introduction to statistics". http://CRAN.R-project.org/package=languageR.

Baglione V, Marcos JM, Canestrari D, Griesser M, Andreotti G, Bardini C, Bogliani G (2005) Does year-round territoriality rather than habitat saturation explain delayed natal dispersal and cooperative breeding in the carrion crow? Journal of Animal Ecology 74:842-851

Bates D, Maechler M, Bolker B (2011) Ime4: linear mixed-effects models using S4 classes. http://cran.rproject.org/package=Ime4.

Bergmüller R, Taborsky M (2005) Experimental manipulation of helping in a cooperative breeder: helpers 'pay to stay' by pre-emptive appeasement. Animal Behaviour 69:19-28

Bertram B (1978) Living in groups:predators and prey. In: Krebs J, Davies N (eds) Behavioural ecology: an evolutionary approach. Blackwell Scientific, Oxford, pp 64-96 
BirdLife International (2012) (Mesitornis variegatus). In: IUCN 2012. IUCN Red List of Threatened Species. Version 2012.2. www.iucnredlist.org. Accessed 15 November 2012.

Birkhead TR, Møller AP (1992) Sperm competition in birds: evolutionary causes and consequences. Academic Press, London

Black JM, Owen M (1989) Parent-offspring relationships in wintering barnacle geese. Animal Behaviour 37, Part 2:187-198

Bourke AFG (1997) Sociality and kin selection in insects. In: Krebs JR, Davies NB (eds) Behavioural ecology: an evolutionry approach. Blackwell Oxford, pp 203-227

Box GEP, Cox DR (1964) An Analysis of transformations. Journal of the Royal Statistical Society. Series B 26:211-252

Brown JW, Payne RB, Mindell DP (2007) Nuclear DNA does not reconcile 'rocks' and 'clocks' in Neoaves: a comment on Ericson et al. Biology Letters 3:257-260

Brylawski AMZ, Whittingham LA (2004) An experimental study of mate guarding and paternity in house wrens. Animal Behaviour 68:1417-1424

Burke T, Daviest NB, Bruford MW, Hatchwell BJ (1989) Parental care and mating behaviour of polyandrous dunnocks Prunella modularis related to paternity by DNA fingerprinting. Nature 338:249-251

Bustnes J, Systad G, Ydenberg R (2013) Changing distribution of flocking sea ducks as nonregenerating food resources are depleted. Marine Ecology Progress Series 484:249-257

Cahan S, Blumstein D, Sundström L, Liebig J, Griffin A (2002) Social trajectories and the evolution of social behavior. Oikos 96:206-216

Carere C, Montanino S, Moreschini F, Zoratto F, Chiarotti F, Santucci D, Alleva E (2009) Aerial flocking patterns of wintering starlings (Sturnus vulgaris) under different predation risk. Animal Behaviour 77:101-107

Caro T (2005) Antipredator defenses in birds and mammals. University of Chicago Press, Chcago

Chapman CA, Chapman LJ, Wrangham RW (1995) Ecological constraints on group size: an analysis of spider monkey and chimpanzee subgroups. Behavioral Ecology and Sociobiology 36:59-70

Charnov EL, Krebs JR (1974) On clutch size and fitness. Ibis 116:217-219

Chuang-Dobbs HC, Webster MS, Holmes RT (2001) The effectiveness of mate guarding by male black-throated blue warblers. Behavioral Ecology 12:541-546 
Clark CW, Mangel M (1986) The evolutionary advantages of group foraging. Theoretical Population Biology 30:45-75

Clarke AL, Sæther B-E, Røskaft E (1997) Sex biases in avian dispersal: a reappraisal. Oikos 79:429438

Clutton-Brock TH (2002) Breeding together: kin selection and mutualism in cooperative vertebrates. Science 296:69-72

Clutton-Brock TH (2009) Cooperation between non-kin in animal societies. Nature 462:51-57

Clutton-Brock TH (1986) Sex ratio variation in birds. Ibis 128:317-329

Clutton-Brock TH (1989) Female transfer and inbreeding avoidance in social mammals. Nature $337: 70-72$

Clutton-Brock TH (1991) The evolution of parental care. Princeton University Press, Princeton, NJ

Clutton-Brock TH, Parker GA (1992) Potential reproductive rates and the operation of sexual selection. The Quarterly Review of Biology 67:437-456

Cockburn A (1998) Evolution of helping behaviour in cooperatively breeding birds. Annual Review of Ecology and Systematics 29:141-177

Cockburn A (2006) Prevalence of different modes of parental care in birds. Proceedings of the Royal Society of London. Series B: Biological Sciences 273:1375-83

Conway CJ, Martin TE (2000) Evolution of passerine incubation behaviour: influence of food, temperature and nest predation. Evolution 54:670-685

Cornwallis CK, West SA, Davis KE, Griffin AS (2010) Promiscuity and the evolutionary transition to complex societies. Nature 466:969-972

Costa JT, Fitzgerald TD (1996) Developments in social terminology: semantic battles in a conceptual war. Trends in Ecology \& Evolution 11:285-289

Côté IM, Poulin R (1995) Parasitism and group size in social animals: a meta-analysis. Behavioral Ecology 6:159-165

Covas R, Griesser M (2007) Life history and the evolution of family living in birds. Proceedings of the Royal Society B: Biological Sciences 274:1349-1357

Cowlishaw G, Lawes MJ, Lightbody M, Martin A, Pettifor R, Rowcliffe JM (2004) A simple rule for the costs of vigilance: empirical evidence from a social forager. Proceedings of the Royal Society of London. Series B: Biological Sciences 271:27-33 
Darwin C (1859) On the origin of species by means of natural selection. Murray, London

Davies N (2000) Multi-male breeding groups in birds: ecological causes and social conflicts. In: Kappeler P (ed) Primate Males. Cambridge University Press, Cambridge, pp 11-20

Davies NB (1991) Mating systems. In: Krebs JR, Davies NB (eds) Behavioural ecology, 3rd edn. Blackwell Science, Oxford, pp 263-294

Dawkins R (1976) The selfish gene. Oxford University Press, Oxford

Dickinson JL (2004) Facultative sex ratio adjustment by western bluebird mothers with stay-at-home helpers-at-the-nest. Animal Behaviour 68:373-380

Diez DM (2012) Olsurv: Survival analysis supplement to OpenIntro guide. http://CRAN.Rproject.org/package=Olsurv

Ebbinge B, Van Biezen J, Van der Voet H (1991) Estimation of annual adult survival rates of barnacle geese (Branta leucopsis) using multiple resightings of marked individuals. Ardea 79:73-112

Eguchi K, Yamagishi S, Randrianasolo V (1993) The composition and foraging behaviour of mixedspecies flocks of forest-living birds in Madagascar. Ibis 135:91-96

Ekman J, Bylin A, Tegelstrom H (2000) Parental nepotism enhances survival of retained offspring in the Siberian jay. Behavioral Ecology 11:416-420

Ekman J, Rosander B (1992) Survival enhancement through food sharing: a means for parental control of natal dispersal. Theoretical Population Biology 42:117-129

Ekman J, Sklepkovych B, Tegelstrom H (1994) Offspring retention in the siberian jay (Perisoreus infaustus): the prolonged brood care hypothesis. Behavioral Ecology 5:245-253

Elgar MA (1989) Predator vigilance and group size in mammals and birds: a critical review of the empirical evidence. Biological Reviews 64:13-33

Emlen S, Oring L (1977) Ecology, sexual selection, and the evolution of mating systems. Science $197: 215-223$

Emlen ST (1982) The evolution of helping. I. An ecological constraints model. The American Naturalist 119:29-39

Emlen ST (1995) An evolutionary theory of the family. Proceedings of the National Academy of Sciences 92:8092-8099 
Ericson PGP, Anderson CL, Britton T, Elzanowski A, Johansson US, Källersjö M, Ohlson JI, Parsons TJ, Zuccon D, Mayr G (2006) Diversification of neoaves: integration of molecular sequence data and fossils. Biology Letters 2:543-547

Evans M, Hawkins AFA, Duckworth J (1996) Family Mesitornithidae (Mesites). In: del Hoyo J, Elliott A, Sargatal $\mathrm{J}$ (eds) Handbook of the birds of the world. Lynx Edicions, Barcelona, pp 34-43

Evans ML, Stutchbury BJM (2012) Nest Attendance and Reproductive Success in the Wood Thrush (Asistencia del Nido y Éxito Reproductivo en Hylocichla mustelina). The Condor 114:401-406 Faraway J (2006) Extending the linear model with R. Chapman \& Hall, London

Fernández-Juricic E, Beauchamp G, Bastain B (2007) Group-size and distance-to-neighbour effects on feeding and vigilance in brown-headed cowbirds. Animal Behaviour 73:771-778

Fox J, Weisberg S (2011) An R companion to applied regression, 2nd edn. Sage, Thousand Oaks, CA Galliard J-FL, Ferrière R (2008) The Adaptive Evolution of Social Traits. In: Danchin È, Giraldeau L-A, Cézilly F (eds) Behavioural Ecology. Oxford University Press, Oxford, pp 547-575

Gamero A, Buser A, Kappeler P (2013a) Characterization of 10 polymorphic microsatellite loci for White-breasted mesites (Mesitornis variegata). Conservation Genetics Resources 5:553-554

Gamero A, Székely T, Kappeler P (2013b) Delayed juvenile dispersal and monogamy, but no cooperative breeding in white-breasted mesites (Mesitornis variegata). Behavioral Ecology and Sociobiology:1-11

Ganzhorn JU, Lowry PP, Schatz GE, Sommer S (2001) The biodiversity of Madagascar: one of the world's hottest hotspots on its way out. Oryx 35:346-348

Ghalambor CK, Martin TE (2000) Parental investment strategies in two species of nuthatch vary with stage-specific predation risk and reproductive effort. Animal Behaviour 60:263-267

Gienapp P, Merilä J (2011) Sex-specific fitness consequences of dispersal in siberian jays. Behavioral Ecology and Sociobiology 65:131-140

Gonzalez J-CT, Sheldon BC, Tobias JA (2013) Environmental stability and the evolution of cooperative breeding in hornbills. Proceedings of the Royal Society B: Biological Sciences 280

Goodale E, Kotagama SW, Holberton RL (2005) Alarm calling in Sri Lankan mixed-species bird flocks. Auk 122:108-120 
Goss-Custard JD, Durell SEALVD (1987) Age-related effects in oystercatchers, (Haematopus ostralegus), feeding on mussels, (Mytilus edulis). I. Foraging efficiency and interference. Journal of Animal Ecology 56:521-536

Greenwood PJ (1980) Mating systems, philopatry and dispersal in birds and mammals. Animal Behaviour 28:1140-1162

Griesser M (2003) Nepotistic vigilance behavior in siberian jay parents. Behavioral Ecology 14:246250

Griffith SC, Owens IPF, Thuman KA (2002) Extra pair paternity in birds: a review of interspecific variation and adaptive function. Molecular Ecology 11:2195-2212

Griffiths R, Double MC, Orr K, Dawson RJG (1998) A DNA test to sex most birds. Molecular Ecology 7:1071-1075

Hackett SJ, Kimball RT, Reddy S, Bowie RCK, Braun EL, Braun MJ, Chojnowski JL, Cox WA, Han KL, Harshman J, Huddleston CJ, Marks BD, Miglia KJ, Moore WS, Sheldon FH, Steadman DW, Witt CC, Yuri T (2008) A phylogenomic study of birds reveals their evolutionary history. Science 320:1763-1768

Hall M (2004) A review of hypotheses for the functions of avian duetting. Behavioral Ecology and Sociobiology 55:415-430

Hamilton WD (1964a) The genetical evolution of social behaviour. I. Journal of Theoretical Biology $7: 1-16$

Hamilton WD (1964b) The genetical evolution of social behaviour. II. Journal of Theoretical Biology 7:17-52

Hanssen SA, Hasselquist D, Folstad I, Erikstad KE (2005) Cost of reproduction in a long-lived bird: incubation effort reduces immune function and future reproduction. Proceedings of the Royal Society B: Biological Sciences 272:1039-1046

Hatchwell BJ (2009) The evolution of cooperative breeding in birds: kinship, dispersal and life history. Philosophical Transactions of the Royal Society B: Biological Sciences 364:3217-3227

Hatchwell BJ, Komdeur J (2000) Ecological constraints, life history traits and the evolution of cooperative breeding. Animal Behaviour 59:1079-1086 
Hawkins AFA (2013) White-breasted mesite (Mesitornis variegatus) Mésite varieé. In: Safford R, Hawkins AFA (eds) The Birds of Africa Volume VIII: The Malagasy Region. Christopher Helm, London

Hawkins AFA (1994) Conservation status and regional population estimates of the white-breasted mesite (Mesitornis variegata), a rare Malagasy endemic. Bird Conservation International 4:279-303

Hawkins AFA, Seddon N (2003) Mesitornithidae, Mesites. In: Goodman SM, Benstead JP (eds) The Natural History of Madagascar. The University of Chicago Press, Chicago and London, pp 1095-1098

Hawkins BA, Porter EE, Diniz-Filho JAF (2003) Productivity and history as predictors of the latitudinal diversity gradient of terrestrial birds. Ecology $84: 1608-1623$

Hedrick PW (2001) Conservation genetics: where are we now? Trends in Ecology \& Evolution 16:629636

Heg D, Bachar Z, Brouwer L, Taborsky M (2004) Predation risk is an ecological constraint for helper dispersal in a cooperatively breeding cichlid. Proceedings of the Royal Society of London. Series B: Biological Sciences 271:2367-2374

Heinsohn R (1987) Age-dependent vigilance in winter aggregations of cooperatively breeding whitewinged choughs (Corcorax melanorhamphos). Behavioral Ecology and Sociobiology 20:303306

Heinsohn RG (1991) Slow learning of foraging skills and extended parental care in cooperatively breeding white-winged choughs. The American Naturalist 137:864-881

Höglung J, Alatalo RV (1995) Leks. Princeton University Press, Princeton, New Jersey

Hollén L, Clutton-Brock T, Manser M (2008) Ontogenetic changes in alarm-call production and usage in meerkats (Suricata suricatta): adaptations or constraints? Behavioral Ecology and Sociobiology 62:821-829

Hughes WOH, Oldroyd BP, Beekman M, Ratnieks FLW (2008) Ancestral monogamy shows kin selection is key to the evolution of eusociality. Science 320:1213-1216

Jackson AL, Brown S, Sherratt TN, Ruxton GD (2005) The effects of group size, shape and composition on ease of detection of cryptic prey. Behaviour 142:811-826 
Jacobsen K-O, Erikstad KE, Sæther B-E (1995) An experimental study of the costs of reproduction in the kittiwake (Rissa tridactyla). Ecology 76:1636-1642

Jeschke JM, Tollrian R (2007) Prey swarming: which predators become confused and why? Animal Behaviour 74:387-393

Jetz W, Rubenstein DR (2011) Environmental uncertainty and the global biogeography of cooperative breeding in birds. Current Biology 21:72-78

Jetz W, Thomas GH, Joy JB, Hartmann K, Mooers AO (2012) The global diversity of birds in space and time. Nature 491:444-448

Jones OR, Wang J (2010) COLONY: a program for parentage and sibship inference from multilocus genotype data. Molecular Ecology Resources 10:551-555

Joste N, Ligon JD, Stacey PB (1985) Shared paternity in the acorn woodpecker (Melanerpes formicivorus). Behavioral Ecology and Sociobiology 17:39-41

Kalmbach E (2006) Why do goose parents adopt unrelated goslings? A review of hypotheses and empirical evidence, and new research questions. Ibis 148:66-78

Kappeler P, Fichtel C (2012) A 15-year perspective on the social organization and life history of sifaka in Kirindy Forest. In: Kappeler P, Watts D (eds) Long-term field studies of primates. Springer, Berlin Heidelberg, pp 101-121

Kappeler PM, Barrett L, Blumstein DT, Clutton-Brock TH (2013) Constraints and flexibility in mammalian social behaviour: introduction and synthesis. Philosophical Transactions of the Royal Society B: Biological Sciences 368

Kappeler PM, van Schaik CP (2002) Evolution of primate social systems. International Journal of Primatology 23:707-740

King AJ, Cowlishaw G (2007) When to use social information: the advantage of large group size in individual decision making. Biology Letters 3:137-139

Koenig W, Dickinson J (2004) Ecology and evolution of cooperative breeding in birds. Cambridge University Press, Cambridge

Koenig WD, Pieltka FA, Carmen WJ, Mumme RL, Stanback MT (1992) The evolution of delayed dispersal in cooperative breeders. Quaterly Review of Biology 67:111-150

Kokko H, Ekman J (2002) Delayed Dispersal as a Route to Breeding: Territorial inheritance, safe havens, and ecological constraints. The American Naturalist 160:468-484 
Kokko H, Lundberg P (2001) Dispersal, migration, and offspring retention in saturated habitats. The American Naturalist 157:188-202

Komdeur J (1992) Importance of habitat saturation and territory quality for evolution of cooperative breeding in the Seychelles warbler. Nature 358:493-495

Komdeur J, Ekman J (2010) Adaptations and constraints in the evolution of delayed dispersal: implications for cooperation. In: Székely T, Moore AJ, Komdeur J (eds) Social behaviour: genes, ecology and evolution. Cambridge University Press, Cambridge, pp 306-327

Komdeur J (1996) Influence of helping and breeding experience on reproductive performance in the Seychelles warbler: a translocation experiment. Behavioral Ecology 7:326-333

Kotogama SW, Goodale E (2004) The composition and spatial organisation of mixed-species flocks in a Sri Lankan rainforest. Forktail 20:63-70

Kranstauber B, Smolla M (2013) move: Visualizing and analyzing animal track data. R package version 1.1.424. http://CRAN.R-project.org/package=move

Krause J, Ruxton GD (2002) Living in groups. Oxford University Press, New York

Krebs J, Davies N (1993) An introduction to behavioural ecology. In, 3rd edn. Blackwell, Oxford

Krebs JR, Ryan JC, Charnov EL (1974) Hunting by expectation or optimal foraging? A study of patch use by chickadees. Animal Behaviour 22, Part 4:953-IN3

Kullberg C, Lind J (2002) An experimental study of predator recognition in great tit fledglings. Ethology $108: 429-441$

Landeau L, Terborgh J (1986) Oddity and the 'confusion effect' in predation. Animal Behaviour $34: 1372-1380$

Langen TA (1996) Skill acquisition and the timing of natal dispersal in the white-throated magpie-jay, (Calocitta formosa). Animal Behaviour 51:575-588

Leggett HC, El Mouden C, Wild G, West S (2012) Promiscuity and the evolution of cooperative breeding. Proceedings of the Royal Society B: Biological Sciences 279:1405-1411

Ligon JD (1999) The evolution of avian breeding systems. Oxford University Press, Oxford

Ligon JD, Burt DB (2004) Evolutionary origins. In: Koenig WD, Dickinson JL (eds) Ecology and evolution of cooperative breeding in birds. Cambridge University Press, Cambridge, pp 5-34

Linden M, Møller AP (1989) Cost of reproduction and covariation of life history traits in birds. Trends in Ecology \& Evolution 4:367-371 
Livezey BC (1998) A phylogenetic analysis of the Gruiformes (Aves) based on morphological characters, with an emphasis on the rails (Rallidae). PhilosophicalTransactions of the Royal Society London B 353:2077-2151

Livezey BC, Zusi RL (2007) Higher-order phylogeny of modern birds (Theropoda, Aves: Neornithes) based on comparative anatomy. II. Analysis and discussion. Zoological Journal of the Linnean Society 149:1-95

Lukas D, Clutton-Brock T (2012) Cooperative breeding and monogamy in mammalian societies. Proceedings of the Royal Society B: Biological Sciences 279:2151-2156

Lukas D, Clutton-Brock TH (2013) The evolution of social monogamy in mammals. Science 341:526530

Macedo RH, Karubian J, Webster MS (2008) Extrapair paternity and sexual selection in socially monogamous birds: are tropical birds different? The Auk 125:769-777

Magrath RD, Whittingham LA (1997) Subordinate males are more likely to help if unrelated to the breeding female in cooperatively breeding white-browed scrubwrens. Behavioral Ecology and Sociobiology 41:185-192

Magurran AE, Oulton WJ, Pitcher TJ (1985) Vigilant behaviour and shoal size in minnows. Zeitschrift für Tierpsychologie 67:167-178

Marchetti K, Price T (1989) Differences in the foraging of juvenile and adult birds: the importance of developmental constraints. Biological Reviews 64:51-70

Martin K (1989) Pairing and adoption of offspring by replacement male willow ptarmigan: behaviour, costs and consequences. Animal Behaviour 37, Part 4:569-578

Mayr G, Ericson PGP (2004) Evidence for a sister group relationship between the Madagascan mesites (Mesitornithidae) and cuckoos (Cuculidae). Senckenbergiana biologica 84:119-135

McGowan KJ, Woolfenden GE (1989) A sentinel system in the Florida scrub jay. Animal Behaviour 37, Part 6:1000-1006

Mcnamara JM, Houston Al, Webb JN (1994) Dynamic kin selection. Proceedings of the Royal Society of London. Series B: Biological Sciences 258:23-28

Meek SB, Robertson RJ (1991) Adoption of young by replacement male birds: an experimental study of eastern bluebirds and a review. Animal Behaviour 42:813-820 
Møller AP, Cuervo JJ (2000) The evolution of paternity and paternal care in birds. Behavioral Ecology $11: 472-485$

Mumme RL (1992) Do helpers increase reproductive success? Behavioral Ecology and Sociobiology $31: 319-328$

Nager RG, Monaghan P, Houston DC (2001) The cost of egg production: increased egg production reduces future fitness in gulls. Journal of Avian Biology 32:159-166

Nijman V (2004) Seasonal variation in naturally occurring mobbing behaviour of drongos (Dicruridae) towards two avian predators. Ethology Ecology \& Evolution 16:25-32

Ochi D (2009) Do large eggs favor the growth of chicks? An experimental study on a semi-precocial seabird: rhinoceros auklet (Cerorhinca monocerata). Ornithological Science 8:97-104

Oommen MA, Shanker K (2010) Shrewd alliances: mixed foraging associations between treeshrews, greater racket-tailed drongos and sparrowhawks on Great Nicobar Island, India. Biology Letters 6:304-307

Owens IPF, Bennett PM (1997) Variation in mating system among birds: ecological basis revealed by hierarchical comparative analysis of mate desertion. Proceedings of the Royal Society of London. Series B: Biological Sciences 264:1103-1110

Peach WJ, Hanmer DB, Oatley TB (2001) Do southern African songbirds live longer than their European counterparts? Oikos 93:235-249

Pen I, Weissing FJ (2000) Towards a unified theory of cooperative breeding: the role of ecology and life history re-examined. Proceedings of the Royal Society of London. Series B: Biological Sciences 267:2411-2418

Petrie M, Kempenaers B (1998) Extra-pair paternity in birds: explaining variation between species and populations. Trends in Ecology \& Evolution 13:52-58

Pienaar J, llany A, Geffen E, Yom-Tov Y (2013) Macroevolution of life-history traits in passerine birds: adaptation and phylogenetic inertia. Ecology Letters 16:571-576

Pinheiro J, Bates D, DebRoy S, Sarkar D, R Develoopmental Core Team (2013) nlme: linear and nonlinear mixed effects models. $\mathrm{R}$ package version 3.1-108.

Pruett-Jones SG, Lewis MJ (1990) Sex ratio and habitat limitation promote delayed dispersal in superb fairy-wrens. Nature 348:541-542 
Pyritz LW, Fichtel C, Huchard E, Kappeler PM (2013) Determinants and outcomes of decision-making, group coordination and social interactions during a foraging experiment in a wild primate. PLoS ONE 8:e53144

Queller DC, Goodnight KF (1989) Estimating relatedness using genetic markers. Evolution 43:258-275

Queller DC, Zacchi F, Cervo R, Turillazzi S, Henshaw MT, Santorelli LA, Strassmann JE (2000) Unrelated helpers in a social insect. Nature 405:784-787

Radford AN, Hollén LI, Bell MBV (2009) The higher the better: sentinel height influences foraging success in a social bird. Proceedings of the Royal Society B: Biological Sciences 276:24372442

Raihani NJ, Clutton-Brock TH (2010) Higher reproductive skew among birds than mammals in cooperatively breeding species. Biology Letters 6:630-632

Ramanitra N, Ravelson B, Randrianaina L (2006) Prospection et etude de l'espece (Mesitornis variegata) a Betampona et a Morondava. Conservation International, unpublished report

Randler C (2005) Vigilance during preening in coots (Fulica atra). Ethology 111:169-178

Reynolds JD (1996) Animal breeding systems. Trends in Ecology \& Evolution 11:68-72

Ricklefs RE (1975) The evolution of co-operative breeding in birds. Ibis 117:531-534

Ricklefs RE (1979) Adaptation, constrain, and compromise in avian postnatal development. Biological Reviews 54:269-290

Ricklefs RE, Wikelski M (2002) The physiology/life-history nexus. Trends in Ecology \& Evolution $17: 462-468$

Ridley A, Raihani N (2007) Facultative response to a kleptoparasite by the cooperatively breeding pied babbler. Behavioral Ecology 18:324-330

Ridley AR, Raihani NJ, Nelson-Flower MJ (2008) The cost of being alone: the fate of floaters in a population of cooperatively breeding pied babblers (Turdoides bicolor). Journal of Avian Biology 39:389-392

Riipi M, Alatalo RV, Lindstrom L, Mappes J (2001) Multiple benefits of gregariousness cover detectability costs in aposematic aggregations. Nature 413:512-514

Roberts G (1996) Why individual vigilance declines as group size increases. Animal Behaviour $51: 1077-1086$ 
Robinson SR (1981) Alarm communication in belding's ground squirrels. Zeitschrift für Tierpsychologie $56: 150-168$

Rollins LA, Browning LE, Holleley CE, Savage JL, Russell AF, Griffith SC (2012) Building genetic networks using relatedness information: a novel approach for the estimation of dispersal and characterization of group structure in social animals. Molecular Ecology 21:1727-1740

Rousset F (2008) genepop'007: a complete re-implementation of the genepop software for Windows and Linux. Molecular Ecology Resources 8:103-106

Rubenstein DR, Lovette IJ (2007) Temporal environmental variability drives the evolution of cooperative breeding in birds. Current Biology 17:1414-1419

Russell A (2004) Mammals: comparisons and contrasts. In: Koenig W, Dickinson J (eds) Ecology and evolution of cooperative breeding in birds Cambridge University Press, Cambridge, pp 210227

Russell EM, Yom-Tov Y, Geffen E (2004) Extended parental care and delayed dispersal: northern, tropical, and southern passerines compared. Behavioral Ecology 15:831-838

Ryer C, Olla B (1998) Shifting the balance between foraging and predator avoidance: the importance of food distribution for a schooling pelagic forager. Environmental Biology of Fishes 52:467475

Samonds KE, Godfrey LR, Ali JR, Goodman SM, Vences M, Sutherland MR, Irwin MT, Krause DW (2013) Imperfect isolation: factors and filters shaping Madagascar's extant vertebrate fauna. PLoS ONE 8:e62086

Schaefer H-C, Eshiamwata GW, Munyekenye FB, Böhning-Gaese K (2004) Life-history of two African Sylvia warblers: low annual fecundity and long post-fledging care. Ibis 146:427-437

Schuelke M (2000) An economic method for the fluorescent labeling of PCR fragments. Nature Biotechnology 18:233-234

Seddon N (2001) The ecology, communication and conservation of the subdesert mesite (Monias benschi). In. University of Cambridge, UK

Seddon N (2002) The structure, context and possible functions of solos, duets and choruses in the subdesert mesite (Monias benschi). Behaviour 139:645-676 
Seddon N, Amos W, Adcock G, Johnson K, Kraaijeveld K, Kraaijeveld-Smit FJL, Lee W, Senapathi GD, Mulder RA, Tobias JA (2005) Mating system, philpatry and patterns of kinship in the cooperatively breeding subdesert mesite (Monias benschi). Molecular Ecology 14:3573-3583

Seddon N, Butchart S, Odling-Smee L (2002) Duetting in the subdesert mesite (Monias benschi): evidence for acoustic mate defence? Behavioral Ecology and Sociobiology 52:7-16

Seddon N, Tobias JA, Butchart SHM (2003) Group living, breeding behaviour and territoriality in the Subdesert Mesite (Monias benschi). Ibis 145:277-294

Sharpe LL, Joustra AS, Cherry MI (2010) The presence of an avian co-forager reduces vigilance in a cooperative mammal. Biology Letters 6:475-477

Sherley GH (1990) Cooperative breeding in rifleman (Acanthisitta chloris): benefits to parents, offspring and helpers. Behaviour 112:1-22

Shultz S, Opie C, Atkinson QD (2011) Stepwise evolution of stable sociality in primates. Nature 479:219-222

Sibley C, Ahlquist J (1990) Phylogeny and classification of birds: a study in molecular evolution. Yale University Press, New Haven, CT

Sibley CG, Monroe BL (1990) Distribution and taxonomy of birds of the World. Yale University Press, New Haven

Skutch AF (1949) Do tropical birds rear as many young as they can nourish? Ibis 91:430-455

Sogard S, Olla B (1997) The influence of hunger and predation risk on group cohesion in a pelagic fish, walleye pollock (Theragra chalcogramma). Environmental Biology of Fishes 50:405-413

Spiering P, Somers M, Maldonado J, Wildt D, Gunther M (2010) Reproductive sharing and proximate factors mediating cooperative breeding in the African wild dog (Lycaon pictus). Behavioral Ecology and Sociobiology 64:583-592

Sridhar H, Beauchamp G, Shanker K (2009) Why do birds participate in mixed-species foraging flocks? A large-scale synthesis. Animal Behaviour 78:337-347

Sridhar H, Shanker K (2013) Using intra-flock association patterns to understand why birds participate in mixed-species foraging flocks in terrestrial habitats. Behavioral Ecology and Sociobiology:112 
Stacey PB, Ligon JD (1991) The benefits-of-philopatry hypothesis for the evolution of cooperative breeding: variation in territory quality and group size effects. The American Naturalist 137:831846

Stark JM, Ricklefs RE (1998) Avian Growth and Development. Oxford University Press, New York

Struhsaker TT (1969) Correlates of ecology and social organization among African cercopithecines. Folia Primatologica 11:80-118

Stutchbury BJM, Morton ES (2001) Behavioral ecology of tropical birds. Academic Press, London, UK

Sullivan KA (1988) Ontogeny of time budgets in yellow-eyed juncos: adaptation to ecological constaints. Ecology 69:118-124

Tarwater CE, Brawn JD (2010a) Family living in a Neotropical bird: variation in timing of dispersal and higher survival for delayed dispersers. Animal Behaviour 80:535-542

Tarwater CE, Brawn JD (2010b) The post-fledging period in a tropical bird: patterns of parental care and survival. Journal of Avian Biology 41:479-487

Temrin H, Tullberg BS (1995) A phylogenetic analysis of the evolution of avian mating systems in relation to altricial and precocial young. Behavioural Ecology 6:296-307

Terborgh J, Janson CH (1986) The socioecology of primate groups. Annual Review of Ecology and Systematics 17:111-136

Treves A (1998) The Influence of group size and neighbors on vigilance in two species of arboreal monkeys. Behaviour 135:453-481

Treves A, Drescher A, Ingrisano N (2001) Vigilance and aggregation in black howler monkeys (Alouatta pigra). Behavioral Ecology and Sociobiology 50:90-95

Trivers R (1972) Parental investment and sexual selection. In: Campbell B (ed) Sexual selection and the decent of man. Heinemann, London, pp 136-179

Turchin P, Kareiva P (1989) Aggregation in (Aphis varians): An effective strategy for reducing predation risk. Ecology 70:1008-1016

Visser ME, Lessells CM (2001) The costs of egg production and incubation in great tits (Parus major). Proceedings of the Royal Society of London. Series B: Biological Sciences 268:1271-1277

Wallander J, Blomqvist D, Lifjeld JT (2001) Genetic and social monogamy - does it occur without mate guarding in the ringed plover? Ethology 107:561-572 
Wang J (2011) coancestry: a program for simulating, estimating and analysing relatedness and inbreeding coefficients. Molecular Ecology Resources 11:141-145

Westneat DF, Sherman PW, Morton ML (1990) The ecology and evolution of extra-pair copulations in birds. Current Ornithology 7:331-369

Wey TW, Blumstein DT (2010) Social cohesion in yellow-bellied marmots is established through age and kin structuring. Animal Behaviour 79:1343-1352

Whitfield DP (1985) Social organisation and feeding behaviour of wintering turnstone (Arenaria interpres). PhD thesis: University of Edinburgh

Williams GC (1966) Natural selection, the costs of reproduction, and a refinement of Lack's principle. The American Naturalist 100:687-690

Wong M, Balshine S (2011) The evolution of cooperative breeding in the African cichlid fish, Neolamprologus pulcher. Biological Reviews 86:511-530

Woolfenden GE, Fitzpatrick JW (1978) The inheritance of territory in group-breeding birds. BioScience 28:104-108

Yang R, Wu X, Yan P, Su X, Yang B (2010) Complete mitochondrial genome of (Otis tarda) (Gruiformes: Otididae) and phylogeny of Gruiformes inferred from mitochondrial DNA sequences. Molecular Biology Reports 37:3057-3066

Zahavi A (1995) Altruism as a handicap: The limitations of kin selection and reciprocity. Journal of Avian Biology 26:1-3 


\section{Appendices}

Table A1. Summary of the characters used to age white-breasted mesites. Adult characters are presented in bold.

\begin{tabular}{|c|c|c|c|c|c|}
\hline & Chick & Juvenile I & Juvenile II & Juvenile III & Adult \\
\hline Age (months) & $0-2$ months & 2 - 4 months & 4 - 7 months & 7 - 12 months & $>12$ months \\
\hline Period of the year & January-April & March-June & June-September & October-January & all year \\
\hline Number of individuals & 27 & 4 & 5 & 4 & 30 \\
\hline Rectrix shape & growing & narrow & narrow & narrow $^{1}$ & broad \\
\hline Tertial shape & growing & pointed & pointed & pointed $^{2}$ & broad \\
\hline Tertial worness & no & no & no & yes $^{2}$ & variable \\
\hline Back pattern & growing & even dark brown & even dark brown & $(\text { even })^{3}$ dark brown & mottled brown \\
\hline Iris colour & brown & brown & brown & red & red \\
\hline Leg colour & grey-yellowish & grey-yellowish & grey-brownish & grey-brownish & grey-brownish \\
\hline Bare skin around eye & pale grey & pale grey & dark grey to blue & dark grey to blue & dark grey to blue \\
\hline
\end{tabular}

${ }^{1}$ some individuals may have molt some of the rectrices, presenting some adult-like new feathers on the tail.

${ }^{2}$ some individuals may have molt some of the tertials, presenting some adult-like new feathers on the wing.

${ }^{3}$ some individuals may show some contrast on the back feathers, but no bleached feathers are present. 


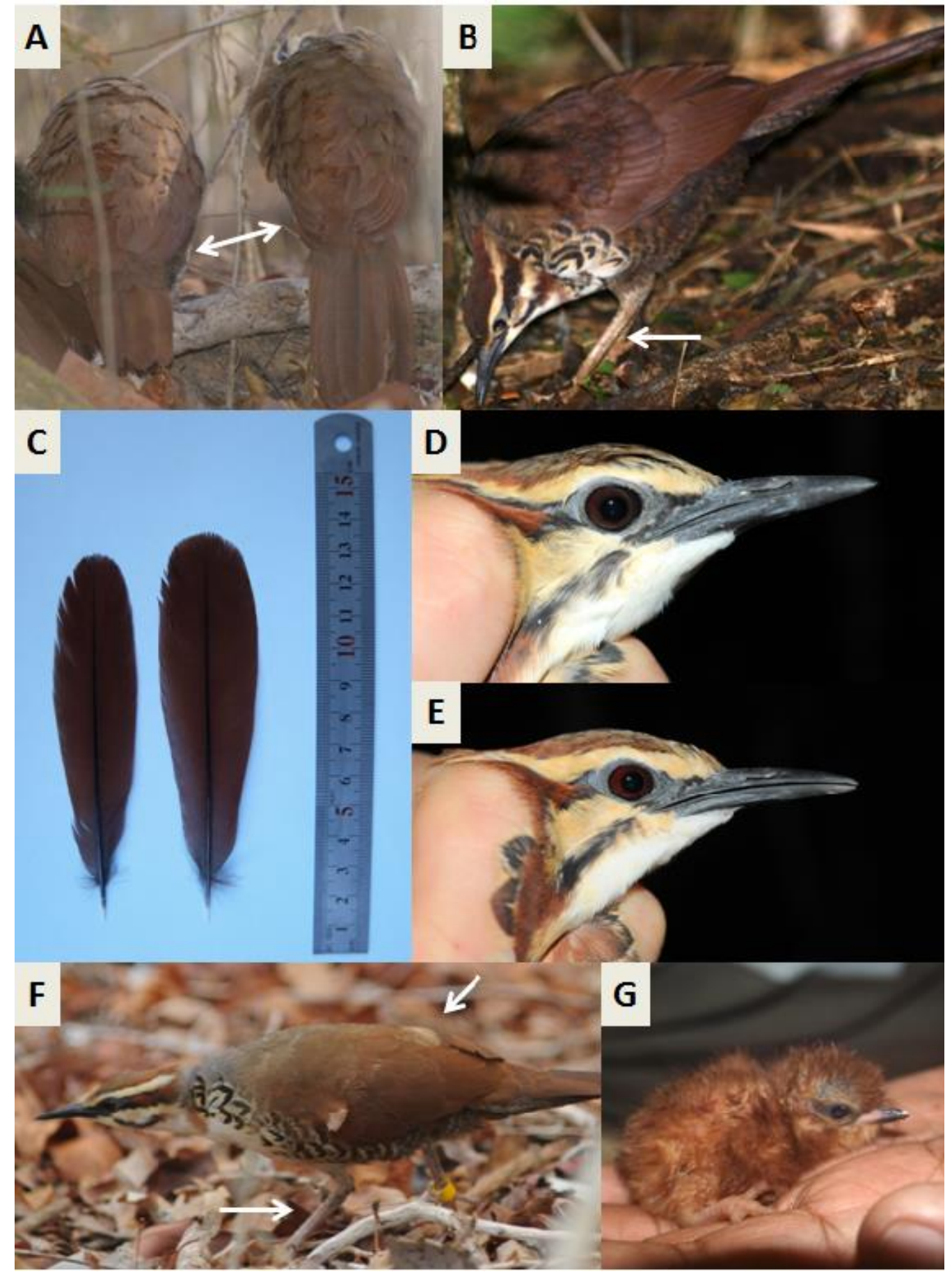

Figure A1. Age differences in white-breasted mesite plumage. A: adult with broad and rounded tertials (left) and juvenile III with pointed and narrow tertials (right) in December; B: juvenile I in March with even brown back, grayyellowish legs and pale gray bare skin around the eye; C: rectrices of an adult (broad and rounded, right side) and of a juvenile II (narrower and pointed, left side) in July; D: juvenile II brown iris coloration in July; E: Adult red iris coloration in July; F: Adult with few bleached old feathers on the back giving the mottled back appearance and light gray legs in November; G: one day-old hatchling in February. Pictures A, B, G (A. Gamero) and C, D, E, F (P. Lehikoinen). 


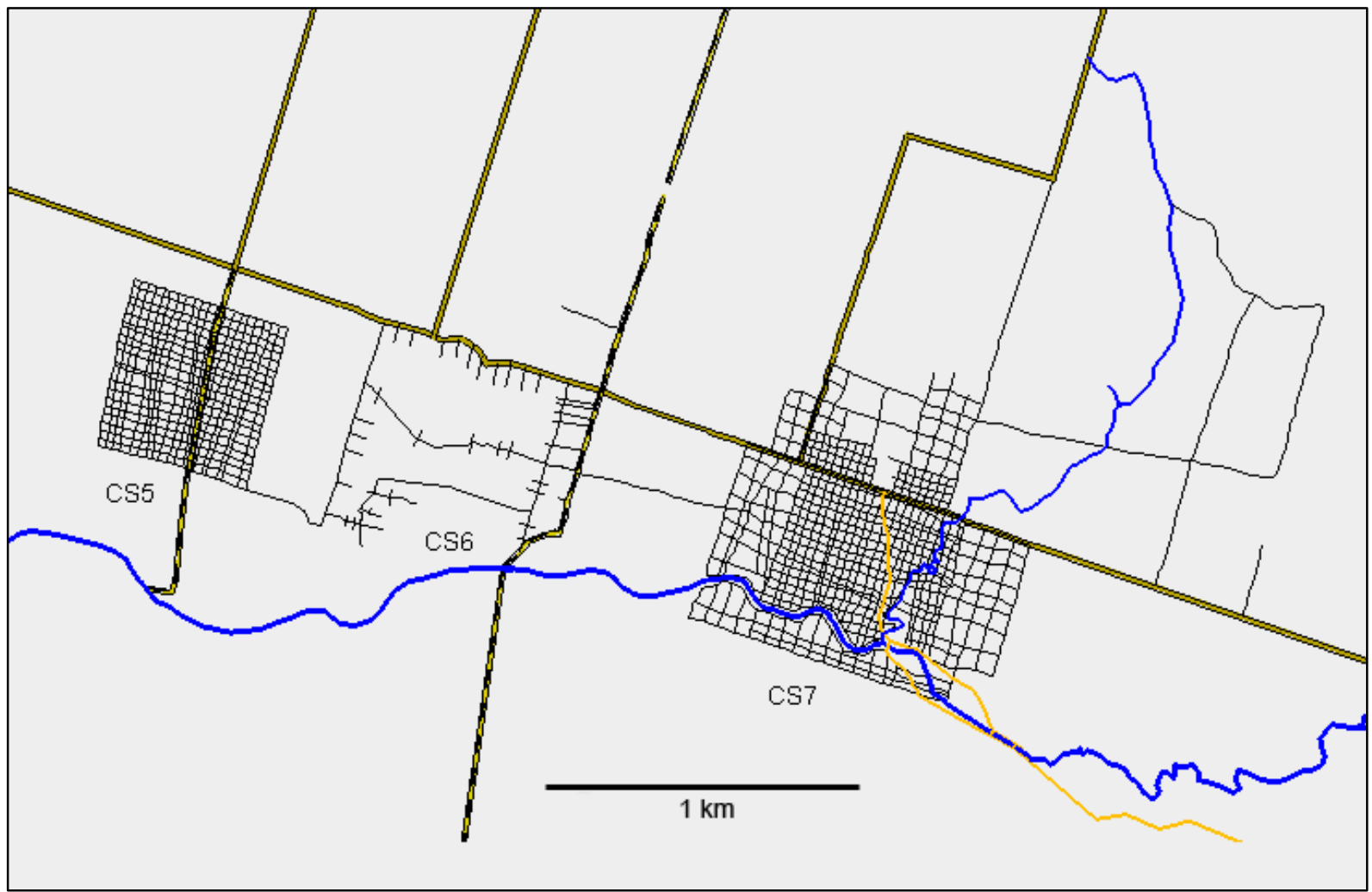

Figure A2. Map of the study site in Kirindy forest, Western Madagascar with paths, rivers and the different grid systems (CS5, CS6, CS7). 
Table A2. Colour ring combinations of the mesites captured in Kirindy forest (B: dark blue, G: green, Lb: light blue, O: orange, P: pink, R: red, W: white and Y: yellow)

\begin{tabular}{|c|c|c|c|c|c|c|}
\hline Date & Grid & Group & Right leg & Left leg & Age & Sex \\
\hline 27.10 .2009 & CS5 & $\mathrm{F}$ & Y & $Y$ & adult & male \\
\hline 27.10.2009 & CS5 & $\mathrm{F}$ & $Y$ & $\mathrm{Lb} Y$ & adult & female \\
\hline 27.10 .2009 & CS5 & $\mathrm{F}$ & $\mathrm{R} L \mathrm{Lb}$ & $\mathrm{Lb}$ & juvenile & male \\
\hline 28.10.2009 & CS7 & K & Lb Y & - & adult & female \\
\hline 28.10 .2009 & CS7 & K & - & $\mathrm{O}$ & adult & male \\
\hline 30.10 .2009 & $\operatorname{cs} 6$ & C & $\mathrm{Lb}$ & $Y$ & juvenile & male \\
\hline 30.10 .2009 & cs6 & C & $\mathrm{Lb} \mathrm{Lb}$ & $\mathrm{Lb}$ & adult & female \\
\hline 30.10 .2009 & $\operatorname{cs} 6$ & C & $\mathrm{R}$ & $\mathrm{R} L b$ & juvenile & male \\
\hline 15.11 .2009 & CS5 & $J$ & $Y$ & $\mathrm{R}$ & juvenile & female \\
\hline 15.11 .2009 & CS5 & $J$ & - & Y Lb & adult & female \\
\hline 08.07.2010 & CS7 & A & - & Y & adult & male \\
\hline 08.07.2010 & CS7 & A & - & B B & adult & female \\
\hline 09.07.2010 & CS7 & $\mathrm{H}$ & $G$ & $G$ & adult & male \\
\hline 09.07.2010 & CS7 & $\mathrm{H}$ & $P$ & $\mathrm{Lb}$ & adult & female \\
\hline 10.07 .2010 & CS5 & B & $\mathrm{Lb}$ & $G$ & adult & female \\
\hline 10.07 .2010 & CS5 & B & WR & - & adult & male \\
\hline 11.07 .2010 & CS7 & 12 & - & $R R$ & adult & male \\
\hline 11.07.2010 & CS7 & 12 & $B$ & $Y$ & adult & female \\
\hline 11.07 .2010 & CS5 & $\mathrm{N}$ & P P & - & adult & female \\
\hline 11.07 .2010 & CS5 & N & W w & - & adult & male \\
\hline 12.07 .2010 & CS7 & M & $G P$ & - & juvenile & female \\
\hline 12.07.2010 & CS7 & M & YR & - & juvenile & male \\
\hline 12.07.2010 & CS7 & M & Lb B & - & adult & female \\
\hline 12.07.2010 & CS7 & M & W P & - & adult & male \\
\hline 16.07 .2010 & CS5 & $G$ & - & v & adult & female \\
\hline 16.07 .2010 & CS5 & $G$ & W & Y & adult & male \\
\hline 16.07.2010 & CS5 & $G$ & R B & - & juvenile & male \\
\hline 21.07.2010 & $\operatorname{cs} 6$ & $E$ & $\mathrm{RP}$ & - & adult & male \\
\hline 23.07.2010 & CS5 & $\mathrm{J} 2$ & - & $B W$ & adult & female \\
\hline 24.07.2010 & $\operatorname{cs} 6$ & $\mathrm{~F} 2$ & - & $G Y$ & adult & female \\
\hline 25.07 .2010 & $\operatorname{cs} 6$ & F2 & - & G Lb & juvenile & female \\
\hline 27.07.2010 & $\operatorname{cs} 6$ & 0 & $G G$ & - & juvenile & male \\
\hline 27.07.2010 & cs6 & O & $P$ & $P$ & adult & male \\
\hline 28.07.2010 & $\operatorname{cs} 6$ & $P$ & $G R$ & - & adult & male \\
\hline 29.07.2010 & $\operatorname{cs} 6$ & $C$ & $\mathrm{R}$ & $\mathrm{R}$ & adult & male \\
\hline 21.01 .2011 & $\operatorname{cs} 6$ & $S$ & $G$ & W & adult & female \\
\hline 21.01 .2011 & $\operatorname{cs} 6$ & $S$ & $\mathrm{P}$ & $B$ & adult & male \\
\hline 27.01.2011 & $\operatorname{cs} 6$ & E & $Y Y$ & - & adult & male \\
\hline 26.11 .2011 & CS5 & B & $B$ & $\mathrm{Lb}$ & juvenile & male \\
\hline 28.11 .2011 & CS5 & $\mathrm{F}$ & $\mathrm{G}$ & $\mathrm{B}$ & juvenile & male \\
\hline
\end{tabular}


Table A3. Summary of all nests found during the study period (December 2009 to April 2012). Laying date = 1 corresponds to the $1^{\text {st }}$ of December of each reproductive season.

\begin{tabular}{|c|c|c|c|c|c|c|c|}
\hline $\begin{array}{l}\text { Group } \\
\text { ID }\end{array}$ & $\begin{array}{l}\text { Nest } \\
\text { code }\end{array}$ & $\begin{array}{l}\text { Clutch } \\
\text { size }\end{array}$ & Outcome & $\begin{array}{l}\text { Num. days } \\
\text { survived }\end{array}$ & $\begin{array}{l}\text { Laying } \\
\text { date }\end{array}$ & $\begin{array}{c}\text { Nest } \\
\text { Height }(\mathrm{m})\end{array}$ & Year \\
\hline$B$ & B_2_2011 & 2 & hatched & 28 & 55 & 1.64 & 2011 \\
\hline$P$ & P_1_2011 & 2 & hatched & 29 & 32 & 2.06 & 2011 \\
\hline$F$ & F_2_2011 & 2 & hatched & 28 & 57 & 1.30 & 2011 \\
\hline O & O_2_2011 & 2 & hatched & 28 & 70 & 1.23 & 2011 \\
\hline 12 & 12_2_2011 & 2 & hatched & 28 & 72 & 1.39 & 2011 \\
\hline $\mathrm{C}$ & C_3_2011 & 2 & hatched & 27 & 85 & 0.86 & 2011 \\
\hline B & B_1_2011 & 2 & predated & 4 & 25 & 0.83 & 2011 \\
\hline C & C_1_2011 & 2 & predated & $?$ & $?$ & 1.70 & 2011 \\
\hline $\mathrm{C}$ & C_2_2011 & $?$ & predated & $?$ & $?$ & 1.04 & 2011 \\
\hline $\mathrm{F}$ & F_1_2011 & 2 & predated & 11 & 37 & 1.37 & 2011 \\
\hline $\mathrm{F} 2$ & F2_1_2011 & 2 & predated & 9 & 52 & 1.58 & 2011 \\
\hline $\mathrm{F} 2$ & F2_2_2011 & 2 & predated & $?$ & $?$ & 0.71 & 2011 \\
\hline G1 & G_1_2011 & 2 & predated & 18 & 36 & 1.05 & 2011 \\
\hline $\mathrm{H}$ & H_1_2011 & 2 & predated & 20 & 15 & 0.93 & 2011 \\
\hline $\mathrm{J} 2$ & J2_1_2011 & 2 & predated & 18 & 68 & 1.30 & 2011 \\
\hline $\mathrm{O}$ & O_1_2011 & 1 & predated & 4 & 34 & 1.61 & 2011 \\
\hline$E$ & E_1_2011 & 2 & failed & 18 & 37 & 1.79 & 2011 \\
\hline 12 & I2_1_2011 & $?$ & failed & 2 & 52 & 2.20 & 2011 \\
\hline$E$ & E_2_2011 & 2 & hatched & 28 & 89 & 0.90 & 2011 \\
\hline$S$ & S_1_2011 & 2 & predated & 26 & 92 & 1.32 & 2011 \\
\hline N5 & N5_1_2011 & 2 & hatched & 28 & 90 & 0.80 & 2011 \\
\hline$B$ & B_1_2010 & 1 & predated & 5 & 15 & 1.52 & 2009 \\
\hline $\mathrm{B}$ & B_2_2010 & 1 & predated & 12 & 35 & $?$ & 2010 \\
\hline$A$ & A_1_2010 & 2 & hatched & 28 & 38 & 2.0 & 2010 \\
\hline $\mathrm{F}$ & F_1_2010 & 2 & predated & 12 & 44 & $?$ & 2010 \\
\hline $\mathrm{G}$ & G_1_2010 & 2 & predated & 9 & 34 & $?$ & 2010 \\
\hline $\mathrm{H}$ & H_1_2010 & 2 & predated & 14 & 32 & 1.62 & 2010 \\
\hline $\mathrm{J} 2$ & J2_1_2010 & 2 & predated & 7 & 38 & $?$ & 2010 \\
\hline $\mathrm{L}$ & L_1_2010 & $?$ & hatched & 27 & 4 & $?$ & 2009 \\
\hline C & C_1_2012 & 2 & hatched & 27 & 52 & 1.43 & 2012 \\
\hline$E$ & E_1_2012 & 2 & hatched & 26 & 61 & 0.90 & 2012 \\
\hline $\mathrm{F}$ & F_1_2012 & 2 & predated & $?$ & $?$ & 1.53 & 2012 \\
\hline $\mathrm{F} 2$ & F2_1_2012 & 2 & predated & 21 & 60 & 1.05 & 2012 \\
\hline G1 & G_1_2012 & 2 & predated & 6 & 64 & 1.56 & 2012 \\
\hline $\mathrm{H}$ & H_1_2012 & 2 & hatched & 27 & 52 & 1.20 & 2012 \\
\hline $\mathrm{O}$ & O_1_2012 & 1 & predated & 2 & 72 & 1.44 & 2012 \\
\hline$P$ & P_1_2012 & 1 & hatched & 27 & 55 & 0.99 & 2012 \\
\hline $\mathrm{J} 2$ & J2_1_2012 & $?$ & predated & $?$ & $?$ & 1.87 & 2012 \\
\hline
\end{tabular}




\begin{tabular}{cccccccc} 
O & O_2_2012 & 2 & hatched & 26 & 94 & 1.30 & 2012 \\
H2 & H_2_2012 & 2 & hatched & 27 & 90 & 1.92 & 2012 \\
G1 & G_2_2012 & 2 & hatched & 26 & 114 & 0.86 & 2012 \\
F2 & F2_2_2012 & 2 & predated & 10 & 110 & 0.97 & 2012 \\
I2 & I2_2_2012 & 2 & hatched & 26 & 107 & 2.08 & 2012 \\
F2 & F2_3_2012 & 2 & $?$ & $?$ & 131 & 0.80 & 2012 \\
\hline
\end{tabular}

Table A4. Juvenile recruitments in the Kirindy population based on a small data set of 8 colour-ringed juveniles, which were observed dispersing and/or were recruited in our study population. Dispersal distance is presented as the number of mesite territories between the natal and the breeding home range.

\begin{tabular}{cccc}
\hline Juvenile & Sex & Recruited & Distance \\
\hline 1 & Female & Yes & 1 \\
2 & Female & Yes & 2 \\
3 & Female & Yes & 2 \\
4 & Male & Yes & 3 \\
5 & Male & No & $*$ \\
6 & Male & No & - \\
7 & Male & No & - \\
8 & Male & No & -
\end{tabular}

${ }^{*}$ Non-recruited juvenile that was observed ranging about $2 \mathrm{Km}$ from his natal home range (about 8 mesite home ranges). 


\section{Acknowledgements}

I would like to thank my supervisor Peter Kappeler for giving me the opportunity to go to Madagascar and meet one of the coolest bird species there is. He also supported me during the whole project and gave me incredibly fast feedback on papers, abstracts and any other question. Although I first planned to include the vocal communication system of white-breasted mesites in my thesis, time constraints only allowed me to collect data in the field and the acoustic analysis are still largely "under construction". I would like to thank Claudia Fichtel for showing me how to use the recording equipment, several acoustic programs and helping in planning the experimental design to investigate mesite vocal communication. Tamás Székely gave very valuable feedback at different stages of my thesis that helped improving it. I also would like to thank Julia Ostner for co-supervising this thesis and the rest of the thesis committee, Eckhard Heymann, Antje Engelhard, Ulrich Brose and Mathias Waltert for evaluating it.

This work was possible due to the support by the Département de Biologie Animale, Université d'Antananarivo, the Commission Tripartite and the CAFF of the Direction des Eaux et Forêts and the CNFEREF Morondava. The University of Göttingen, the Deutsches Primatenzentrum and the Vokswagen Stiftung provided the necessary financial support.

The time I spent in the field in Madagascar was memorable in many ways and without the help of several field assistants this project would not have been possible. First I would like to thank T. Andrianjanahary, P. Lehikoinen, A. Nickel, J. Ramírez, A. Szabadvari, M. Razafindrasamba and J.P. Tolojanahary for their help and dedication during the data collection in Kirindy and for rarely complaining about radio-tracking mesites $300 \mathrm{~m}$ outside the grid systems, having to wake up at $4 \mathrm{am}$, or carrying car batteries all over the forest. I am particularly grateful to P. Lehikoinen for his invaluable help in the field, working very precise and hard during the capturing sessions, taking a million mesite pictures and for very fruitful discussions on trapping procedures and how to age mesites. L. Razafimanantsoa, N. Rabarijaona "Bary" and R. Rasoloarison made the project possible by providing the logistics and helping in obtaining the research permits for the study. Many other colleagues made the field work a great experience, so thanks to Flávia, Susanne, Mia, Anna, Anni, Eva, Elise, Josué, Lennard, Melanie, Conny and all équipe Kirindy. I would also like to thank all Kirindy "beasts" from 
mesites to fossas, chameleons, lemurs, snakes and many more for being such nice, interesting and curious neighbors and making every day different and fascinating for wildlife watching.

C. Oberdieck M. Markolf and S. Schliehe-Diecks taught me the necessary steps to do microsatellite analysis. Although at first I was skeptic I could remember so many rules and protocols (I can't even follow a cooking recipe), I have to admit from time to time I even enjoyed the pipetting time. Thanks for your patience and help!

I want to thank my office mates and friends both at the University of Göttingen and the German Primate Centre Anna, Anni, Conny and Chacka, Elise, Flávia, Iris, Maren, Melanie, Mia, Rebecca, and Susanne for the great time in Germany and their invaluable help solving "R crisis", statistical problems and inspiring discussions on new results. In the final phase of this thesis A. Hämäläinen, I. Dröscher and T. Székely provided very helpful feedback on manuscript drafts. Also thanks to all the members of our "double department" that provided feedback and suggestions to improve this study in seminars and coffee breaks. Many thanks to the two Anjas for their help with the german burocracy and Henning for solving technical problems, suggestions about electronic equipment and all the mensa lunches liven up with some football talk. Big thanks to Joachim and Iris for translating the abstract of this thesis to German.

M'agradaria donar les gràcies a la meva familia, particularment als meus pares pel seu suport durant els meus estudis i en les meves decisions en general encara que això signifiques no veure'm gaire sovint. Gràcies també a la Mercè i al meu grup de rates descarrilades que amb la seva amistat, bon humor i ironia m'han acompanyat des de la distància. Finally, thanks Joachim for giving feedback from an outsider-non-biologist point of view on my work, for keeping me sane and happy throughout this thesis and for everything else. 


\section{Curriculum vitae}

\section{Personal information}

Name: $\quad$ Anna Gamero Cabrellez

Born: $\quad$ Barcelona, 18.01 .1981

Citizenship Spanish

\section{Education and positions}

2009 - Dec. 2013 PhD. position at the Department of Sociobiology/ Anthropology, University of Göttingen (Germany): "The social system of white-breasted mesites (Mesitornis variegata)"

2008

Research officer Birdwatch Ireland (Ireland): "Breeding dunlin (Calidris alpina) ecology"

2007

Msc. Degree in Experimental Biology, University of Barcelona (Spain):

"Arthropod availability as a limiting factor in the breeding behaviour of the little bustard (Tetrax tetrax) in Lleida, Spain"

2006

Bachelor degree in Biology, University of Barcelona (Spain)

$2003-2004$

Exchange year at the Department of Biology University of Oulu (Finland)

$2002-2007$

Field ornithologist and research assistant for several projects at the University of Girona, University of Oulu, Catalan Institute of Ornithology, University of Vienna and University of Barcelona.

\section{Publication list}

Gamero A, Székely T, Kappeler PM. 2013 Delayed juvenile dispersal and monogamy, but not cooperative breeding in white-breasted mesites (Mesitornis variegata). Behavioral Ecology and Sociobiology. DOI: 10.1007/s00265-013-1624-4 
Gamero A, Buser A, Kappeler PM. 2013 Characterization of 10 polymorphic microsatellite loci for white-breasted mesites (Mesitornis variegata). Conservation Genetics Resources 5: 553-554

Lapiedra O, Ponjoan A, Gamero A, Bota G, Mañosa S. 2011 Brood ranging behaviour and breeding success of the threatened little bustard in an intensified cereal farmland area. Biological Conservation 144: $2882-2890$

Broggi J, Gamero A, Hohtola E, Orell M, Nilsson J-Å. 2011 Interpopulation variation in contour feather structure is environmentally determined in great tits. PLOS ONE 6(9): e24942

Suddaby D, Gamero A, McNaghten L, Thompson L \& Newton SF. 2008 Research of breeding dunlin (Calidris alpina) ecology associated with machair and upland NATURA 2000 sites in NW Mayo. Irish birds 8(3): 483-484

Gamero A, McNaghten L, Suddaby D. 2008 Research of breeding dunlin ecology associated with machair and upland NATURA 2000 sites in N.W. Mayo. Birdwatch Ireland conservation report 


\section{Declaration}

I hereby declare that I have written this thesis entitled "The social system of white-breasted mesites (Mesitornis variegata)" independently and with no other aids or sources than quoted.

Anna Gamero

Göttingen, 15.11.2013 